Cochrane Database of Systematic Reviews

\title{
Acupuncture for polycystic ovarian syndrome (Review)
}

Lim CED, Ng RWC, Cheng NCL, Zhang GS, Chen H

Lim CED, Ng RWC, Cheng NCL, Zhang GS, Chen H.

Acupuncture for polycystic ovarian syndrome.

Cochrane Database of Systematic Reviews 2019, Issue 7. Art. No.: CD007689.

DOI: 10.1002/14651858.CD007689.pub4.

www.cochranelibrary.com 
TABLE OF CONTENTS

HEADER 1

ABSTRACT

PLAIN LANGUAGE SUMMARY

SUMMARY OF FINDINGS

BACKGROUND

OBJECTIVES

METHODS

Figure 1.

Figure 2.

RESULTS

Figure 3.

Figure 4.

Figure 5.

Figure 6.

DISCUSSION

AUTHORS' CONCLUSIONS

ACKNOWLEDGEMENTS

REFERENCES

CHARACTERISTICS OF STUDIES

DATA AND ANALYSES

Analysis 1.1. Comparison 1 True acupuncture versus sham acupuncture, Outcome 1 Live birth rate.

Analysis 1.2. Comparison 1 True acupuncture versus sham acupuncture, Outcome 2 Multiple pregnancy rate.

Analysis 1.3. Comparison 1 True acupuncture versus sham acupuncture, Outcome 3 Ovulation rate.

Analysis 1.4. Comparison 1 True acupuncture versus sham acupuncture, Outcome 4 Clinical pregnancy rate.

Analysis 1.5. Comparison 1 True acupuncture versus sham acupuncture, Outcome 5 Restored regular menstrual period. ........

Analysis 1.6. Comparison 1 True acupuncture versus sham acupuncture, Outcome 6 Miscarriage rate.

Analysis 1.7. Comparison 1 True acupuncture versus sham acupuncture, Outcome 7 Adverse events.

Analysis 2.1. Comparison 2 Low-frequency electroacupuncture versus physical exercise or no intervention, Outcome 1 Restored regular menstrual period.

Analysis 2.2. Comparison 2 Low-frequency electroacupuncture versus physical exercise or no intervention, Outcome 2 Adverse events.

Analysis 3.1. Comparison 3 True acupuncture versus relaxation, Outcome 1 Ovulation rate.

Analysis 4.1. Comparison 4 True acupuncture versus clomiphene, Outcome 1 Restored regular menstrual period.

Analysis 4.2. Comparison 4 True acupuncture versus clomiphene, Outcome 2 Adverse events.

Analysis 5.1. Comparison 5 True acupuncture versus Diane-35, Outcome 1 Ovulation rate.

Analysis 5.2. Comparison 5 True acupuncture versus Diane-35, Outcome 2 Adverse events.

APPENDICES

WHAT'S NEW

HISTORY

CONTRIBUTIONS OF AUTHORS

DECLARATIONS OF INTEREST

SOURCES OF SUPPORT

DIFFERENCES BETWEEN PROTOCOL AND REVIEW

INDEX TERMS 
[Intervention Review]

\title{
Acupuncture for polycystic ovarian syndrome
}

\author{
Chi Eung Danforn Lim ${ }^{1}$, Rachel Wai Chung Ng², Nga Chong Lisa Cheng 3 , George Shengxi Zhang ${ }^{4}$, Hui Chen 5
}

${ }^{1}$ Faculty of Science, University of Technology Sydney, Earlwood, Australia. ${ }^{2}$ Westmead Hospital, Westmead, Australia. ${ }^{3}$ South Western Sydney Clinical School, Faculty of Medicine, University of New South Wales, Blakehurst, Australia. ${ }^{4}$ School of Science and Health, Western Sydney University, Campbelltown, Australia. ${ }^{5}$ School of Life Sciences, University of Technology Sydney, Sydney, Australia

Contact address: Chi Eung Danforn Lim, Faculty of Science, University of Technology Sydney, C/O Specialist Medical Services Group, 356 Homer Street, Earlwood, New South Wales, 2206, Australia. celim@unswalumni.com, profdanfornlim@gmail.com.

Editorial group: Cochrane Gynaecology and Fertility Group.

Publication status and date: Edited (no change to conclusions), published in Issue 7, 2019.

Citation: Lim CED, Ng RWC, Cheng NCL, Zhang GS, Chen H. Acupuncture for polycystic ovarian syndrome. Cochrane Database of Systematic Reviews 2019, Issue 7. Art. No.: CD007689. DOI: 10.1002/14651858.CD007689.pub4.

Copyright @ 2019 The Cochrane Collaboration. Published by John Wiley \& Sons, Ltd.

\section{A B S T R A C T}

\section{Background}

Polycystic ovarian syndrome (PCOS) is characterised by the clinical signs of oligo-amenorrhoea, infertility and hirsutism. Conventional treatment of PCOS includes a range of oral pharmacological agents, lifestyle changes and surgical modalities. Beta-endorphin is present in the follicular fluid of both normal and polycystic ovaries. It was demonstrated that the beta-endorphin levels in ovarian follicular fluid of otherwise healthy women who were undergoing ovulation were much higher than the levels measured in plasma. Given that acupuncture impacts on beta-endorphin production, which may affect gonadotropin-releasing hormone (GnRH) secretion, it is postulated that acupuncture may have a role in ovulation induction via increased beta-endorphin production effecting GnRH secretion. This is an update of our previous review published in 2016.

\section{Objectives}

To assess the effectiveness and safety of acupuncture treatment for oligo/anovulatory women with polycystic ovarian syndrome (PCOS) for both fertility and symptom control.

\section{Search methods}

We identified relevant studies from databases including the Gynaecology and Fertility Group Specialised Register, CENTRAL, MEDLINE, Embase, PsycINFO, CNKI, CBM and VIP. We also searched trial registries and reference lists from relevant papers. CENTRAL, MEDLINE, Embase, PsycINFO, CNKI and VIP searches are current to May 2018. CBM database search is to November 2015.

\section{Selection criteria}

We included randomised controlled trials (RCTs) that studied the efficacy of acupuncture treatment for oligo/anovulatory women with PCOS. We excluded quasi- or pseudo-RCTs.

\section{Data collection and analysis}

Two review authors independently selected the studies, extracted data and assessed risk of bias. We calculated risk ratios (RR), mean difference (MD), standardised mean difference (SMD) and 95\% confidence intervals (Cls). Primary outcomes were live birth rate, multiple pregnancy rate and ovulation rate, and secondary outcomes were clinical pregnancy rate, restored regular menstruation period, miscarriage rate and adverse events. We assessed the quality of the evidence using GRADE methods.

\section{Main results}

We included eight RCTs with 1546 women. Five RCTs were included in our previous review and three new RCTs were added in this update of the review. They compared true acupuncture versus sham acupuncture (three RCTs), true acupuncture versus relaxation (one RCT), true 
acupuncture versus clomiphene (one RCT), low-frequency electroacupuncture versus physical exercise or no intervention (one RCT) and true acupuncture versus Diane-35 (two RCTs). Studies that compared true acupuncture versus Diane-35 did not measure fertility outcomes as they were focused on symptom control.

Seven of the studies were at high risk of bias in at least one domain.

For true acupuncture versus sham acupuncture, we could not exclude clinically relevant differences in live birth (RR $0.97,95 \% \mathrm{Cl} 0.76$ to 1.24; $1 \mathrm{RCT}, 926$ women; low-quality evidence); multiple pregnancy rate (RR $0.89,95 \% \mathrm{Cl} 0.33$ to 2.45 ; 1 RCT, 926 women; low-quality evidence); ovulation rate (SMD $0.02,95 \% \mathrm{Cl}-0.15$ to $0.19, \mathrm{I} 2=0 \%$; $2 \mathrm{RCTs}, 1010$ women; low-quality evidence); clinical pregnancy rate (RR $1.03,95 \% \mathrm{Cl} 0.82$ to $1.29 ; \mathrm{I}^{2}=0 \%$; $3 \mathrm{RCTs}, 1117$ women; low-quality evidence) and miscarriage rate (RR $1.10,95 \% \mathrm{Cl} 0.77$ to $1.56 ; 1 \mathrm{RCT}$, 926 women; low-quality evidence).

Number of intermenstrual days may have improved in participants receiving true acupuncture compared to sham acupuncture (MD 312.09 days, $95 \% \mathrm{Cl}-344.59$ to $-279.59 ; 1 \mathrm{RCT}, 141$ women; low-quality evidence).

True acupuncture probably worsens adverse events compared to sham acupuncture (RR $1.16,95 \% \mathrm{Cl} 1.02$ to $1.31 ;\left.\right|^{2}=0 \% ; 3$ RCTs, 1230 women; moderate-quality evidence).

No studies reported data on live birth rate and multiple pregnancy rate for the other comparisons: physical exercise or no intervention, relaxation and clomiphene. Studies including Diane-35 did not measure fertility outcomes.

We were uncertain whether acupuncture improved ovulation rate (measured by ultrasound three months post treatment) compared to relaxation (MD $0.35,95 \%$ Cl 0.14 to 0.56 ; 1 RCT, 28 women; very low-quality evidence) or Diane-35 (RR $1.45,95 \%$ Cl 0.87 to $2.42 ; 1$ RCT, 58 women; very low-quality evidence).

Overall evidence ranged from very low quality to moderate quality. The main limitations were failure to report important clinical outcomes and very serious imprecision.

\section{Authors' conclusions}

For true acupuncture versus sham acupuncture we cannot exclude clinically relevant differences in live birth rate, multiple pregnancy rate, ovulation rate, clinical pregnancy rate or miscarriage. Number of intermenstrual days may improve in participants receiving true acupuncture compared to sham acupuncture. True acupuncture probably worsens adverse events compared to sham acupuncture.

No studies reported data on live birth rate and multiple pregnancy rate for the other comparisons: physical exercise or no intervention, relaxation and clomiphene. Studies including Diane-35 did not measure fertility outcomes as the women in these trials did not seek fertility.

We are uncertain whether acupuncture improves ovulation rate (measured by ultrasound three months post treatment) compared to relaxation or Diane-35. The other comparisons did not report on this outcome.

Adverse events were recorded in the acupuncture group for the comparisons physical exercise or no intervention, clomiphene and Diane-35. These included dizziness, nausea and subcutaneous haematoma. Evidence was very low quality with very wide Cls and very low event rates.

There are only a limited number of RCTs in this area, limiting our ability to determine effectiveness of acupuncture for PCOS.

\section{PLAIN LANGUAGE SUMMARY}

\section{Acupuncture for polycystic ovarian syndrome}

\section{Review question}

What is the effectiveness and safety of acupuncture treatment for ovulation disorders in women with polycystic ovarian syndrome (PCOS)?

\section{Background}

PCOS is where women have multiple cysts (fluid-filled sacs) on their ovaries (organs that produce eggs) and is characterised by the clinical signs of infrequent or very light menstruation (periods), failure to conceive (become pregnant) and excessive hair growth. Women may or may not have symptoms. The current standard western treatments for women with PCOS are prescription medicines, surgery and lifestyle changes. There has been evidence suggesting acupuncture may influence ovulation (release of the egg) by affecting levels of various hormones. Acupuncture is a Chinese therapy where fine needles are inserted into the skin in certain places. The exact mechanism of how acupuncture works for PCOS is not known and we aimed to explore the use of it for PCOS in this review.

\section{Study characteristics}


We searched medical databases for clinical studies where people were randomly put into one of two or more treatment groups including acupuncture treatment for women with PCOS who were infrequently or never ovulating. Acupuncture was compared with pretend acupuncture (sham), no treatment, lifestyle changes (e.g. relaxation) and conventional treatment.

We included eight studies with 1546 women in this review. The studies compared true acupuncture versus sham acupuncture, clomiphene (medicines to induce ovulation), relaxation and Diane-35 (combined oral contraceptive pill); and low-frequency electroacupuncture (where small electrical currents are passed through the acupuncture needles) versus physical exercise. We included women who wanted to get pregnant and women who wanted regular ovulation and symptom control as our two main populations of interest.

\section{Key results}

Our main interests were live birth rate, multiple pregnancy rate (for women who wanted to get pregnant) and ovulation rate (for women who wanted regular ovulation/symptom control). Due to the very low quality of the evidence and imprecise results, we were uncertain of the effect of acupuncture on live birth rate, multiple pregnancy rate and ovulation rate compared to sham acupuncture. For the same reasons, we were also uncertain of the effect of acupuncture on clinical pregnancy and miscarriage rate. Acupuncture may have improved restoration of regular menstrual periods. Acupuncture probably worsened side effects when compared to sham acupuncture.

No studies reported data on live birth rate and multiple pregnancy rate for the other comparisons: physical exercise or no intervention, relaxation and clomiphene. Studies including Diane-35 did not measure fertility outcomes as women were only interested in symptom control.

We were uncertain whether acupuncture improved ovulation rate compared to relaxation or Diane-35 (measured by ultrasound, which uses high-frequency sound waves to create an image, three months after treatment). The other comparisons did not report on ovulation rate.

Side effects were recorded in the acupuncture group for the comparisons physical exercise or no intervention, clomiphene and Diane-35. These included dizziness, nausea (feeling sick) and bruising.

The overall evidence was low or very low quality. There is currently insufficient evidence to support the use of acupuncture for treatment of ovulation disorders in women with PCOS.

\section{Quality of the evidence}

The evidence ranged from very low to moderate quality, the main limitations were not reporting important clinical results and not enough data. 
SUMMARY OF FINDINGS

\section{Summary of findings for the main comparison. True acupuncture compared to sham acupuncture for polycystic ovarian syndrome}

True acupuncture compared to sham acupuncture for polycystic ovarian syndrome

Patient or population: polycystic ovarian syndrome

Setting: outpatient

Intervention: true acupuncture

Comparison: sham acupuncture

\begin{tabular}{|c|c|c|c|c|c|}
\hline \multirow[t]{2}{*}{ Outcomes } & \multicolumn{2}{|c|}{ Anticipated absolute effects* $(95 \% \mathrm{Cl})$} & \multirow{2}{*}{$\begin{array}{l}\text { Relative effect } \\
(95 \% \mathrm{CI})\end{array}$} & \multirow{2}{*}{$\begin{array}{l}\text { № of partici- } \\
\text { pants } \\
\text { (studies) }\end{array}$} & \multirow{2}{*}{$\begin{array}{l}\text { Quality of the } \\
\text { evidence } \\
\text { (GRADE) }\end{array}$} \\
\hline & Risk with sham acupuncture & Risk with true acupuncture & & & \\
\hline Live birth rate & 224 per 1000 & $\begin{array}{l}218 \text { per } 1000 \\
\text { (171 to } 278)\end{array}$ & $\begin{array}{l}\text { RR } 0.97 \\
(0.76 \text { to } 1.24)\end{array}$ & $\begin{array}{l}926 \\
(1 \mathrm{RCT})\end{array}$ & $\begin{array}{l}\oplus \oplus \ominus \ominus \\
\text { Low }^{\mathrm{a}, \mathrm{b}}\end{array}$ \\
\hline $\begin{array}{l}\text { Multiple pregnancy } \\
\text { rate }\end{array}$ & 17 per 1000 & $\begin{array}{l}15 \text { per } 1000 \\
(6 \text { to } 42)\end{array}$ & $\begin{array}{l}\text { RR } 0.89 \\
(0.33 \text { to } 2.45)\end{array}$ & $\begin{array}{l}926 \\
(1 \mathrm{RCT})\end{array}$ & $\begin{array}{l}\oplus \oplus \ominus \ominus \\
\text { Low }^{\mathrm{a}, \mathrm{b}}\end{array}$ \\
\hline Ovulation rate & The mean ovulation rate was 0 & $\begin{array}{l}\text { SMD } 0.02 \text { higher } \\
\text { ( } 0.15 \text { lower to } 0.19 \text { higher) }\end{array}$ & - & $\begin{array}{l}1010 \\
\text { (2 RCTs) }\end{array}$ & $\begin{array}{l}\oplus \oplus \ominus \ominus \\
\text { Lowc, d }\end{array}$ \\
\hline $\begin{array}{l}\text { Clinical pregnancy } \\
\text { rate }\end{array}$ & \multicolumn{2}{|l|}{ Study population } & $\begin{array}{l}\text { RR } 1.03 \\
(0.82 \text { to } 1.29)\end{array}$ & $\begin{array}{l}1117 \\
\text { (3 RCTs) }\end{array}$ & $\begin{array}{l}\oplus \oplus \ominus \ominus \\
\text { Low }^{\mathrm{d}, \mathrm{e}}\end{array}$ \\
\hline $\begin{array}{l}\text { Restored regular } \\
\text { menstrual period }\end{array}$ & $\begin{array}{l}\text { The mean restored regular men- } \\
\text { strual period was } 0\end{array}$ & $\begin{array}{l}\text { MD } 312.09 \text { days lower } \\
\text { (344.59 lower to } 279.59 \text { lower) }\end{array}$ & - & $\begin{array}{l}141 \\
(1 \mathrm{RCT})\end{array}$ & $\begin{array}{l}\oplus \oplus \odot \ominus \\
\text { Low }^{f}\end{array}$ \\
\hline \multirow[t]{2}{*}{ Miscarriage rate } & \multicolumn{2}{|l|}{ Study population } & \multirow{2}{*}{$\begin{array}{l}\text { RR } 1.10 \\
(0.77 \text { to } 1.56)\end{array}$} & \multirow{2}{*}{$\begin{array}{l}926 \\
(1 \mathrm{RCT})\end{array}$} & \multirow{2}{*}{$\begin{array}{l}\oplus \oplus \ominus \ominus \\
\text { Low }^{\mathrm{a}, \mathrm{b}}\end{array}$} \\
\hline & 113 per 1000 & $\begin{array}{l}125 \text { per } 1000 \\
\text { ( } 87 \text { to } 177)\end{array}$ & & & \\
\hline Adverse events & Study population & & $\begin{array}{l}\text { RR } \mathbf{1 . 1 6} \\
\text { (1.02 to } 1.31)\end{array}$ & $\begin{array}{l}1230 \\
\text { (3 RCTs) }\end{array}$ & $\begin{array}{l}\oplus \oplus \oplus \ominus \\
\text { Moderate }\end{array}$ \\
\hline
\end{tabular}




400 per $1000 \quad 464$ per 1000

(408 to 524)

*The risk in the intervention group (and its $95 \%$ confidence interval) is based on the assumed risk in the comparison group and the relative effect of the intervention (and its $95 \% \mathrm{Cl})$.

CI: confidence interval; MD: mean difference; $\mathbf{R C T}$ : randomised controlled trial; RR: risk ratio; SMD: standardised mean difference.

\section{GRADE Working Group grades of evidence}

High quality: we are very confident that the true effect lies close to that of the estimate of the effect.

Moderate quality: we are moderately confident in the effect estimate: the true effect is likely to be close to the estimate of the effect, but there is a possibility that it is substantially different.

Low quality: our confidence in the effect estimate is limited: the true effect may be substantially different from the estimate of the effect.

Very low quality: we have very little confidence in the effect estimate: the true effect is likely to be substantially different from the estimate of effect.

aDowngraded one level for high risk of detection bias in one study.

bDowngraded one level for imprecision - single study and confidence intervals compatible with benefit in either arm or no effect.

cDowngraded one level for high risk of performance bias in one study.

dDowngraded one level for imprecision - confidence intervals compatible with benefit in either arm or no effect.

eDowngraded one level for high risk of attrition bias and detection bias in two studies.

fDowngraded two levels for imprecision - single study with small sample size.

Summary of findings 2 . Low-frequency electroacupuncture compared to physical exercise or no intervention for polycystic ovarian syndrome

\section{Low-frequency electroacupuncture compared to physical exercise or no intervention for polycystic ovarian syndrome}

Patient or population: polycystic ovarian syndrome

Setting: outpatient

Intervention: low-frequency electroacupuncture

Comparison: physical exercise or no intervention

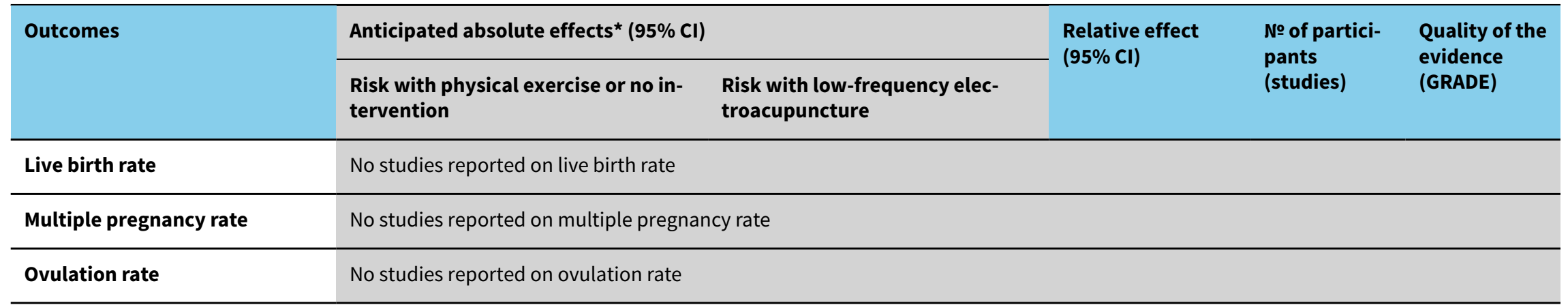




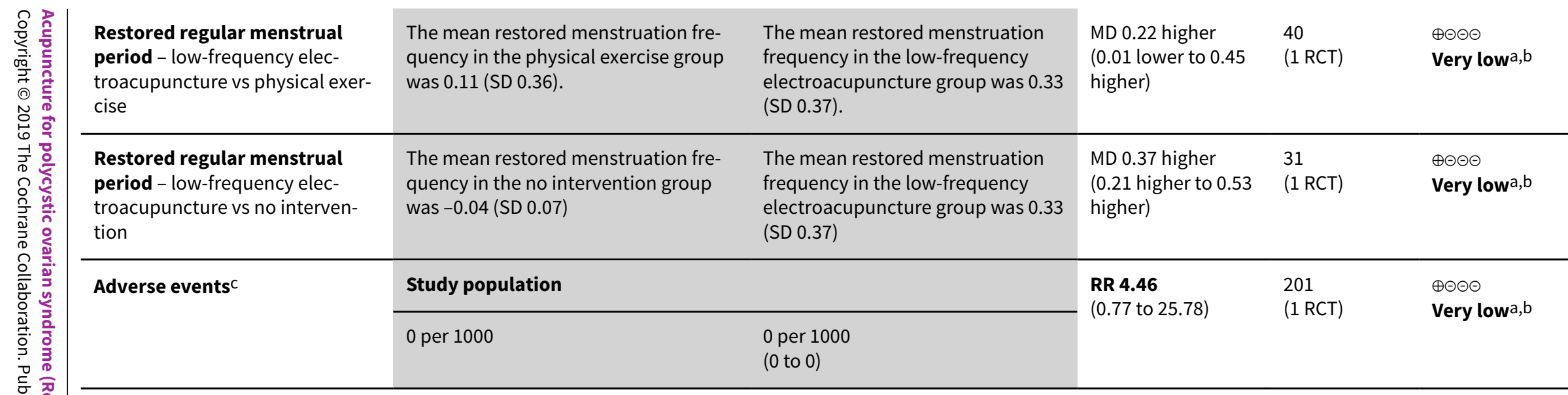

${ }^{*}$ The risk in the intervention group (and its 95\% confidence interval) is based on the assumed risk in the comparison group and the relative effect of the intervention (and its $95 \% \mathrm{Cl})$.

Cl: confidence interval; MD: mean difference; $\mathbf{R C T}$ : randomised controlled trial; RR: risk ratio; SD: standard deviation.

\section{GRADE Working Group grades of evidence}

High quality: we are very confident that the true effect lies close to that of the estimate of the effect.

Moderate quality: we are moderately confident in the effect estimate: the true effect is likely to be close to the estimate of the effect, but there is a possibility that it is sub-

stantially different.

Low quality: our confidence in the effect estimate is limited: the true effect may be substantially different from the estimate of the effect.

Very quality: we have very little confidence in the effect estimate: the true effect is likely to be substantially different from the estimate of effect.

aDowngraded two levels for high risk of performance bias and detection bias.

bDowngraded two levels for imprecision - single study with small sample size.

cFive cases of adverse events were recorded in the low-frequency electroacupuncture group and no adverse events were reported in the physical exercise or no intervention group.

\section{Summary of findings 3. True acupuncture compared to relaxation for polycystic ovarian syndrome}

True acupuncture compared to relaxation for polycystic ovarian syndrome

Patient or population: polycystic ovarian syndrome

Setting: outpatient

Intervention: true acupuncture

Comparison: relaxation

Outcomes

Anticipated absolute effects ${ }^{\star}(95 \% \mathrm{Cl})$

Risk with relaxation

Risk with true acupuncture
Relative effect № of participants

$(95 \% \mathrm{CI})$

(studies)

Quality of the evidence

(GRADE) 


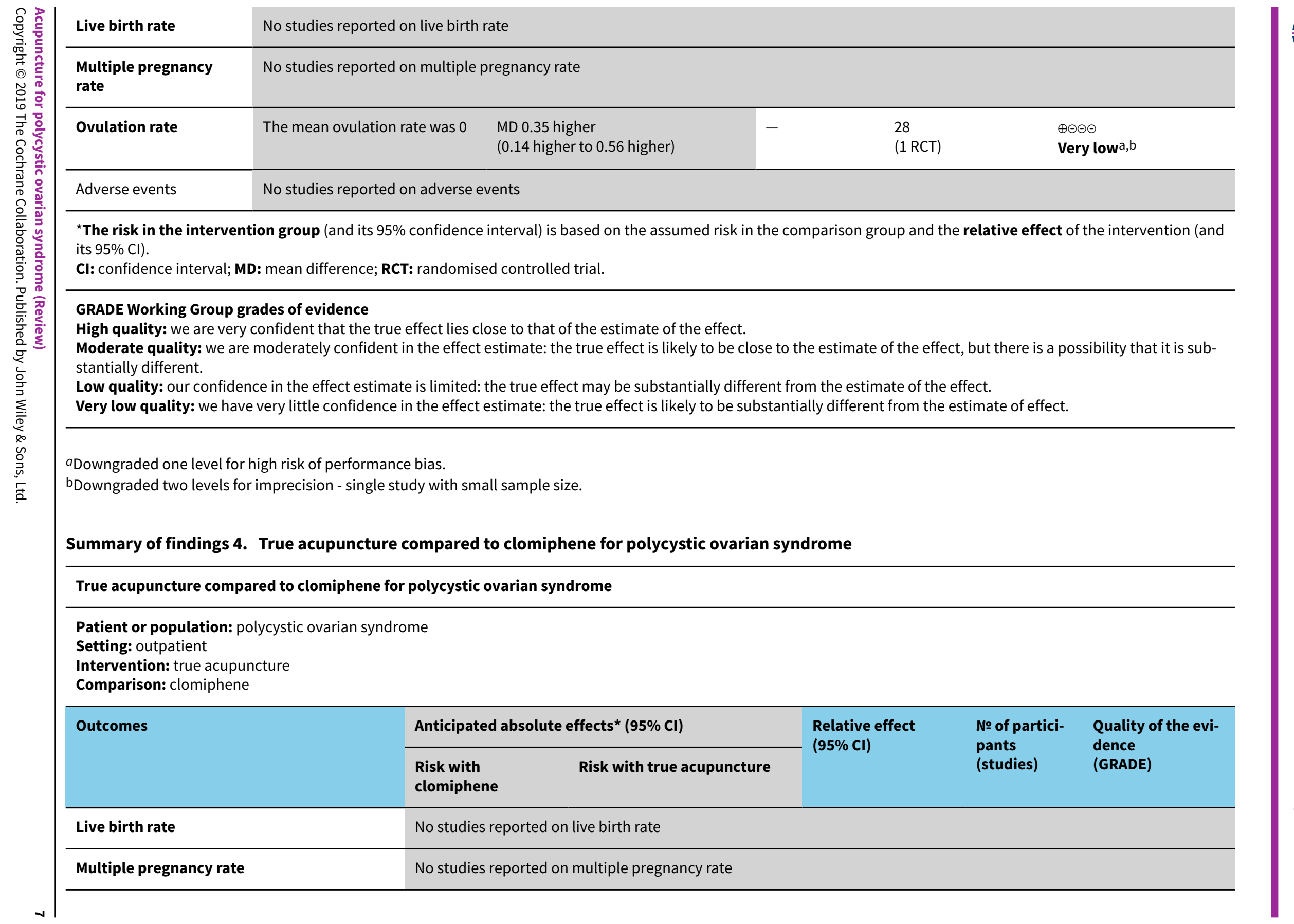




\begin{tabular}{|c|c|c|c|c|c|c|}
\hline \multirow{3}{*}{\multicolumn{2}{|c|}{ 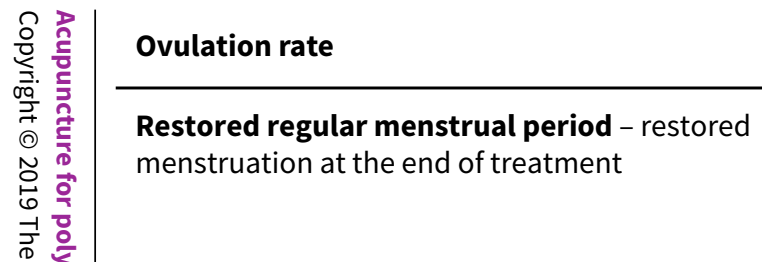 }} & \multicolumn{5}{|c|}{ No studies reported on ovulation rate } \\
\hline & & \multicolumn{2}{|c|}{ Study population } & \multirow{2}{*}{$\begin{array}{l}\text { RR } 1.64 \\
\text { (0.94 to } 2.85 \text { ) }\end{array}$} & \multirow{2}{*}{$\begin{array}{l}60 \\
(1 \mathrm{RCT})\end{array}$} & \multirow{2}{*}{$\begin{array}{l}\oplus \odot \Theta \odot \\
\text { Very low } a, b\end{array}$} \\
\hline & & 367 per 1000 & $\begin{array}{l}601 \text { per } 1000 \\
\text { (345 to } 1000)\end{array}$ & & & \\
\hline $\bar{n}$ & Restored regular menstrual period - restored & \multicolumn{2}{|c|}{ Study population } & \multirow{2}{*}{$\begin{array}{l}\text { RR 1.50 } \\
\text { (1.03 to } 2.19)\end{array}$} & \multirow{2}{*}{$\begin{array}{l}60 \\
(1 \mathrm{RCT})\end{array}$} & \multirow{2}{*}{$\begin{array}{l}\oplus \ominus \Theta \Theta \\
\text { Very lowa,c }\end{array}$} \\
\hline 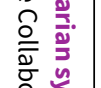 & & 533 per 1000 & $\begin{array}{l}800 \text { per } 1000 \\
(549 \text { to } 1000)\end{array}$ & & & \\
\hline 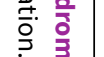 & \multirow[t]{2}{*}{ Adverse events } & \multicolumn{2}{|c|}{ Study population } & \multirow{2}{*}{$\begin{array}{l}\text { RR } \mathbf{1 . 3 3} \\
\text { (0.30 to } 5.83 \text { ) }\end{array}$} & \multirow{2}{*}{$\begin{array}{l}120 \\
(1 \mathrm{RCT})\end{array}$} & \multirow{2}{*}{$\begin{array}{l}\oplus \ominus \ominus \ominus \\
\text { Very lowa,b }\end{array}$} \\
\hline 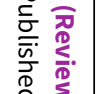 & & 33 per 1000 & $\begin{array}{l}44 \text { per } 1000 \\
(10 \text { to } 194)\end{array}$ & & & \\
\hline
\end{tabular}

${ }^{\star}$ The risk in the intervention group (and its $95 \%$ confidence interval) is based on the assumed risk in the comparison group and the relative effect of the intervention (and its $95 \% \mathrm{Cl})$.

CI: confidence interval; RCT: randomised controlled trial; RR: risk ratio.

\section{GRADE Working Group grades of evidence}

High quality: we are very confident that the true effect lies close to that of the estimate of the effect.

Moderate quality: we are moderately confident in the effect estimate: the true effect is likely to be close to the estimate of the effect, but there is a possibility that it is sub-

stantially different.

Low quality: our confidence in the effect estimate is limited: the true effect may be substantially different from the estimate of the effect.

Very low quality: we have very little confidence in the effect estimate: the true effect is likely to be substantially different from the estimate of effect.

aDowngraded two levels for high risk of performance bias, detection bias, reporting bias and other bias.

bDowngraded two levels for imprecision - single study with small sample size and confidence intervals compatible with benefit in either arm or no effect.

cDowngraded two levels for imprecision - single study with small sample size.

Summary of findings 5. True acupuncture compared to Diane-35 for polycystic ovarian syndrome

True acupuncture compared to Diane-35 for polycystic ovarian syndrome

Patient or population: polycystic ovarian syndrome

Setting: outpatient

Intervention: true acupuncture

Comparison: Diane-35

Outcomes Anticipated absolute effects* $(95 \% \mathrm{C})$




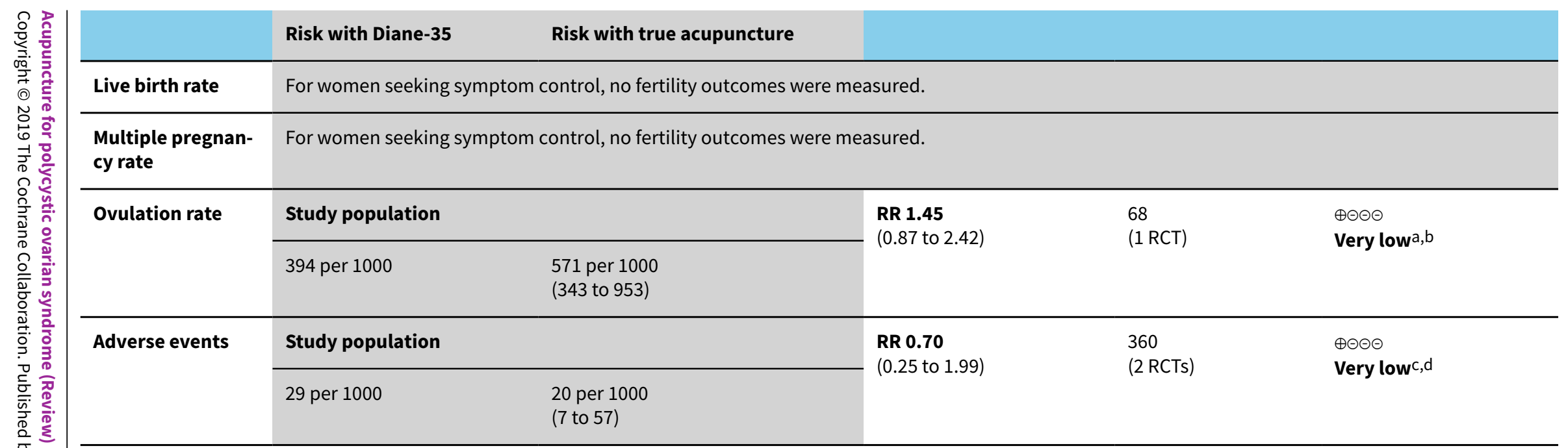

${ }^{*}$ The risk in the intervention group (and its 95\% confidence interval) is based on the assumed risk in the comparison group and the relative effect of the intervention (and its $95 \% \mathrm{Cl})$.

Cl: confidence interval; RCT: randomised controlled trial; RR: risk ratio.

\section{GRADE Working Group grades of evidence}

High quality: we are very confident that the true effect lies close to that of the estimate of the effect.

Moderate quality: we are moderately confident in the effect estimate: the true effect is likely to be close to the estimate of the effect, but there is a possibility that it is substantially different.

Low quality: our confidence in the effect estimate is limited: the true effect may be substantially different from the estimate of the effect.

Very low quality: we have very little confidence in the effect estimate: the true effect is likely to be substantially different from the estimate of effect.

aDowngraded two levels for high risk of performance bias, detection bias, attrition bias and other bias.

bDowngraded two levels for imprecision - single study with small sample size and confidence intervals compatible with benefit in either arm or no effect.

cDowngraded two levels for high risk of performance bias, detection bias and attrition bias in two studies; additional high risk of other bias in one study.

dDowngraded two levels for imprecision - small sample size and confidence intervals compatible with benefit in either arm or no effect. 


\section{B A C K G R O U N D}

\section{Description of the condition}

Polycystic ovarian syndrome (PCOS) is characterised by the clinical signs of oligo-amenorrhoea (infrequent or very light menstruation), infertility (failure to conceive) and hirsutism (excessive hair growth). Biochemically, women with PCOS often show signs of hyperandrogenism (excessive production of androgen). They often have anovulatory infertility (failure to conceive due to no ovulation), and metabolic disorders (e.g. diabetes mellitus) (Wild 2000). In addition, PCOS can have substantial implications on a woman's psychological well-being across the entire lifespan (Teede 2010). PCOS has become a major healthcare issue that deserves an increase in focus, from both clinical and public health perspectives.

Clinically, PCOS is one of the most common endocrine conditions seen in gynaecology and general endocrinology practice (Norman 2004). The diagnostic criteria for PCOS that we applied in this review were based on the Rotterdam Criteria established by the European Society of Human Reproduction and Embryology (ESHRE) and the American Society of Reproductive Medicine (ASRM) consensus in Rotterdam, 2003 (ESHRE/ASRM 2004). Any woman with at least two of the following three criteria were considered to have PCOS: ovulatory dysfunction (oligoor anovulation), hyperandrogenaemia or polycystic ovaries on ultrasound evaluation; after the exclusion of other aetiologies of hyperandrogenism (excessive production of androgens such as androgen-secreting tumours, hyperprolactinaemia, dysthyroid disease, Cushing's syndrome and congenital adrenal cortical hyperplasia).

In 2012, the prevalence rate of PCOS was between $6 \%$ and $10 \%$ based on the National Institute of Health criteria and was as high as $15 \%$ based on the Rotterdam criteria (Fauser 2012). Limited data are available regarding prevalence of this condition in Australia. One south Australian survey identified that $12 \%$ to $18 \%$ of women of reproductive age were affected (March 2010). National differences in prevalence rates exist, for example, one study showed a rate of $26 \%$ in the UK (Michelmore 1999). Results from these surveys are dependent on the protocol used. If the US criteria that do not consider ovarian morphology were adopted, the prevalence rate ranged from $4.5 \%$ to $11.2 \%$ from an unselected group of white and black Americans in a population-based study in Alabama (Knochenhauer 1998). There was a prevalence rate of $9 \%$ in Greece (Diamanti-Kandarakis 1999), and 6.5\% in Spain (Asunicón 2000). The highest reported prevalence of PCOS was $52 \%$ among South Asian immigrants in the UK, of whom $49.1 \%$ had menstrual irregularities (Rodin 1998).

In traditional Chinese medicine, all diseases are classified into different syndromes (e.g. deficiency or excess) according to the person's clinical presentations (signs and symptoms). It is believed that kidney deficiency is the major concern relating to the reproductive function of women with PCOS (Ni 2007; Wang 2008).

\section{Description of the intervention}

Body acupuncture and ear acupuncture have been used as treatments for oligo/anovulatory women with PCOS. Body acupuncture involves stimulation of body acupuncture points through body needling using different sized sterile needles; while ear acupuncture involves points on the external ears that are stimulated either by needles or pellets. In randomised controlled trials (RCTs) of acupuncture, sham acupuncture is also known as placebo acupuncture. However, how sham acupuncture should be performed still remains controversial and can be different from study to study. The general principle of administering sham acupuncture is not to stimulate the actual acupuncture point with needles or electrostimulation.

Electroacupuncture is also known as electrostimulation. It is performed using stimulation with electrical impulses of acupuncture needles on selected acupuncture points.

Acupuncture is known to be a safe treatment. Transient adverse effects, such as skin erythema, bruising, bleeding and pain, are uncommon. Reports of significant complications are exceedingly rare. One observational study including more than 200,000 participants who received acupuncture for pain found an adverse event rate of $8.6 \%$ (Witt 2009). Another similar study estimated that the serious adverse event rate was between 0 and 1.1 per 10,000 treatments (MacPherson 2001).

Currently the first-line pharmacological therapy for anovulatory infertility in women with PCOS is the administration of oral selective oestrogen receptor modulator such as clomiphene (Teede 2011). However, up to $40 \%$ of affected women show little clinical improvement with clomiphene therapy (Brown 2009). Other agents, such as insulin sensitisers, are used. This is based on the hypothesis that increasing insulin sensitivity reduces serum androgen levels thus improving fertility (Acbay 1996). Evidence suggests that metformin offers some improvement beyond clomiphene therapy (Tang 2012). Women resistant to these therapies can be further trialled on exogenous gonadotrophin preparations (ESHRE 1997). Alternatively, surgical options, such as laparoscopic ovarian drilling, can be explored (Gadir 1990). Women who respond to clomiphene therapy have higher risks of ovarian hyperstimulation syndrome and multiple pregnancy (Farhi 1996). Combined oral contraceptive pills such as Diane-35 (ethinylestradiol and cyproterone acetate) are also used in women with PCOS to achieve symptom control. Oestrogen increases sex hormone binding globulin (SHBG) while progestin suppress luteinising hormone (LH) levels resulting in decreased production of androgen by the ovaries and decreased bioavailable androgen. This results in improvement in symptoms including hirsutism, acne and menstrual irregularity seen in women with PCOS. Thus, oral contraceptives are recommended as first-line therapy for hirsutism, acne and menstrual abnormalities in women with PCOS (Legro 2013).

In recent years there has been extensive interest into non-steroidal aromatase inhibitors such as letrozole. In anovulatory women, aromatase inhibitors downregulate oestrogen biosynthesis and reduce negative feedback to the hypothalamus, which leads to stronger gonadotropin-releasing hormone $(\mathrm{GnRH})$ pulses (Franik 2018). One Cochrane Review suggested a significant efficacy advantage to clomiphene, despite low to moderate quality of evidence (Franik 2018). Aromatase inhibitors are also free from adverse effects associated with antioestrogenic effects in the endometrium and cervix. Nevertheless, currently, use of such therapy is limited by low quality of supportive evidence. 


\section{How the intervention might work}

Scientific studies have investigated the acupuncture meridians and the neuroendocrinological aspects of the meridians. Mayer 1977 proposed that acupuncture may stimulate the production of endorphin, an effect antagonised (counteracted) by the narcotic antagonist naloxone, in order to provide an analgesic effect. Ku 2001, Petti 1998, and Ulett 1998 have carried out further research in this area and postulated that beta-endorphin and various neuropeptides (e.g. protein pro-opiomelanocortin) within the nervous system may be implicated in producing the effects of acupuncture.

Aleem 1987 identified the presence of beta-endorphin in the follicular fluid from both normal and polycystic ovaries. Petraglia 1987 demonstrated that the beta-endorphin levels in ovarian follicular fluid of otherwise healthy women who were undergoing ovulation were much higher than the levels measured in plasma. Studies have shown that acupuncture decreases cortisol concentrations and modulates central and peripheral betaendorphin production and secretion, influencing the release of $\mathrm{GnRH}$ and gonadotrophin (Stener-Victorin 2007). Different nonrandomised preliminary observational studies have shown that acupuncture may normalise the production of LH and folliclestimulating hormone (FSH) (Aso 1976; Cai 1997; Mo 1993). Chen 1991 considered that electroacupuncture has a role in normalising the hypothalamic-pituitary ovarian axis, which in turn affects the menstruation cycle pattern. Clinically, the selection of acupuncture points is based on traditional Chinese medicine principles and can be variable.

Gerhard 1992 (in a case series) used ear acupuncture on 45 infertile women with dysfunction of ovulation and compared the treatment group with women receiving conventional medical treatment (e.g. dexamethasone, clomiphene citrate and gonadotropin). They concluded that the rate of return of menstruation was comparatively better in the ear acupuncture group despite no difference between the two groups on pregnancy rates.

Stener-Victorin 2000 (in a case series) investigated its efficacy on ovulation induction in women with PCOS. Although the sample size was small (24 participants), two-thirds of the women in the study reported a regular menstruation pattern for up to three months after cessation of the electroacupuncture treatment.

\section{Why it is important to do this review}

Women with PCOS seek both fertility and symptom control such as irregular menstrual cycles, amenorrhoea, insulin resistance, polycystic ovaries, androgen disturbance, hirsutism, acne, or a combination of these. Currently the main forms of treatment for women with PCOS are pharmacological-based therapies such as clomiphene for fertility and the combined oral contraceptive pill for symptoms control (e.g. irregular menstrual cycles). However, pharmacological-based therapies are also associated with different adverse effects.

Acupuncture is growing in popularity among western countries. Xue 2007 reported that $68.9 \%$ of the Australian population are users of complementary and alternative medicine, while $9.2 \%$ of the Australian population have used acupuncture according to a national population-based survey performed in 2005. In the UK, a steady increase over time in the utilisation of acupuncture was reported from 3 million per year in 2001 to about 4 million in 2012 (Hopton 2012; Thomas 2001). In the USA, the number of acupuncture users increased by $50 \%$ over the 10 -year period from 2002 to 2012 (Cui 2017).

Previously there was uncertainty regarding the efficacy of acupuncture for oligo/anovulatory women with PCOS due to absence of RCTs and systematic reviews. This present review will contribute to the clinical knowledge in this area by summarising currently available knowledge. From a clinical point of view, the management of PCOS has been an evolving area where current paradigms were continuously challenged with novel modalities. This review aimed to address both women with PCOS who seek fertility and those that seek symptom control. This is an update of a Cochrane Review first published in 2011, which aimed to provide an objective basis for healthcare practitioners to recommend acupuncture treatment for women where complementary therapy may be appropriate.

\section{O B JECT IVES}

To assess the effectiveness and safety of acupuncture treatment for oligo/anovulatory women with polycystic ovarian syndrome (PCOS) for both fertility and symptom control.

\section{METHODS}

\section{Criteria for considering studies for this review Types of studies}

RCTs studying the efficacy of acupuncture treatment for oligo/ anovulation in women with PCOS. We excluded quasi-, pseudoor non-RCTs. We excluded cross-over trials unless first-phase data were available.

\section{Types of participants}

Women of reproductive age (18 to 44 years) with PCOS and oligo/ anovulation. We included both women who sought fertility and those that sought symptom control.

The diagnostic criteria of PCOS applied in this review were based on the ESHRE and ASRM consensus in Rotterdam in 2003 (ESHRE/ASRM 2004). We considered any woman with any two of the three listed criteria as having PCOS. After the exclusion of other aetiologies of hyperandrogenism (such as androgen-secreting tumour, hyperprolactinaemia, dysthyroid disease, Cushing's syndrome and congenital adrenal cortical hyperplasia), these were the presence of:

- oligo or anovulation;

- hyperandrogenaemia or

- polycystic ovaries.

Ideally the diagnostic criteria for PCOS should have been stated and described in trials selected for this review. If the trials did not use the Rotterdam consensus, the review authors evaluated the diagnostic criteria for each individual study to confirm whether they met the Rotterdam consensus. If the diagnostic criteria were not clearly stated, we contacted the trial authors to obtain clarification. Where clarification was not available, we excluded the trials. Differences in diagnostic criteria may produce variability in the clinical characteristics of the women included and the results 
obtained. We had planned to consider, document and explore these changes in a sensitivity analysis.

\section{Types of interventions}

Acupuncture, including body needling and low-frequency electroacupuncture, was the main intervention.

Eligible comparators were placebo, no intervention, lifestyle intervention and conventional treatment of PCOS (e.g. clomiphene citrate).

Sham acupuncture is also known as placebo acupuncture and uses techniques that are not intended to stimulate known acupuncture points. Normally it is used for the control group in a RCTs of acupuncture.

We excluded clinical trials using Chinese herbal medicine for the management of PCOS from this review because it is assessed in another Cochrane Review (Zhang 2010). We also excluded clinical trials that included ovarian wedge resection as the control intervention because this method is no longer applied by surgeons since the development of laparoscopic ovarian drilling.

\section{Types of outcome measures}

\section{Primary outcomes}

- Live birth rate (defined as delivery of live foetus after 20 completed weeks of gestation) - for women seeking fertility.

- Multiple pregnancy rate (defined as more than one intrauterine pregnancy) - for women seeking fertility.

- Ovulation rate (as determined by ultrasound or increased progesterone) - for women seeking symptom control.

\section{Secondary outcomes}

- Clinical pregnancy rate (defined as evidence of gestational sac or foetal heart motion, confirmed with ultrasound).

- Restored regular menstrual period (as defined by study authors, including rate or continuous measurements).

- Miscarriage rate (loss of intrauterine pregnancy before 20 completed weeks of gestation).

- Adverse events (as defined by study authors).

\section{Search methods for identification of studies}

We developed a comprehensive search strategy to identify all RCTs regardless of language or publication status (published, unpublished, in press or in progress).

\section{Electronic searches}

We identified relevant studies from:

- the Gynaecology and Fertility Group Specialised Register (searched 22 May 2018);

- CENTRAL via the Cochrane Central Register of Studies Online (CRSO) (searched 22 May 2018);

- Ovid MEDLINE (searched from 1946 to 22 May 2018);

- Ovid Embase (searched from 1980 to 22 May 2018);

- Ovid PsycINFO (searched from 1806 to 22 May 2018);
- Ovid AMED (searched from 1985 to 22 May 2018);

- Chinese National Knowledge Infrastructure (CNKI; including the Chinese journal full-text database (CJFD), China's important Conference Papers Database and China dissertation database) (searched from 2010 to 24 May 2018);

- Chinese BioMedical Literature Database (CBM) (searched from 2010 to 21 November 2015);

- VIP database for Chinese Technical Periodicals (searched from 2010 to 24 May 2018).

We combined the MEDLINE search with the Cochrane highly sensitive search strategy for identifying randomised trials, which appears in Chapter 6 of the Cochrane Handbook for Systematic Reviews of Interventions (Higgins 2011). We combined the Embase search with trial filters developed by the Scottish Intercollegiate Guidelines Network (SIGN) (www.sign.ac.uk/search-filters.html).

We constructed search strategies by using a combination of subject headings and text words relating to the use of acupuncture for the management of PCOS (Appendix 1; Appendix 2; Appendix 3; Appendix 4; Appendix 5; Appendix 6; Appendix 7; Appendix 8; Appendix 9). All the terms were translated into Chinese for the searches in Chinese databases to be conducted. There was no language restriction in these searches.

We searched trial registers for ongoing and registered trials on 22 May 2018: ClinicalTrials.gov, a service of the US National Institutes of Health (clinicaltrials.gov/ct2/home); the World Health Organization International Trials Registry Platform search portal (www.who.int/trialsearch/Default.aspx); the Australian and New Zealand Clinical Trial Registry (www.anzctr.org.au/ Default.aspx) (Appendix 10); and Chinese Clinical Trial Registry (www.chictr.org.cn/).

\section{Searching other resources}

We checked the reference lists of relevant trials, reviews and textbooks.

\section{Data collection and analysis}

\section{Selection of studies}

In this update, two review authors (RN, GZ) performed the searches and retrieved the articles. We retrieved and reviewed all studies that claimed to be randomised and had not already been reviewed as part of earlier versions of this review. We judged trials as adequately randomised if they met the set criteria (Higgins 2011).

\section{Data extraction and management}

In this update, two review authors (RN, GZ) independently extracted data using a piloted data extraction form, which included details of methods, participants, interventions and outcomes. All studies were then assessed independently and any dispute was resolved by a third independent review author $(\mathrm{HC})$.

\section{Assessment of risk of bias in included studies}

We assessed the methodological quality using the six domains described in Cochrane's tool for assessing risk of bias (Figure 1; Figure 2): 
Figure 1. Risk of bias graph: review authors' judgements about each risk of bias item presented as percentages across all included studies.

Random sequence generation (selection bias)

Allocation concealment (selection bias)

Blinding of participants and personnel (performance bias)

Blinding of outcome assessment (detection bias)

Incomplete outcome data (attrition bias)

Selective reporting (reporting bias)

Other bias

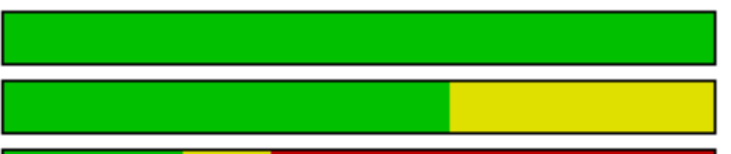

L
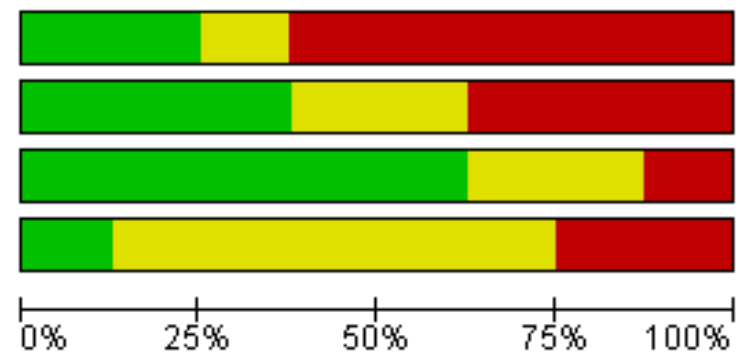

Low risk of bias

Unclear risk of bias

High risk of bias 
Figure 2. Risk of bias summary: review authors' judgements about each risk of bias item for each included study.

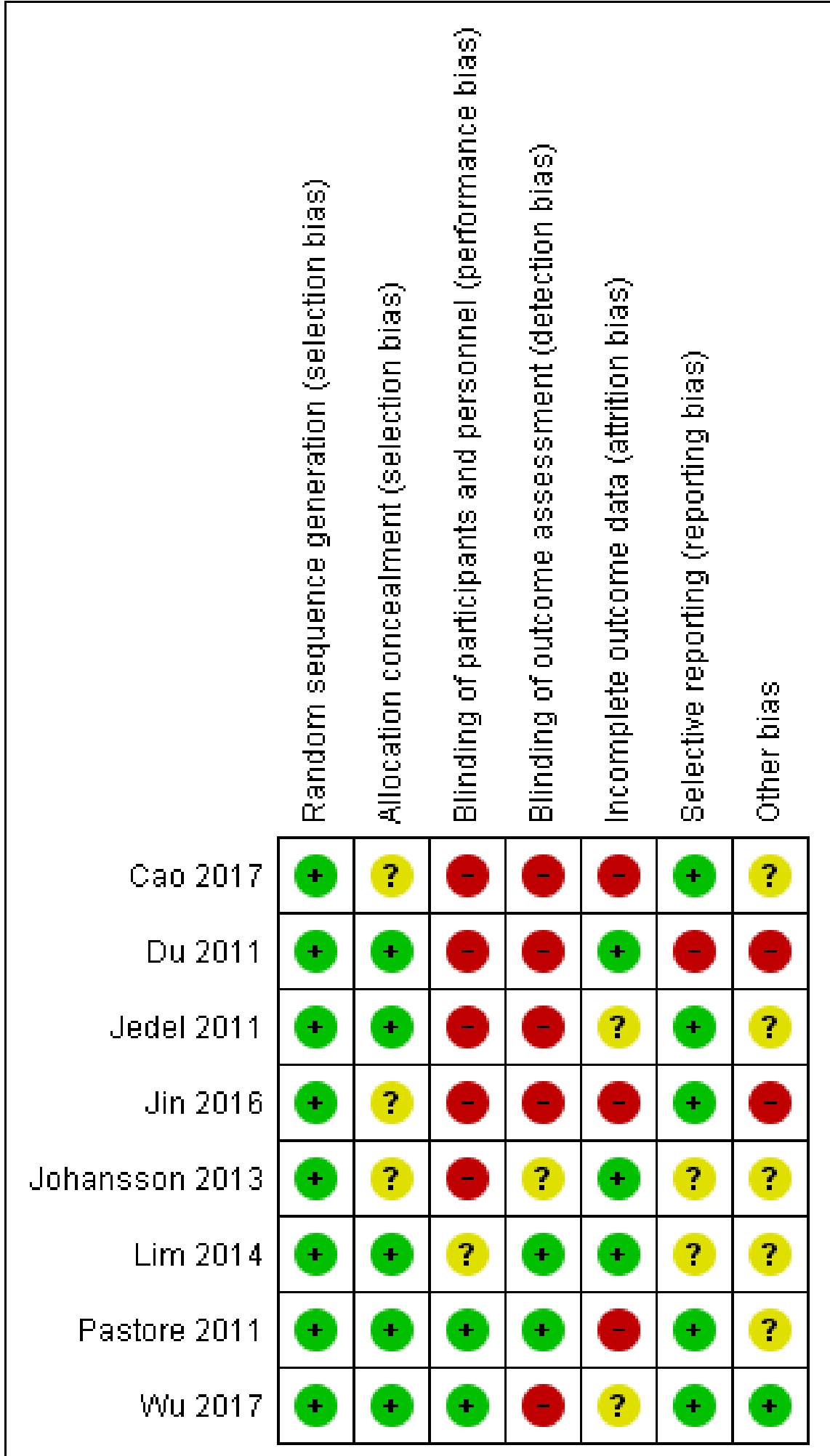

- sequence generation;

- allocation concealment;

- blinding of participants and personnel;

- blinding of outcome assessment;
- incomplete outcome data;

- selective outcome reporting;

- other sources of bias. 


\section{Measures of treatment effect}

We used risk ratio (RR) to measure binary outcomes. For continuous outcomes, we used mean difference (MD) if the studies used same measurement scales. If studies used different scales, we used the standardised mean difference (SMD). We calculated 95\% confidence intervals $(\mathrm{Cl})$ for all outcomes.

\section{Unit of analysis issues}

The unit of analysis was the woman for all outcomes.

\section{Dealing with missing data}

We analysed the data on an intention-to-treat (ITT) basis as far as possible (i.e. including all randomised participants in analysis, in the groups to which they were randomised). Where data were not obtainable, we analysed only the available data.

\section{Assessment of heterogeneity}

We assessed heterogeneity using the $\mathrm{Chi}^{2}$ test (with a $10 \%$ level of statistical significance). We planned to use the $1^{2}$ statistic to estimate the total variation across studies, with less than $25 \%$ considered as low-level heterogeneity; $25 \%$ to $50 \%$ as moderate level and greater than $50 \%$ as a high level of heterogeneity (Higgins 2002). In addition, we scanned forest plots visually for evidence of heterogeneity (non-overlapping Cls). We planned further investigation such as subgroup analysis to be carried out to consider possible causes of any heterogeneity. In addition, we planned to use a random-effects model if statistical heterogeneity was evident from the formal tests.

\section{Assessment of reporting biases}

We planned to assess publication bias using a funnel plot, if there were sufficient studies (at least 10) in one analysis.

\section{Data synthesis}

If the studies were sufficiently similar, we combined the data using a fixed-effect model. Comparisons included in this review were:

- true acupuncture versus sham acupuncture;

- low-frequency electroacupuncture versus physical exercise or no intervention;

- true acupuncture versus lifestyle intervention (relaxation);

- true acupuncture versus conventional treatment (clomiphene);

- true acupuncture versus conventional treatment (Diane-35).

\section{Subgroup analysis and investigation of heterogeneity}

If there is a sufficient number of RCTs for inclusion in the review in future updates, we plan to conduct a subgroup analysis to explore sources of heterogeneity. We plan to base subgroups on differences observed, for example, content of acupuncture prescription or clinical differences between participants.

\section{Sensitivity analysis}

We planned to conduct sensitivity analyses for the primary outcomes to determine whether the conclusions were robust to arbitrary decisions made regarding the eligibility and analysis. These analyses included consideration of whether the review conclusions would have differed if:

- eligibility had been restricted to studies at low risk of bias, defined as studies at low risk of selection bias and not at high risk of bias in any domain;

- a fixed-effect model had been adopted;

- alternative imputation strategies had been implemented;

- the summary effect measure had been RR rather than odds ratio.

Sensitivity analyses was not conducted for this review due to insufficient number of studies.

\section{Quality of the evidence: 'Summary of findings' table}

We presented 'Summary of findings tables' using GRADEpro and Cochrane methods. One table evaluated the overall quality of the body of evidence for the main review outcomes (live birth rate, multiple pregnancy rate, ovulation rate, clinical pregnancy rate, restored regular menstrual period, miscarriage rate and adverse events) for the main review comparison (true acupuncture compared to sham acupuncture).

Additional 'Summary of findings' tables were prepared for the main review outcomes for other important comparisons (lowfrequency electroacupuncture compared to physical exercise or no intervention, true acupuncture compared to relaxation, true acupuncture compared to clomiphene, and true acupuncture compared to Diane-35). We assessed the quality of the evidence using GRADE criteria: risk of bias, consistency of effect, imprecision, indirectness and publication bias). Two review authors (RN, GZ) independently made judgements about evidence quality (high, moderate, low or very low) and resolved disagreements by discussion. Judgements were justified, documented and incorporated into reporting of results for each outcome. We extracted study data, formatted our comparisons in data tables and prepared 'Summary of findings' tables before writing the results and conclusions of our review.

\section{RES U L T S}

\section{Description of studies}

\section{Results of the search}

The initial search combined with the new updated search identified 1263 articles from databases and registers specified in the Methods section. After screening and removal of duplicates, we assessed 44 full-text articles for eligibility. We excluded other articles on the basis of their titles or abstracts because they did not meet the inclusion criteria. After screening the full text of the selected articles, 13 articles met the inclusion criteria. Five RCTs were included in our previous review (Du 2011; Jedel 2011; Johansson 2013; Lim 2014; Pastore 2011). Three new studies (seven articles) were included in this version of the review (Cao 2017; Jin 2016; Wu 2017). Five articles were publications relating to the same study (Wu 2017). Thus, we included eight RCTs in this review (Figure 3 ). 
Figure 3. Study flow diagram. PCOS: polycystic ovarian syndrome.

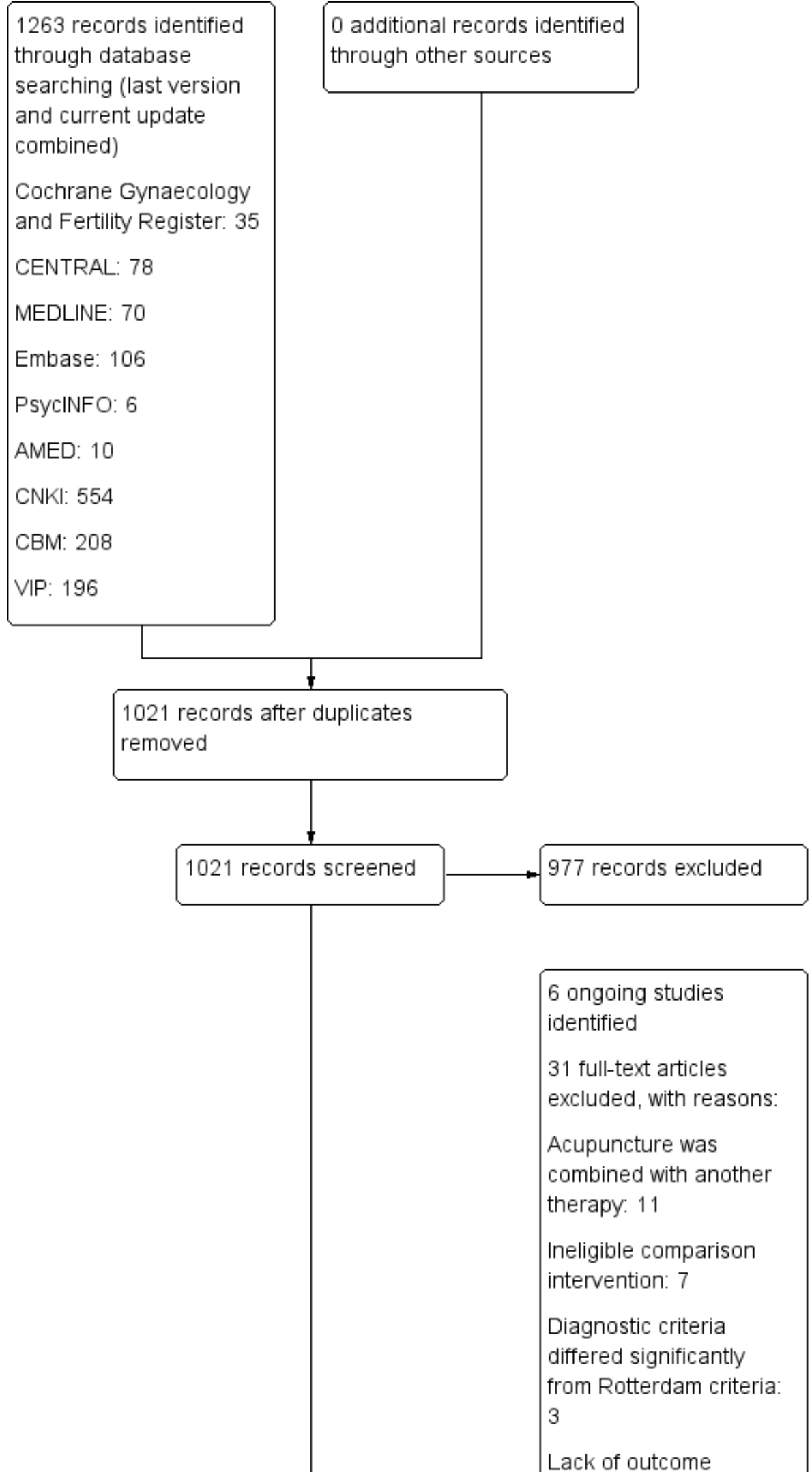


Figure 3. (Continued)

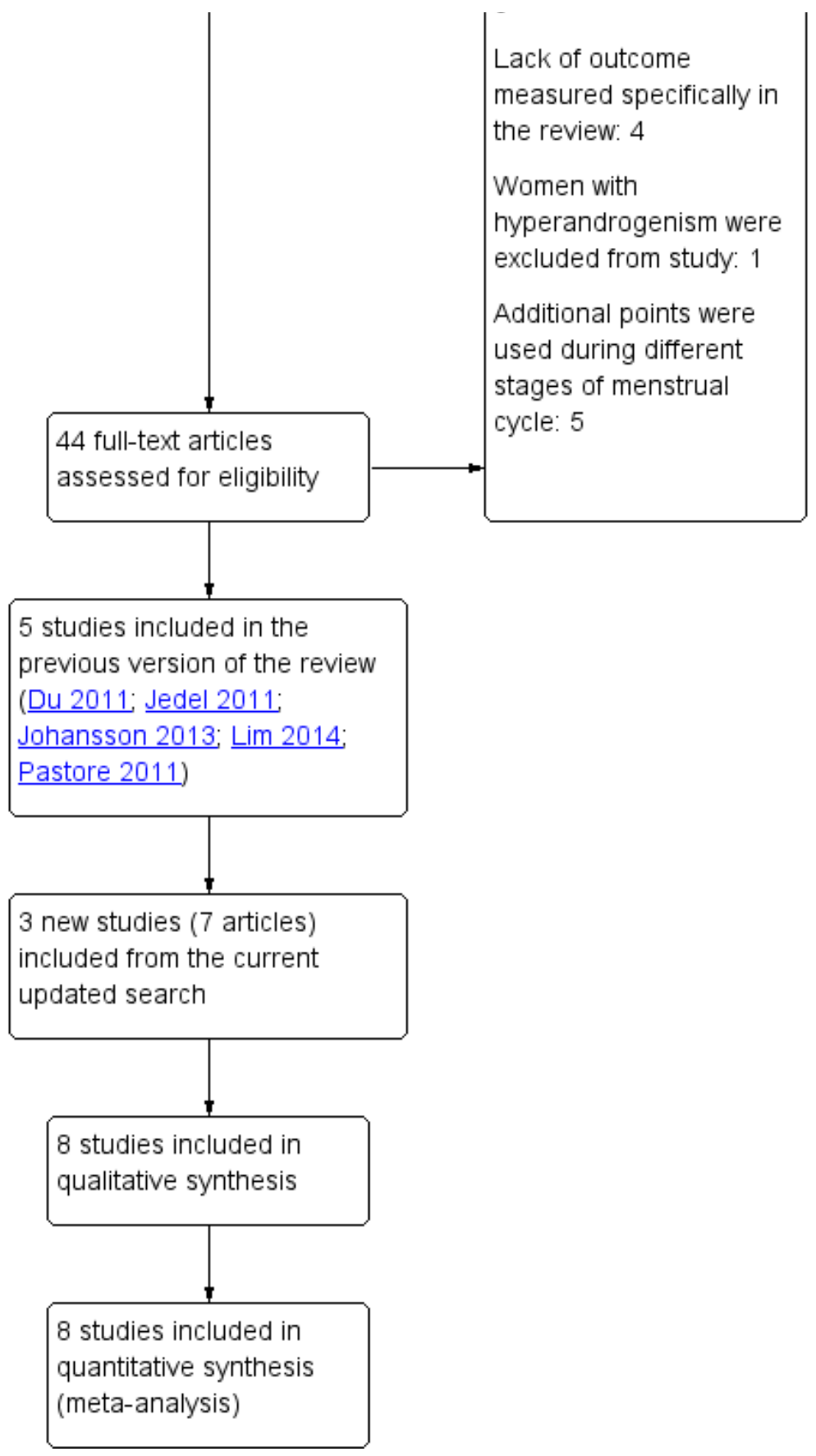

\section{Included studies}

See Characteristics of included studies table.

\section{Study design}

We included eight RCTs in this review. One multicentre, twoarm parallel study was conducted in Australia and China (Lim 2014); one single-centre, three-arm parallel study was conducted in Sweden (Jedel 2011); one single-centre, two-arm parallel study was conducted in the US (Pastore 2011); three single-centre, twoarm parallel studies conducted in China (Cao 2017; Du 2011; Jin 2016), one single-centre, two-arm parallel trial was conducted in
Sweden (Johansson 2013), and one multicentre, $2 \times 2$ factorial trial was conducted in China (Wu 2017).

\section{Participants}

The trials included 1546 women with PCOS. This included 1418 women who were seeking fertility (Du 2011; Jedel 2011; Johansson 2013; Lim 2014; Pastore 2011; Wu 2017), and 128 women who were seeking symptom control (Cao 2017; Jin 2016). Cao 2017 included 56 participants; Du 2011 included 60 participants; Jedel 2011 included 84 participants; Jin 2016 included 72 participants; Johansson 2013 included 32 participants; Lim 2014 included 146 participants; Pastore 2011 included 96 participants; and Wu 
2017 included 1000 participants. All participants had a diagnosis of PCOS made on the basis of Rotterdam consensus, which included either ultrasound or presence of oligo-amenorrhoea and hyperandrogenism, or both. Two studies included additional diagnoses based on Chinese medicine principles (Du 2011; Lim 2014).

The main inclusion criteria were:

- ultrasound-verified polycystic ovaries with 10 or 12 follicles of $2 \mathrm{~mm}$ to $9 \mathrm{~mm}$ or an ovarian volume of $10 \mathrm{~mL}$ in one or both ovaries, or both (Cao 2017; Du 2011; Jedel 2011; Jin 2016; Johansson 2013; Lim 2014; Wu 2017);

- presence of oligo-amenorrhoea and hyperandrogenism (Cao 2017; Du 2011; Jedel 2011; Jin 2016; Lim 2014; Pastore 2011; Wu 2017);

- kidney yang deficiency syndrome as per Chinese medicine diagnosis (Lim 2014);

- traditional Chinese medicine diagnosis of menstrual irregularity, amenorrhoea and infertility (Du 2011).

The main exclusion criteria were:

- any pharmacological treatment including Chinese herbal prescriptions or breastfeeding in period prior to entering study (Cao 2017; Jedel 2011; Jin 2016; Johansson 2013; Lim 2014; Wu 2017);

- diabetes mellitus, and endocrine or neoplastic causes of hyperandrogenaemia, including Cushing's syndrome, congenital adrenal hyperplasia and hyperprolactinaemia (Cao 2017; Du 2011; Jedel 2011; Jin 2016; Johansson 2013; Pastore 2011; Wu 2017);

- aged below 18 years (Cao 2017; Jin 2016; Lim 2014), or above 35 years (Jin 2016); above 38 years (Johansson 2013); or above 45 years (Cao 2017).

- abnormal full blood count, renal or liver function tests (Cao 2017; Jin 2016; Lim 2014);

- pregnancy within the past six weeks or within six weeks postabortion or postpartum (Wu 2017).

There were no significant differences between baseline characteristics of all studies (Cao 2017; Du 2011; Jedel 2011; Jin 2016; Johansson 2013; Lim 2014; Pastore 2011; Wu 2017).

\section{Interventions}

Five studies compared true acupuncture versus sham acupuncture (Cao 2017; Jin 2016; Johansson 2013; Lim 2014; Pastore 2011; Wu 2017). Jin 2016, Johansson 2013, Pastore 2011, Cao 2017, and Wu 2017 used a combination of manual stimulation and low-frequency electroacupuncture at specified acupuncture points in the intervention group. Lim 2014 used body needling with manual stimulation only. Two different sets of acupuncture points were used alternately in Johansson 2013 and Wu 2017. In Johansson 2013, participants allocated to the control group received relaxation sessions of equal length with the same therapist. Wu 2017 was a $2 \times 2$ factorial study that used clomiphene citrate as the second main intervention. Participants were therefore allocated to active acupuncture plus clomiphene, active acupuncture plus placebo, control acupuncture plus clomiphene and control acupuncture plus placebo. Participants who received

Acupuncture for polycystic ovarian syndrome (Review)

Copyright (c) 2019 The Cochrane Collaboration. Published by John Wiley \& Sons, Ltd. clomiphene and placebo were pooled in both arms of the metaanalysis.

One study assessed low-frequency electroacupuncture and physical exercise (Jedel 2011). Women in the acupuncture intervention group met regularly with researchers to receive treatment and women who received physical exercise only met once with researchers and received weekly telephone calls. There was a third arm to this study of no active intervention where women received telephone information only.

One study compared acupuncture with conventional treatment with clomiphene (Du 2011). In this study, the acupuncture group received three cycles of the monthly acupuncture regimen. The comparison group received clomiphene $50 \mathrm{mg}$ daily for five days. In both groups, treatment was given on the fifth day after beginning of menstruation. In the case of amenorrhoea, progesterone was used to induce withdrawal bleeding before treatment was given in either group.

Two studies compared acupuncture versus Diane-35 (ethinylestradiol and cyproterone acetate tablets) (Cao 2017; Jin 2016). In Cao 2017, the acupuncture group received continuous twice weekly acupuncture treatment for 12 weeks; while in Jin 2016, the treatments were given three times weekly for three months. The comparison group received three cycles of Diane-35, one tablet daily for 21 days and a seven-day break. Both groups received treatment on the fifth day after beginning of menstruation or withdrawal bleeding.

\section{Outcomes}

\section{Primary outcomes}

\section{Live birth rate}

One study reported live birth rates (Wu 2017).

\section{Multiple pregnancy rate}

One study reported multiple pregnancy rate (Wu 2017).

\section{Ovulation rate}

Five studies reported ovulation rate (Du 2011; Jin 2016; Johansson 2013; Pastore 2011; Wu 2017).

\section{Secondary outcomes \\ Clinical pregnancy rate}

Three studies reported clinical pregnancy rate (Lim 2014; Pastore 2011; Wu 2017). Ascertainment of pregnancy was by participant self-report in Lim 2014 and Pastore 2011. One trial measured serum human chorionic gonadotropin concentration and confirmed pregnancy with pelvic ultrasound (Wu 2017).

\section{Restored regular menstrual period}

Five studies reported restored regular menstrual period (Cao 2017; Du 2011; Jedel 2011; Jin 2016; Lim 2014).

\section{Miscarriage rate}

One study reported miscarriage rate (Wu 2017).

\section{Adverse events}

Six studies reported adverse events secondary to treatment (Cao 2017; Du 2011; Jedel 2011; Jin 2016; Pastore 2011; Wu 2017). The 
other studies did not report adverse events (Johansson 2013; Lim 2014).

\section{Excluded studies}

We excluded 31 studies after evaluation of the full-text articles. See Characteristics of excluded studies table.

\section{Risk of bias in included studies}

\section{Allocation}

\section{Sequence generation}

All studies described adequate methods of randomisation (computer generated) and were at low risk of bias (Cao 2017; Du 2011; Jedel 2011; Jin 2016; Johansson 2013; Lim 2014; Pastore 2011; Wu 2017).

\section{Allocation concealment}

Johansson 2013, Jin 2016, and Cao 2017 did not describe allocation concealment and were at unclear risk of bias. Du 2011 concealed allocation in opaque envelopes that were distributed sequentially and was at low risk of bias. The other four studies were at low risk of bias as they adequately described method of concealment including use of sealed, opaque envelopes (Lim 2014; Pastore 2011), preprinted barcode labels (Wu 2017), or concealing until interventions were assigned (Jedel 2011).

\section{Blinding}

\section{Blinding of participants and personnel (performance bias)}

Pastore 2011 reported blinding of the participants and principal investigator (low risk of bias). Wu 2017 reported blinding of participants in the acupuncture arm and blinding of participants and study investigators in the clomiphene and placebo group (low risk of bias).

Lim 2014 reported blinding of participants only (unclear risk of bias).

Cao 2017, Du 2011, Jedel 2011, and Jin 2016 did not report any blinding methods (high risk of bias).

Johansson 2013 did not blind participants or therapists in the study due to the nature of the intervention and the control in the study (high risk of bias).

\section{Blinding of outcome assessment (detection bias)}

Cao 2017, Du 2011, Jedel 2011, Jin 2016, and Wu 2017 did not report any blinding methods used (high risk of bias).

Johansson 2013 reported biological outcomes were measured at an independent laboratory and investigators were blinding until statistical analyses; however, it was unclear if investigators were blinded during statistical analyses (unclear risk of bias).

Outcome assessment was completed by statisticians independent to the study in Lim 2014 (low risk of bias).

Pastore 2011 reported blinding of clinical research co-ordinator and biostatistician (low risk of bias).

\section{Incomplete outcome data}

Eleven of 96 women dropped out during the intervention phase in Pastore 2011 with no age, education, body-mass index (BMI) or race difference between the dropouts and the remainder of the cohort. One woman entered menopausal transition during the trial and was also excluded. The trial did not report number of women lost to follow-up. There was no ITT analysis (high risk of bias).

Lim 2014 excluded four out of 146 women between enrolment and randomisation phase. There were no dropouts during intervention phase reported. They reported reasons for excluding the women (low risk of bias).

Jedel 2011 reported 10 dropouts between allocation and baseline assessments, 15 between baseline and week 16 and nine between weeks 16 and 32. They conducted an ITT analysis on the 74 participants who went through baseline assessments. They did not report a comparison of baseline characteristics of dropouts and women remaining in the trial (unclear risk of bas).

Johansson 2013 reported five dropouts after randomisation. In the active treatment arm, four women were excluded before baseline assessment and one woman was lost before final assessment. ITT analysis was performed of 12 women from the treatment arm and all 16 women from the control arm. The authors described reasons for dropouts adequately in the published reports (low risk of bias).

Du 2011 reported that all participants completed the study (low risk of bias).

Four women out of 56 dropped out during the intervention phase in Cao 2017, and four out of 72 dropped out during the intervention phase in Jin 2016. The difference between age, BMI or clinical feature of the dropouts and the remainder of the cohort was not performed. There was no ITT analysis (high risk of bias).

Wu 2017 reported four participants who conceived after randomisation and before intervention commenced. These women completed the last visit and were included in the primary analysis. During the intervention phase, 74 participants dropped out from the study. Fifteen participants dropped out from the active acupuncture and clomiphene arm; 14 participants dropped out from the control acupuncture and clomiphene arm; 27 participants dropped out from the active acupuncture and placebo arm and 18 participants dropped out from the control acupuncture and placebo arm. Out of the 14 participants who dropped out from the control acupuncture and clomiphene arm, two were due to intervention adverse effects. Out of the 27 participants who dropped out from the active acupuncture and placebo arm, three were due to intervention adverse effects. There was no ITT analysis. The authors described reasons for dropouts adequately in the published reports (unclear risk of bias).

\section{Selective reporting}

Two studies did not report adverse events in their published reports and were at unclear risk of bias (Johansson 2013; Lim 2014). Du 2011 did not report the number of women who had no ovulation during treatment period (high risk of bias). The remaining studies reported all listed outcomes (low risk of bias). 


\section{Other potential sources of bias}

We identified no other potential sources of bias in four studies (Cao 2017; Jedel 2011; Johansson 2013; Lim 2014; Pastore 2011). Jin 2016 and Du 2011 are both unpublished studies from thesis. We graded them at high risk of bias for possible lack of adequate peer review. Wu 2017 was supported by various government and nongovernment grants. One author in the study reported conflict of interest due to grant funding. They reported that funding agencies had no role in the design or conduct of the study (low risk of bias).

\section{Effects of interventions}

See: Summary of findings for the main comparison True acupuncture compared to sham acupuncture for polycystic ovarian syndrome; Summary of findings 2 Low-frequency electroacupuncture compared to physical exercise or no intervention for polycystic ovarian syndrome; Summary of findings 3 True acupuncture compared to relaxation for polycystic ovarian syndrome; Summary of findings 4 True acupuncture compared to clomiphene for polycystic ovarian syndrome; Summary of findings 5 True acupuncture compared to Diane-35 for polycystic ovarian syndrome

We examined two populations in this review - women seeking fertility (comparisons 1, 2, 3 and 4) and women seeking symptom control (comparison 5 True acupuncture versus conventional treatment Diane-35).

\section{True acupuncture versus sham acupuncture}

Three studies compared true acupuncture versus sham acupuncture (Lim 2014; Pastore 2011; Wu 2017).

\section{Primary outcomes}

\section{Live birth rate}

For true acupuncture versus sham acupuncture, we could not exclude clinically relevant differences in live birth (RR $0.97,95 \% \mathrm{Cl}$ 0.76 to 1.24 ; 1 RCT, 926 women; low-quality evidence; Analysis 1.1; Wu 2017). This means, low-quality evidence suggested that if $22 \%$ of women achieved live birth with sham acupuncture, between $17 \%$ and $28 \%$ would achieve live birth with true acupuncture.

\section{Multiple pregnancy rate}

For true acupuncture versus sham acupuncture, we could not exclude clinically relevant differences in multiple pregnancy rate (RR $0.89,95 \% \mathrm{Cl} 0.33$ to $2.45 ; 1 \mathrm{RCT}, 926$ women; low-quality evidence; Analysis 1.2; Wu 2017). This means, low-quality evidence suggested that if $2 \%$ of women achieved multiple pregnancy with sham acupuncture, between $0.6 \%$ and $4 \%$ would achieve multiple pregnancy with true acupuncture.

\section{Ovulation rate}

For true acupuncture versus sham acupuncture, we could not exclude clinically relevant differences in ovulation rate (SMD 0.02, $95 \% \mathrm{Cl}-0.15$ to $0.19 ; \mathrm{I}^{2}=0 \% ; 2$ RCTs, 1010 women; low-quality evidence; Analysis 1.3; Figure 4; Pastore 2011; Wu 2017).

Figure 4. Forest plot of comparison: 1 True acupuncture versus sham acupuncture, outcome: 1.3 Ovulation rate.

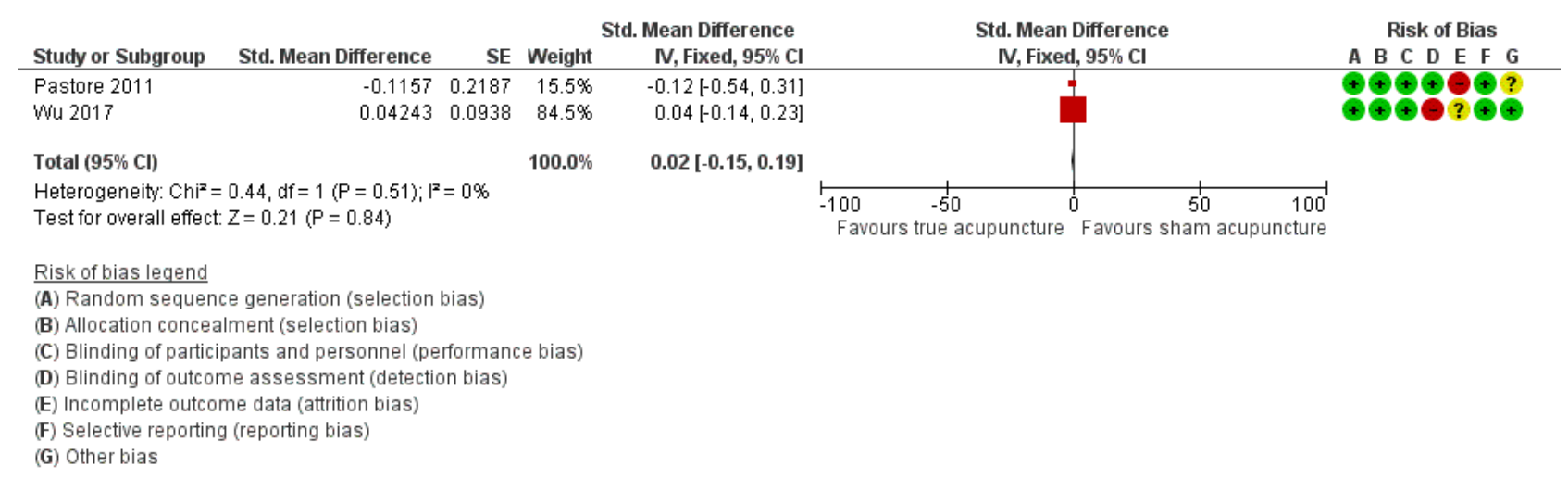

\section{Secondary outcomes}

\section{Clinical pregnancy rate}

For true acupuncture versus sham acupuncture, we could not exclude clinically relevant differences in clinical pregnancy rate (RR
$1.03,95 \% \mathrm{Cl} 0.82$ to $1.29 ;\left.\right|^{2}=0 \% ; 3 \mathrm{RCTs}, 1117$ women; low-quality evidence; Analysis 1.4; Figure 5; Lim 2014; Pastore 2011; Wu 2017). This means, low-quality evidence suggested that if $21 \%$ of women achieved clinical pregnancy with sham acupuncture, between $17 \%$ and $27 \%$ would achieve clinical pregnancy with true acupuncture. 
Figure 5. Forest plot of comparison: 1 True acupuncture versus sham acupuncture, outcome: 1.4 Clinical pregnancy rate.

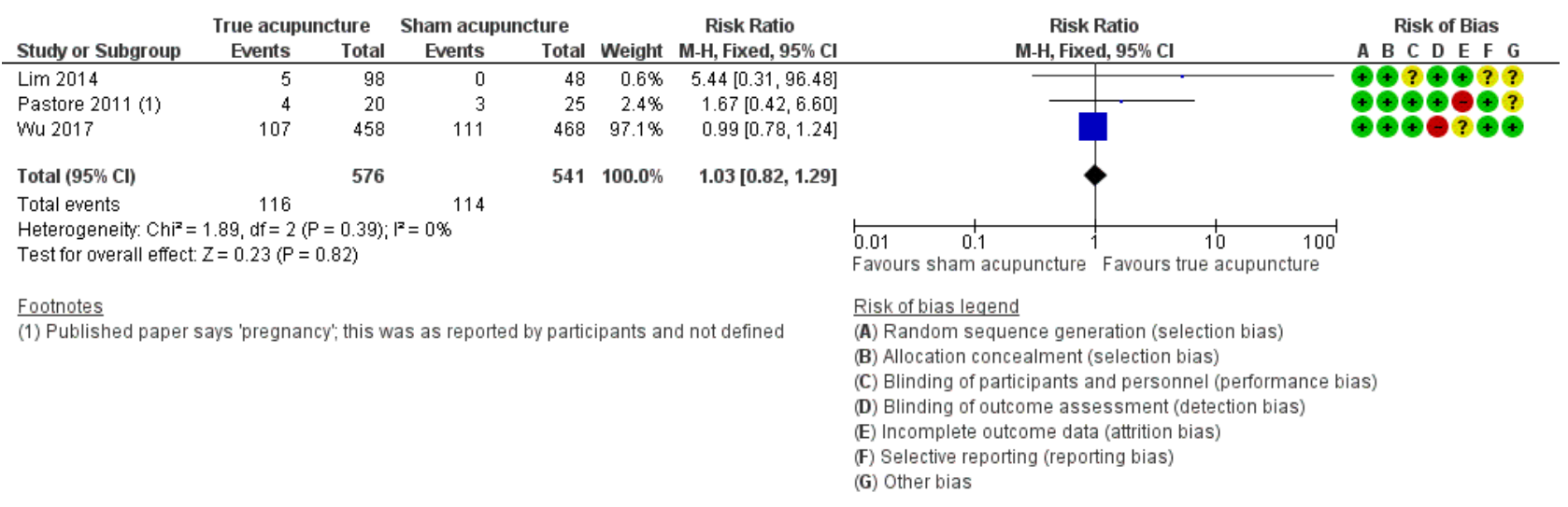

\section{Restored regular menstrual period}

Lim 2014 reported difference in intermenstrual days pre and post treatment. Number of intermenstrual days may have improved in participants receiving true acupuncture compared to sham acupuncture (MD -312.09 days, $95 \% \mathrm{Cl}-344.59$ to $-279.59 ; 1 \mathrm{RCT}$, 141 women; low-quality evidence; Analysis 1.5; Lim 2014).

\section{Miscarriage rate}

For true acupuncture versus sham acupuncture, we could not exclude clinically relevant differences in miscarriage rate (RR 1.10, $95 \% \mathrm{Cl} 0.77$ to 1.56 ; $1 \mathrm{RCT}, 926$ women; low-quality evidence; Analysis 1.6; Wu 2017). This means, low-quality evidence suggested that if $11 \%$ of women had a miscarriage with sham acupuncture, between $9 \%$ and $18 \%$ would have a miscarriage with true acupuncture.

\section{Adverse events}

All three studies reported adverse events. True acupuncture probably worsened adverse events compared to sham acupuncture (RR $1.16,95 \% \mathrm{Cl} 1.02$ to $1.31 ;\left.\right|^{2}=0 \% ; 3$ RCTs, 1230 women; moderate-quality evidence; Analysis 1.7; Figure 6; Lim 2014; Pastore 2011; Wu 2017). This means, moderate-quality evidence suggested that if $40 \%$ of women had adverse events with sham acupuncture, between $41 \%$ and $52 \%$ of women had adverse events with true acupuncture.

Figure 6. Forest plot of comparison: 1 True acupuncture versus sham acupuncture, outcome: 1.7 Adverse events.

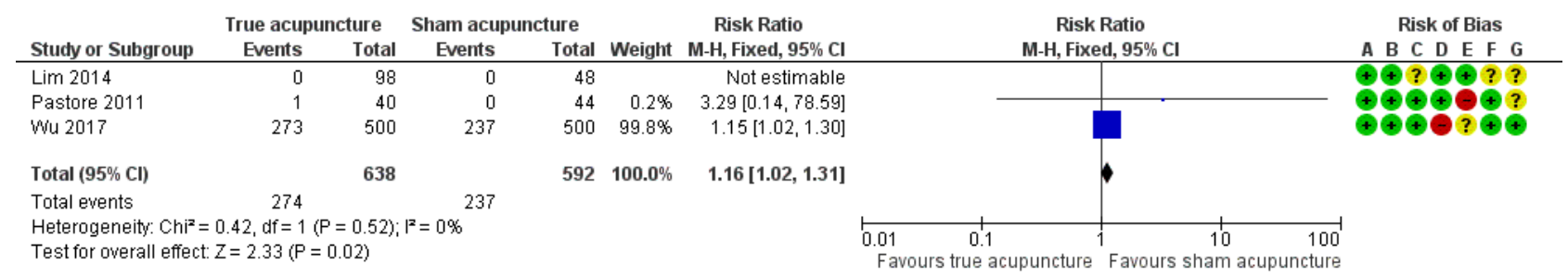

Risk of bias legend

(A) Random sequence generation (selection bias)

(B) Allocation concealment (selection bias)

(C) Blinding of participants and personnel (performance bias)

(D) Blinding of outcome assessment (detection bias)

(E) Incomplete outcome data (attrition bias)

(F) Selective reporting (reporting bias)

(G) Other bias

Pastore 2011 reported one adverse event (back muscle spasm) and Lim 2014 found no adverse events (based on unpublished data). Wu 2017 reported 99 adverse events in 500 women who received true acupuncture compared to 55 adverse events in 500 women who received sham acupuncture before conception. The most common adverse events in the true acupuncture group were bruising and diarrhoea. One participant with liver dysfunction and one participant with fracture of coccyx were reported in the true acupuncture plus Clomiphene group. Among participants who conceived there were 174 adverse events in 159 women in the true acupuncture group compared to 182 adverse events in
161 women in the sham acupuncture group. The most common adverse events in the true acupuncture group were oedema and threatened abortion. In terms of serious adverse effects, there were two participants with ectopic pregnancy, two participants with late abortion, seven participants with preterm labour, eight participants with gestational diabetes, one participant with severe pre-eclampsia, three participants with placenta previa and one participant with preterm labour. 
2 Low-frequency electroacupuncture versus lifestyle intervention (physical exercise) or no intervention

Jedel 2011 compared low-frequency electroacupuncture to physical exercise or no intervention.

\section{Primary outcomes}

\section{Live birth rate}

No studies reported live birth rate.

\section{Multiple pregnancy rate}

No studies reported multiple pregnancy rate.

\section{Ovulation rate}

No studies reported ovulation rate.

\section{Secondary outcomes}

\section{Clinical pregnancy rate}

No studies reported pregnancy rate.

\section{Restored regular menstrual period}

Jedel 2011 reported difference in menstrual frequency before and after treatment. In this study, one menstruation per month was defined as a menstrual frequency of 1.0. We were uncertain whether low-frequency electroacupuncture improved menstruation frequency at 32 weeks in women who received low-frequency electroacupuncture compared to physical exercise (MD $0.22,95 \% \mathrm{Cl}-0.01$ to $0.45 ; 1 \mathrm{RCT}, 40$ women; very lowquality evidence). We were uncertain whether low-frequency electroacupuncture improved menstrual frequency at 32 weeks compared to no intervention (MD $0.37,95 \% \mathrm{Cl} 0.21$ to $0.53 ; 1 \mathrm{RCT}$, 31 women; very low-quality evidence; Analysis 2.1).

\section{Miscarriage rate}

No studies reported miscarriage rate.

\section{Adverse events}

There were three cases of skin erythema, one case of dizziness and one case of nausea following low-frequency electroacupuncture. No other short-term or long-term adverse events were reported in either physical exercise group or no intervention group (Analysis 2.2).

\section{True acupuncture versus lifestyle intervention (relaxation)}

Johansson 2013 compared true acupuncture on a twice weekly regimen to relaxation sessions at the same settings.

\section{Primary outcomes}

\section{Live birth rate}

No studies reported live birth rate.

\section{Multiple pregnancy rate}

No studies reported multiple pregnancy rate.

\section{Ovulation rate}

We were uncertain whether true acupuncture improved ovulation frequency (defined as ovulations per month) compared to relaxation (MD 0.35, 95\% $\mathrm{Cl} 0.14$ to $0.56 ; 1 \mathrm{RCT}, 28$ women; very lowquality evidence; Analysis 3.1).

\section{Secondary outcomes}

Clinical pregnancy rate

No studies reported pregnancy rate. One participant in Johansson 2013 became pregnant before baseline assessment and she was not included in the ITT analysis.

\section{Restored regular menstrual period}

No studies reported restored regular menstrual period.

\section{Miscarriage rate}

No studies reported miscarriage rate.

\section{Adverse events}

No studies reported adverse events.

\section{True acupuncture versus conventional treatment (clomiphene)}

Du 2011 compared true acupuncture to conventional treatment (clomiphene).

\section{Primary outcomes}

\section{Live birth rate}

No studies reported live birth rate.

\section{Multiple pregnancy rate}

No studies reported multiple pregnancy rate.

\section{Ovulation rate}

No studies reported ovulation rate. Du 2011 reported number of ovulations during treatment. However, we could not calculate ovulation rate because the number of women who had no ovulation was not reported. Du 2011 did not report ovulation during the follow-up period.

\section{Secondary outcomes \\ Clinical pregnancy rate}

No studies reported pregnancy rate.

\section{Restored regular menstrual period}

We were uncertain whether true acupuncture improved restored regular menstrual period compared to clomiphene. Du 2011 reported restoration of menstruation at the end of treatment and one month after the end of treatment. During treatment, $14 / 30$ women from the acupuncture group reported restored menstruation, defined as three normal menstruations during three months. Eleven out of 30 women in the clomiphene group reported restored menstruation at the end of treatment (RR 1.64, 95\% $\mathrm{Cl} 0.94$ to 2.85; $1 \mathrm{RCT}, 60$ women; very low-quality evidence; Analysis 4.1). This means, very low-quality evidence suggested that if $37 \%$ of women achieved restored menstruation at end of treatment with clomiphene, between $34 \%$ and $100 \%$ would achieve restored menstruation at end of treatment with true acupuncture. At one month after treatment, 24/30 women in the acupuncture group reported normal menstruation while 16/30 women in the clomiphene group reported normal menstruation (RR 1.50, 95\% Cl 
1.03 to 2.19; 1 RCT, 60 women; very low-quality evidence; Analysis 4.1). This means, very low-quality evidence suggested that if $53 \%$ of women achieved normal menstruation at one after treatment with clomiphene, between $55 \%$ and $100 \%$ would achieve normal menstruation at one month with true acupuncture.

\section{Miscarriage rate}

No studies reported miscarriage rate.

\section{Adverse events}

Du 2011 reported three cases of mild subcutaneous haematoma in the acupuncture group. There were two cases of minor gastrointestinal adverse effects in the clomiphene group (Analysis 4.2).

\section{True acupuncture versus conventional treatment (Diane-35)}

Cao 2017 and Jin 2016 compared acupuncture to Diane-35. The focus population in this comparison was women seeking symptom control.

\section{Primary outcomes}

\section{Live birth rate}

For women seeking symptom control, no fertility outcomes were measured.

\section{Multiple pregnancy rate}

For women seeking symptom control, no fertility outcomes were measured.

\section{Ovulation rate}

We were uncertain whether true acupuncture improved ovulation rate compared to Diane-35 (RR $1.45,95 \% \mathrm{Cl} 0.87$ to 2.42 ; $1 \mathrm{RCT}$, 58 women; very low-quality evidence; Analysis 5.1; Jin 2016). This means, very low-quality evidence suggested that if $39 \%$ of women achieved ovulation with Diane-35, between $34 \%$ and $95 \%$ would achieve ovulation with true acupuncture. Ovulation was measured by ultrasound three months after treatment.

\section{Secondary outcomes}

\section{Clinical pregnancy rate}

For women seeking symptom control, no fertility outcomes were measured. However, Jin 2016 observed that two participants in the acupuncture group reported pregnancy and were subsequently withdrawn from the study.

\section{Restored regular menstrual period}

We were uncertain whether true acupuncture restored regular menstrual period compared to Diane-35.

Quantitative meta-analysis of data was not possible due to heterogeneity in, and reporting of, outcomes.

We were uncertain whether true acupuncture improved menstrual restoration rate three months after end of treatment compared to Diane-35 (RR 1.27, 95\% Cl 0.92 to 1.77; 1 RCT, 68 women; very lowquality evidence; Jin 2016). This means, very low-quality evidence suggested that if $61 \%$ of women achieved menstrual restoration three months after end of treatment with Diane-35, between $56 \%$ and $107 \%$ would achieve menstrual restoration three months after the end of treatment with true acupuncture.

We were uncertain whether true acupuncture improved menstrual frequency within three months before and after treatment compared to Diane-35 (MD $-0.77,95 \% \mathrm{Cl}-1.20$ to -0.34 ; one RCT, 52 women; very low-quality evidence; Cao 2017).

We were uncertain whether true acupuncture improved menstrual duration within three months before and after treatment compared to Diane-35 (MD $-0.71,95 \% \mathrm{Cl}-3.48$ to 2.06 ; one RCT, 52 women; very low-quality evidence; Cao 2017).

\section{Miscarriage rate}

No studies reported miscarriage rate.

\section{Adverse events}

There were one (Jin 2016) and two (Cao 2017) cases of mild subcutaneous haematoma in the true acupuncture group. There were two cases of nausea (Cao 2017), one case of headache (Cao 2017), one case of gastrointestinal upset ( Jin 2016), and one case of weight gain (Jin 2016) following Diane-35 (Analysis 5.2).

\section{Other analyses}

There were too few studies to conduct any of our planned subgroup and sensitivity analyses, or to construct a funnel plot to assess risk of publication bias.

\section{DISCUSSION}

\section{Summary of main results}

This review assessed the effectiveness and safety of acupuncture treatment for oligo/anovulatory women with PCOS. We found five studies that compared true acupuncture versus sham acupuncture, one study compared low-frequency electroacupuncture and physical exercise and no intervention, one study compared acupuncture with clomiphene and two studies compared acupuncture and Diane-35. A total of 1546 women with PCOS were included in this review.

For true acupuncture versus sham acupuncture, we could not exclude clinically relevant differences in live birth, multiple pregnancy rate, ovulation rate, clinical pregnancy rate and miscarriage rate. Number of intermenstrual days may have improved in participants receiving true acupuncture compared to sham acupuncture. True acupuncture probably worsened adverse events compared to sham acupuncture. Quality of evidence ranged from moderate to very low quality.

No studies reported data on live birth rate and multiple pregnancy rate for the other comparisons: physical exercise or no intervention, relaxation and clomiphene. Studies including Diane-35 did not measure fertility outcomes.

We were uncertain whether acupuncture improved ovulation rate (measured by ultrasound three months post treatment) compared to relaxation or Diane-35. The other comparisons did not report ovulation rate.

Adverse events were recorded in the acupuncture group for the comparisons physical exercise or no intervention, clomiphene and Diane-35. These included dizziness, nausea and subcutaneous 
haematoma. Evidence was very low quality with very wide $\mathrm{Cls}$ and very low event rates.

\section{Overall completeness and applicability of evidence}

The included studies poorly addressed the primary outcomes of this review, with only one study reporting the primary outcomes live birth rate and multiple pregnancy rate. Five of eight studies addressed the primary outcome ovulation rate; however, there was significant heterogeneity in reporting and measurement of ovulation rate. Moreover, there were insufficient data on adverse events for comparisons other than true acupuncture versus sham acupuncture, to determine the overall safety of acupuncture as a treatment for oligo/anovulation in women with PCOS.

\section{Quality of the evidence}

We included only eight RCTs in the present review and most had small sample sizes. Seven of the studies were at high risk of bias in at least one domain (Cao 2017; Du 2011; Jedel 2011; Jin 2016; Johansson 2013; Pastore 2011; Wu 2017). The evidence ranged from very low quality to moderate quality, the main limitations being failure to report important clinical outcomes, and very serious imprecision.

\section{Potential biases in the review process}

We did not search any non-English or non-Chinese databases, hence studies published in languages other than English or Chinese may not have been identified in the review process. However, there was no exclusion of study that was due to language. There may also have been unpublished data that our searches did not find. In addition, one included study was published by an author (DL) of this review (Lim 2014).

In order to minimise any potential risk of bias during the review process, two review authors (RN, GZ) independently extracted data using a piloted data extraction form. Specifically, the author (DL) of one of the primary studies (Lim 2014) was excluded to extract data from their own study. All studies were then assessed independently and any dispute was resolved by a fifth independent author (HC).

\section{Agreements and disagreements with other studies or reviews}

Several systematic reviews have examined acupuncture for PCOS. Jo 2017 conducted a systematic review and meta-analysis on acupuncture for PCOS which included 27 RCTs comparing acupuncture with sham acupuncture, medication, no treatment or acupuncture combined with medication. The review found similar results to this review, reporting very limited evidence for acupuncture in improving ovulation, menstruation rates and hormonal changes. Qu 2016 included nine RCTs in a systematic review and meta-analysis which included studies comparing acupuncture with sham acupuncture or acupuncture in addition to other treatment. Unlike this study, the authors found significant improvement in recovery of menstrual cycles and lower BMI and LH levels. However, there was no evidence in improvement of other hormonal parameters. Similar to this study, Qu 2016 found that studies had unclear or high risks of bias in multiple domains and limited quality.

\section{AUTHORS' CONCLUSIONS}

\section{Implications for practice}

For true acupuncture versus sham acupuncture, we cannot exclude clinically relevant differences in live birth rate, multiple pregnancy rate, ovulation rate, clinical pregnancy rate or miscarriage. Number of intermenstrual days may improve in participants receiving true acupuncture compared to sham acupuncture. True acupuncture probably worsens adverse events compared to sham acupuncture.

No studies reported data on live birth rate and multiple pregnancy rate for the other comparisons: physical exercise or no intervention, relaxation and clomiphene. Studies including Diane-35 did not measure fertility outcomes.

We are uncertain whether acupuncture improves ovulation rate (measured by ultrasound three months post treatment) compared to relaxation or Diane-35. The other comparisons did not report on this outcome.

There were adverse events in the acupuncture group for the comparisons physical exercise or no intervention, clomiphene and Diane-35. These included dizziness, nausea and subcutaneous haematoma. Evidence was very low quality with very wide confidence intervals and very low event rates.

There are only a limited number of randomised controlled trials (RCT) in this area, limiting our ability to determine effectiveness of acupuncture for polycystic ovarian syndrome (PCOS).

\section{Implications for research}

Given the lack of evidence for acupuncture for PCOS, further largescale, properly designed RCTs are needed to assess the use of acupuncture in the management of PCOS. Women with PCOS meeting standard diagnostic criteria (e.g. Rotterdam consensus) seeking fertility or symptom control should be recruited and an acupuncture regimen involving a set of standard acupuncture points and mode of stimulation should be considered. Controls should also receive a standard regimen of sham acupuncture in order to minimise the potential therapeutic effects of sham acupuncture. Consistent, standard outcome measures including live birth rate should be reported.

\section{A CKN OWLEDGEMENTS}

The review authors would like to thank Dr Zhen Zheng from the Royal Melbourne Institute of Technology (RMIT) University for her kind assistance throughout the pre-title registration period. We wish to acknowledge Dr Wei Chen, Prof A O'Sullivan, Prof Felix Wong, Ke Xu, Charlie CL Xue, Nini Chen and Liu J as authors of previous versions of this review. We also acknowledge Dr Yang Liu from the Institute of History of Chinese Medicine and Medical Literature, China Academy of Chinese Medical Sciences (CACMS) for the assistance of Chinese literature search in the second review update. We would like to thank Jane Marjoribanks, Jane Thomas, Katie Stocking and Gabriela Cooper for their valuable peer review comments. 


\section{RE F E R E N C E S}

\section{References to studies included in this review}

Cao 2017 \{published data only\}

Cao Y, Zhang L, Zhao D, Liu Z. DONG's extraordinary acupoints for the ovarian function of polycystic ovary syndrome: a randomized controlled pilot trial [董氏针炎改善多囊卵巢综 合征患者卵巢功能: 随机对照预试验]. Zhongguo Zhenjiu 2017;37(7):710-14.

\section{Du 2011 \{published data only\}}

Du Y. [腹针治疗多囊卵巢综合征排卵障碍的临床研究] . Clinical Observation of Abdominal Acupuncture for Polycystic Ovarian Syndrome with Ovulatory Dysfunction [thesis]. Guangzhou (China): Guangzhou University of Chinese Medicine, 2011.

\section{Jedel 2011 \{published data only\}}

Jedel E, Labrie F, Oden A, Holm G, Nilsson L, Janson PO, et al. Impact of electro-acupuncture and physical exercise on hyperandrogenism and oligo/amenorrhea in women with polycystic ovary syndrome: a randomized controlled trial. American Journal of Physiology. Endocrinology and Metabolism 2011;300:E37-45.

Stener-Victorin E, Holm G, Janson PO, Gustafson D, Waern M. Acupuncture and physical exercise for affective symptoms and health-related quality of life in polycystic ovary syndrome: secondary analysis from a randomized controlled trial. BMC Complementary and Alternative Medicine 2013;13(1):131.

\section{Jin 2016 \{published data only\}}

Jin CL. [针刺疏肝调气法治疗多囊卵巢综合征临床研究] . Clinical Study on Treatment of Polycystic Ovary Syndrome with Acupuncture and Shugan Tiaoqi Method [PhD thesis]. Beijing (China): Beijing University of Traditional Chinese Medicine, 2016.

\section{Johansson 2013 \{published data only\}}

Johansson J, Redman L, Veldhuis PP, Sazonova A, Labrie F, Holm G, et al. Acupuncture for ovulation induction in polycystic ovary syndrome: a randomized controlled trial. American Journal of Physiology. Endocrinology and Metabolism 2013;304:E934-43.

\section{Lim 2014 \{published and unpublished data\}}

Lim CED, Luo X, Zhan X, Wong WS. ACUPCOS: acupuncture \& PCOS - a multi-centre randomised controlled trial. International Journal of Gynecological and Obstetrical Research 2014;2:1-13.

\section{Pastore 2011 \{published and unpublished data\}}

Pastore LM, Williams CD, Jenkins J, Patrie JT. True and sham acupuncture produced similar frequency of ovulation and improved LH to FSH ratios in women with polycystic ovary syndrome. Journal of Clinical Endocrinology \& Metabolism 2011;96:3143-50.

\section{Wu 2017 \{published data only\}}

Deng Y, Xie L, Wu XK, Ng EH, Victorin ES, Zhang H, et al. Prediction models for ovulation, conception, pregnancy and live birth in infertile women with polycystic ovary syndrome. Human Reproduction 2017;32 Suppl 1:i454-5.

Wen Y, Ma HL, Wu XK. Acupuncture and clomiphene interventions in PCOS conversely affect the insulin resistance profiles in early pregnancy subjects: a secondary analysis of a randomized controlled trial. Journal of Obstetrics and Gynaecology Research 2017;43 Suppl 1:160-1.

Wu X, Stener-Victorin E, Liu J, Wu T, Ng E, Legro RS, et al. Acupuncture and clomiphene for infertility in the polycystic ovary syndrome: a multicentre randomized controlled trial. Fertility and Sterility 2016;106(3 Suppl 3):e375.

* Wu XK, Stener-Victorin E, Kuang HY, Ma HL, Gao JS, Xie LZ, et al. Effect of acupuncture and clomiphene in Chinese women with polycystic ovary syndrome: a randomized clinical trial. Journal of the American Medical Association 2017;317(24):2502-14.

Xu L, Qiao X. Acupuncture is not as effective as infertility treatment in women with PCOS. Evidence-Based Medicine 2017;22(6):229-30.

\section{References to studies excluded from this review}

\section{Cai 2016 \{published data only\}}

Cai X, Li Y, Wang J, Cao J. Clinical observation of electroacupuncture and acupoint catgut-embedding therapy in the treatment of obese polycystic ovary syndrome [电针及穴位 埋线治疗肥胖型多囊卵巢综合征的临床观察]. Guangming Journal of Chinese Medicine 2016;31(4):538-41.

Chen 2014 \{published data only\}

Chen R, Wang C, Yan QY. Observation on therapeutic effect of polycystic ovary syndrome of damp-phlegm constitution treated with embedding therapy on back-shu points and frontmu points combined with needle-pricking therapy on Sifeng (EX-UE 10) [Chinese]. Zhongguo Zhen Jiu 2014;34(4):355-8.

Chen 2015b \{published data only\}

Chen M, Zhang H, Zhang YC. Clinical observation of acupuncture plus medication for obesity-type polycystic ovary syndrome [ 针 刺配合药物干预肥胖型多囊卵巢综合征临床观察]. Shanghai Journal of Acupuncture and Moxibustion 2015;4:310-3.

\section{Fang 2016 \{published data only\}}

Fang Q, Zou P, Li K. Effect of acupuncture induced ovulation on follicular development and reproductive hormones in patients with polycystic ovary syndrome [针刺促排卵对多囊卵巢综 合征患者卵泡发育及生殖激素的影响]. Beijing Journal of Traditional Chinese Medicine 2016;35(3):198-201.

\section{Hao 2015 \{published data only\}}

Hao C, Zhang T, Qi J, Ji L. Acupuncture at Zhibian (BL 54) through Shuidao (ST 28) for polycystic ovary syndrome [Chinese]. Zhongguo Zhen Jiu 2015;35(5):461-4. 
He 2017 \{published data only\}

He X, Pan Z, Huang J. Clinical effect of acupuncture treatment of polycystic ovary syndrome guided by TCM syndrome [中医辩 证指导的针刺疗法治疗多囊卵巢综合征的临床研究]. Medical Innovation of China 2017;14(22):66-8.

\section{Huang 2016 \{published data only\}}

Huang L. [通元针法治疗多囊卵巢综合征合并不孕的临床疗 效观察]. Observation of acupuncture treatment of Tongyuan Polycystic ovary syndrome with infertility [Master's thesis]. Guangzhou (China): Guangzhou University of Chinese Medicine, 2016.

\section{Jiang 2014 \{published data only\}}

Jiang DS, Wu XQ, Zhang YC. Effects of warm needling combined with zhangmo decoction on endometrial receptivity in patient with ovulation induction [Chinese]. Zhongguo Zhen Jiu 2014;34(2):130-4.

\section{Jiang 2015a \{published data only\}}

Jiang D, Zhang Y, Wu X, Wu S. Infertility in polycystic ovary syndrome treated with acupuncture and clomiphene: a randomized controlled trial [Chinese]. Zhongguo Zhen Jiu 2015;35(2):114-8.

\section{Jiang 2015b \{published data only\}}

Jiang D, Zhang Y, Wu X, Wu S. Clinical study on infertility due to polycystic ovary syndrome of kidney deficiency and blood stasis type treated with integrated Chinese and western medicine [中西医结合治疗肾虚血㿈型多囊卵巢综合征性不孕症的 临床研究]. Liaoning Journal of Traditional Chinese Medicine 2015;42(4):803-5.

\section{Jin 2014 \{published data only\}}

Jin CL, Wei LX, Zhao JP, Wu ZC. Efficacy comparison between electroacupuncture and Dyne-35 in treatment of polycystic ovary syndrome [Chinese]. Zhongguo Zhen Jiu 2014;34(12):1174-8.

\section{Kuang 2013 \{published data only\}}

Kuang H, Li Y, Wu X, Hou L, Wu T, Liu J, et al. Acupuncture and clomiphene citrate for live birth in polycystic ovary syndrome: study design of a randomized controlled trial. Evidence-based Complementary and Alternative Medicine : ECAM 2013;2013:527303.

\section{Li 2010 \{published data only\}}

Li B, Han J. Clinical observation of acupuncture plus medicine in the treatment of polycystic ovarian syndrome [针药结合治 疗多囊卵巢综合征临床观察]. Journal of Clinical Acupuncture and Moxibustion 2010;26(1):20-1.

\section{Li 2011a \{published data only\}}

Li C, Zhang S. Clinical observation of acupuncture for polycystic ovarian syndrome in 30 cases [ 针刺治疗多囊卵巢综合征30 例临床观察] . Beijing Journal of Traditional Chinese Medicine 2011;30(2):128-30.

\section{Li 2011b \{published data only\}}

Li Y. [电针对IVF-ET周期的PCOS患者卵泡液LIF和卵细胞质量的 临床研究]. Clinical Study of Electroacupuncture for Leukemia
Inhibitory Factor of Follicular Fluid and Quality of Oocytes in the Treatment of Polycystic Ovarian Syndrome with In Vitro Fertilization and Embryo Transfer [thesis]. Jinan City, China: Shandong University of Traditional Chinese Medicine, 2011.

\section{Li 2013 \{published data only\}}

Li N. Efficacy and safety evaluation of acupuncture combined with auricular point sticking therapy in the treatment of polycystic ovary syndrome [Chinese]. Zhongguo Zhen Jiu 2013;33(11):961-4.

\section{Li 2014 \{published data only\}}

Li J, Cui W, Sun W, Wen J. Effect of electroacupuncture on egg quality and tumor necrosis factor-alpha of patients with polycystic ovarian syndrome. World Journal of Acupuncture 2014; Vol. 24, issue 3:9-15.

\section{Li 2015 \{published data only\}}

Li S. Metformin and auxiliary acupuncture in the treatment of obese women infertility with polycystic ovary syndrome for 75 cases [针炎辅助二甲双胍治疗肥胖型多囊卵巢综合征不孕症 75例] . Chinese Medicine Modern Distance Education of China 2015;13(6):78-9.

\section{Li 2017 \{published data only\}}

Li N, Zhang N. Therapeutic effect of midnight-midday ebb flow theory on the treatment of ovulation disorders in women with polycystic ovary syndrome [子午流注开穴法治疗多囊卵巢 综合征排卵障碍的疗效观察]. Beijing Journal of Traditional Chinese Medicine 2017;36(1):74-6.

\section{Liu 2012 \{published data only\}}

Liu Y, Liu X, Li X, Liang R. Clinical study of acupuncture and acupoint injection combined intrauterine insemination for polycystic ovarian syndrome with infertility [针刺及封闭穴位 联合宫腔内人工授精治疗PCOS不孕症的临床研究] . Journal of Chengdu Medical College 2012;7(2z):3.

\section{Liu 2017 \{published data only\}}

Liu S, Jia N, Cai S, Lu X, Li H. A comparative study on monitoring clinical effects of acupuncture on polycystic ovary syndrome by ultrasound [超声监测针炎治疗后多囊卵巢综合症患者疗效的 对比研究] . Clinical Journal of Chinese Medicine 2017;9(5):116-8.

\section{Peng 2017 \{published data only\}}

Peng Y, Cong J, Hu N, Chang H, Lu N, Yang X. Acupuncture with resolving phlegm therapy in the treatment of polycystic ovary syndrome: evaluation of clinical efficacy [针刺化痰法对多囊 卵巢综合征的临床疗效评价]. Journal of Clinical Acupuncture and Moxibustion 2017;33(2):5-8.

\section{Qu 2012 \{published data only\}}

Qu H. [腹针治疗肾虚血瘀型多囊卵巢综合征排卵障碍的临 床研究] . Clinical Observation of Abdominal Acupuncture for Polycystic Ovarian Syndrome with Ovulatory Dysfunction in Kidney Deficiency and Blood Stasis Pattern [thesis]. Guangzhou, China: Guangzhou University of Chinese Medicine, 2012.

Rashidi 2013 \{published data only\}

Rashidi BH, Tehrani ES, Hamedani NA, Pirzadeh L. Effects of acupuncture on the outcome of in vitro fertilisation and 
intracytoplasmic sperm injection in women with polycystic ovarian syndrome. Acupuncture in Medicine 2013;31(2):151-6.

Sun 2010 \{published data only\}

Sun W, Cui W, Li J. Study of effect mechanism of electroacupuncture for polycystic ovarian syndrome in kidney deficiency pattern [电针干预对肾虚型PCOS患者影 响机制的研究] . Chinese Journal of Birth Health \& Heredity 2010;18(1):105-7.

Wang 2013 \{published data only\}

Wang $\mathrm{H}, \mathrm{Gu}$ Z. Clinical observation of acupuncture plus medicine for polycystic ovarian syndrome with infertility [ 针 药结合治疗多囊卵巢性不孕症临床观察]. Journal of Hubei University of Chinese Medicine 2013;15(6):57-8.

Yang 2015 \{published data only\}

Yang J, Xu J, Liu Y, Huang J. Clinical investigation on the effect of acupuncture-induced artificial menstrual cycle on polycystic ovary syndrome related follicular dysplasia [针炎人工周期疗 法治疗多囊卵巢综合征卵泡发育不良的临床研究]. Lishizhen Medicine and Materia Medica Research 2015;26(12):2954-5.

Yang 2017 \{published data only\}

Yang D, Zhao M, Tan J. Effect of polycystic ovary syndrome treated with the periodic therapy of acupuncture [针刺调周 法治疗多囊卵巢综合征的临床疗效分析]. Zhongguo Zhenjiu 2017;37(8):825-9.

\section{Yu 2013 \{published data only\}}

Yu L, Liao Y, Wu H, Zhao J, Wu L, Shi Y, et al. Effects of electroacupuncture and Chinese kidney-nourishing medicine on polycystic ovary syndrome in obese patients. Journal of Traditional Chinese Medicine 2013;33(3):287-93.

\section{Zhang 2013 \{published data only\}}

Zhang $\mathrm{H}$. Acupuncture plus medicine for polycystic ovarian syndrome in 30 cases [针刺配合西药治疗多囊卵巢综合征30 例] . China's Naturopathy 2013;21(11):60-1.

Zhou 2016 \{published data only\}

Zhou Y, Wu J, Lin W, Pi M, Chen P, Yang Z. The "regulating conception-governor vessel" acupuncture method for infertility of polycystic ovarian syndrome [调任通督针刺法”治疗多 囊卵巢综合征不孕症的临床疗效观察]. Zhongguo ZhenJiu 2016;36(12):1237-40.

\section{References to ongoing studies}

\section{ChiCTR1800015738 \{published data only\}}

ChiCTR1800015738. Intervention of acupuncture based on metabonomics on key targets of PCOS dampness syndrome [基于代谢组学的针刺对PCOS痰湿证关键靶点的干预研究]. www.chictr.org.cn/showprojen.aspx?proj=26694 (first received 18 April 2018).

\section{ChiCTR1800017304 \{published data only\}}

ChiCTR1800017304. A multicenter, randomized, controlled trial for comparing personalized acupuncture versus standardized acupuncture, versus letrozole, placebo in the treatment of anovulatory women with polycystic ovary syndrome [个性化
针炎、标准化针炎、来曲唑和安慰剂对多囊卵巢综合症无排 卵妇女活产率影响：多中心随机试验].www.chictr.org.cn/ showprojen.aspx?proj=28407 (first received 23 July 2018).

ChicTR-IOR-15007358 \{published data only\}

ChiCTR-IOR-15007358. A randomized controlled trial to evaluate the effectiveness of electroacupuncture for polycystic ovary syndrome [针刺治疗多囊卵巢综合症的随机对照研究]. www.chictr.org.cn/showproj.aspx?proj=12273 (first received 26 October 2015).

\section{NCT02491333 \{published data only\}}

NCT02491333. The effect of acupuncture on insulin sensitivity of women with polycystic ovary syndrome and insulin resistance: a randomized controlled trial. clinicaltrials.gov/ct2/show/ NCT02491333 (first received 8 July 2015).

\section{NCT02647827 \{published data only\}}

NCT02647827. Acupuncture or metformin for insulin resistance in women with polycystic ovary syndrome: a randomized controlled trial. clinicaltrials.gov/ct2/show/NCT02647827 (first received 6 January 2016).

\section{NCT02653911 \{published data only\}}

NCT02653911. Efficacy of acupuncture on menstrual frequency in women with polycystic ovary syndrome: protocol for a randomized, controlled trial. clinicaltrials.gov/ct2/show/ NCT02653911 (first received 13 January 2016).

\section{Additional references}

\section{Acbay 1996}

Acbay O, Gundogdu S. Can metformin reduce insulin resistance in polycystic ovary syndrome?. Fertility and Sterility 1996;65(5):946-9.

\section{Aleem 1987}

Aleem FA, Eltabbakh GH, Omar RA, Couthren AL. Ovarian follicular fluid beta-endorphin levels in normal and polycystic ovaries. American Journal of Obstetrics and Gynecology 1987;156:1197-200.

\section{Aso 1976}

Aso T, Motohashi T, Murata M, Nishimura T, Kakizaki K. The influence of acupuncture stimulation on plasma levels of $\mathrm{LH}$, $\mathrm{FSH}$, progesterone and estradiol in normally ovulating women. American Journal of Chinese Medicine 1976;4:391-401.

\section{Asunicón 2000}

Asunción M, Calvo RM, San Millán JL, Sancho J, Avila S, EscobarMorreale HF. A prospective study of the prevalence of the polycystic ovary syndrome in unselected Caucasian women in Spain. Journal of Clinical Endocrinology and Metabolism 2000;85:243-8.

\section{Brown 2009}

Brown J, Farquhar C, Beck J, Boothroyd C, Hughes E. Clomiphene and anti-oestrogens for ovulation induction in PCOS. Cochrane Database of Systematic Reviews 2009, Issue 4. [DOI: 10.1002/14651858.CD002249.pub4] 


\section{Cai 1997}

Cai X. Substitution of acupuncture for human chorionic gonadotropin in ovulation induction. Journal of Traditional Chinese Medicine 1997;17:19-21.

\section{Chen 1991}

Chen BY, Yu J. Relationship between blood radioimmunoreactive beta-endorphin and hand skin temperature during the electro-acupuncture induction of ovulation. Acupuncture \& Electro-therapeutics Research 1991;16:1-5.

\section{Cui 2017}

Cui J, Wang S, Ren J. Zhang J, Jing J. Use of acupuncture in the USA: Changes over a decade (2002-2012). Acupuncture in Medicine 2017;35(3):200-7.

\section{Diamanti-Kandarakis 1999}

Diamanti-Kandarakis E, Kouli CR, Bergiele AT, Filandra FA, Tsianateli TC, Spina GG, et al. A survey of the polycystic ovary syndrome in Greek island of Lesbos: hormonal and metabolic profile. Journal of Clinical Endocrinology and Metabolism 1999;84:4006-11.

\section{ESHRE 1997}

European Society of Human Reproduction and Embryology Capri Workshop. Female infertility: treatment options for complicated cases. Human Reproduction 1997;12:1191-6.

\section{ESHRE/ASRM 2004}

The Rotterdam European Society of Human Reproduction and Embryology/American Society of Reproductive Medicine sponsored PCOS consensus workshop group. Revised 2003 consensus on diagnostic criteria and long term health risks related to polycystic ovary syndrome (PCOS). Human Reproduction 2004;19(1):41-7.

\section{Farhi 1996}

Farhi J, West C, Patel A, Jacobs HS. Treatment of anovulatory infertility: the problem of multiple pregnancy. Human Reproduction 1996;11:429-34.

\section{Fauser 2012}

Fauser B, Tarlatzis B, Reber R, Legro R, Balen A, Lobo R, et al. Consensus on women's health aspects of polycystic ovary syndrome (PCOS): the Amsterdam ESHRE/ASRM-Sponsored 3rd PCOS Consensus Workshop Group. Fertility and Sterility 2012;97(1):28-38.

\section{Franik 2018}

Franik S, Eltrop SM, Kremer JA, Kiesel L, Farquhar C. Aromatase inhibitors (letrozole) for subfertile women with polycystic ovary syndrome. Cochrane Database of Systematic Reviews 2018, Issue 5. [DOI: 10.1002/14651858.CD010287.pub3]

\section{Gadir 1990}

Gadir AA, Mowafi RS, Alnaser HM, Alrashid AH, Shaw RW. Ovarian electrocautery versus $\mathrm{hMG}$ and pure FSH therapy in the treatment of patients with polycystic ovarian disease. Clinical Endocrinology 1990;33:585-92.

\section{Gerhard 1992}

Gerhard I, Postneek F. Auricular acupuncture in the treatment of female infertility. Gynecological Endocrinology 1992;6:171-81.

\section{Higgins 2002}

Higgins JP, Thompson SG. Quantifying heterogeneity in a metaanalysis. Statistics in Medicine 2002;21(11):1539-58.

\section{Higgins 2011}

Higgins JP, Green S, editor(s). Cochrane Handbook for Systematic Reviews of Interventions Version 5.1.0 (updated March 2011). The Cochrane Collaboration, 2011. Available from handbook.cochrane.org.

\section{Hopton 2012}

Hopton AK, Curnoe S, Kanaan M, Macpherson H. Acupuncture in practice: mapping the providers, the patients and the settings in a national cross-sectional survey. BMJ Open 2012;2(1):e000456.

\section{Jo 2017}

Jo J, Lee YJ, Lee HS. Acupuncture for polycystic ovarian syndrome: a systematic review and meta-analysis. Medicine 2017;96(23):e7066.

\section{Knochenhauer 1998}

Knochenhauer ES, Key TJ, Kashar-Miller M, Waggoner W, Boots LR, Azziz R. Prevalence of the polycystic ovary syndrome in unselected black and white women of the south eastern United States: a prospective study. Journal of Clinical Endocrinology and Metabolism 1998;83:3078-82.

\section{Ku 2001}

Ku Y, Chang Y. Beta-endorphin and GABA-mediated depressor effect of specific electroacupuncture surpasses pressor response of emotional circuit. Peptides 2001;22:1465-70.

\section{Legro 2013}

Legro RS, Arslanian SA, Ehrmann DA, Hoeger KM, Murad MH, Paquali R, et al. Diagnosis and treatment of polycystic ovary syndrome: an Endocrine Society Clinical Practice guideline. Journal of Clinical Endocrinology \& Metabolism 2013;98(12):4565-92.

\section{MacPherson 2001}

MacPherson H, Thomas K, Walters S, Fitter M. The York acupuncture safety study: prospective survey of 34000 treatments by traditional acupuncturists. BMJ 2001;323:486-7.

\section{March 2010}

March WA, Moore VM, Willson KJ, Phillips DI, Norman RJ, Davies MJ. The prevalence of polycystic ovary syndrome in a community sample assessed under contrasting diagnostic criteria. Human Reproduction 2010;25:544-51.

\section{Mayer 1977}

Mayer DJ, Price DD, Rafil A. Antagonism of acupuncture analgesia in man by the narcotic antagonist naloxone. Brain Research 1977;121:368-72. 


\section{Michelmore 1999}

Michelmore KF, Balen AH, Dunger DB, Vessey MP. Polycystic ovaries and associated clinical and biochemical features in young women. Clinical Endocrinology 1999;51:779-86.

\section{Mo 1993}

Mo X, Li D, Pu Y, Xi G, Le X, Fu Z. Clinical studies on the mechanism of acupuncture stimulation of ovulation. Journal of Traditional Chinese Medicine 1993;13:115-9.

\section{Ni 2007}

$\mathrm{Ni} \mathrm{HY}$, Gong J. Research progress on Chinese herbal medicine in treating PCOS. Liaoning Journal of Traditional Chinese Medicine 2007;34(1):123-4.

\section{Norman 2004}

Norman RJ, Wu R, Stankiewicz MT. Polycystic ovary syndrome. Medical Journal of Australia 2004;180(3):132-7.

\section{Petraglia 1987}

Petraglia F, DiMeo G, Storchi R, Segre A, Facchinette F, Szalay S. Proopiomelanocortin-related peptides and methionine enkephalin in human follicular fluid: changes during the menstrual cycle. American Journal of Obstetrics and Gynecology 1987;157:142-6.

\section{Petti 1998}

Petti F, Bangrazi A, Liguori A, Reale G, Ippoliti F. Effects of acupuncture on immune response related to opioid-like peptides. Journal of Traditional Chinese Medicine 1998;18:55-63.

\section{Qu 2016}

Qu F, Wu Y, Hu XY, Barry J, Zhou J, Wang FF, et al. The effects of acupuncture on polycystic ovary syndrome: a systematic review and meta-analysis. European Journal of Integrative Medicine 2016;8(1):12-8

\section{Rodin 1998}

Rodin DA, Bano G, Bland JM, Taylor K, Nussey SS. Polycystic ovaries and associated metabolic abnormalities in Indian subcontinent Asian women. Clinical Endocrinology 1998;49:91-9.

\section{Stener-Victorin 2000}

Stener-Victorin E, Waldenstrom U, Tagnfors U, Lundeberg T, Lundstedt G, Janson PO. Effects of electro-acupuncture on anovulation in women with polycystic ovary syndrome. Acta Obstetricia et Gynecologica Scandinavica 2000;79:180-8.

\section{Stener-Victorin 2007}

Stener-Victorin E, Jedel E, Manneras L. Acupuncture in polycystic ovary syndrome: current experimental and clinical evidence. Journal of Neuroendocrinology 2007;20(3):290-8.

\section{Tang 2012}

Tang T, Lord JM, Norman RJ, Yasmin E, Balen AH. Insulinsensitising drugs (metformin, rosiglitazone, pioglitazone, Dchiro-inositol) for women with polycystic ovary syndrome, oligo amenorrhoea and subfertility. Cochrane Database of Systematic Reviews 2012, Issue 5. [DOI: 10.1002/14651858.CD003053.pub5]

\section{Teede 2010}

Teede H, Deeks A, Moran L. Polycystic ovary syndrome: a complex condition with psychological, reproductive and metabolic manifestations that impacts on health across the lifespan. BMC Medicine 2010;8:41.

\section{Teede 2011}

Teede HJ, Misso ML, Deeks AA, Moran LJ, Stuckey BG, Wong JL, et al. Assessment and management of polycystic ovary syndrome: summary of an evidence-based guideline. Medical Journal of Australia 2011;195:S65-112.

\section{Thomas 2001}

Thomas KJ, Nicholl JP, Coleman P. Use and expenditure on complementary medicine in England: a population based survey. Complementary Therapies in Medicine 2001;9:2-11.

\section{Ulett 1998}

Ulett GA, Han S, Han JS. Electroacupuncture: mechanisms and clinical application. Biological Psychiatry 1998;44:129-38.

\section{Wang 2008}

Wang BQ, Ling M. Research development of Chinese herbal medicine for PCOS. Shandong Journal of Traditional Chinese Medicine 2008;27(2):138-40.

\section{Wild 2000}

Wild S, Pierpoint T, Jacobs H, McKeigue P. Long-term consequences of polycystic ovary syndrome: results of a 31 year follow-up study. Human Fertility 2000;3(2):101-5.

\section{Witt 2009}

Witt CM, Pach D, Brinkhaus B, Wruck K, Tag B, Mank S, et al. Safety of acupuncture: results of a prospective observational study with 229,230 patients and introduction of a medical information and consent form. Forschende Komplementärmedizin/Research in Complementary Medicine 2009;16:91-7.

\section{Xue 2007}

Xue CC, Zhang AL, Lin V, Da Costa C, Story D. Complementary and alternative medicine use in Australia: a national population-based survey. Journal of Alternative and Complementary Medicine 2007;13(6):643-50.

\section{Zhang 2010}

Zhang J, Li T, Zhou L, Tang L, Xu L, Wu T, et al. Chinese herbal medicine for subfertile women with polycystic ovarian syndrome. Cochrane Database of Systematic Reviews 2010, Issue 9. [DOI: $10.1002 / 14651858 . C D 007535 . p u b 2]$

\section{References to other published versions of this review}

\section{Lim 2016}

Lim CE, Ng RW, Xu K, Cheng NC, Xue CC, Liu JP, Chen N. Acupuncture for polycystic ovarian syndrome. Cochrane Database of Systematic Reviews 2016, Issue 5. [DOI: 10.1002/14651858.CD007689.pub3] 
* Indicates the major publication for the study

\section{CHARACTERISTICS OF STUDIES}

Characteristics of included studies [ordered by study ID]

Cao 2017

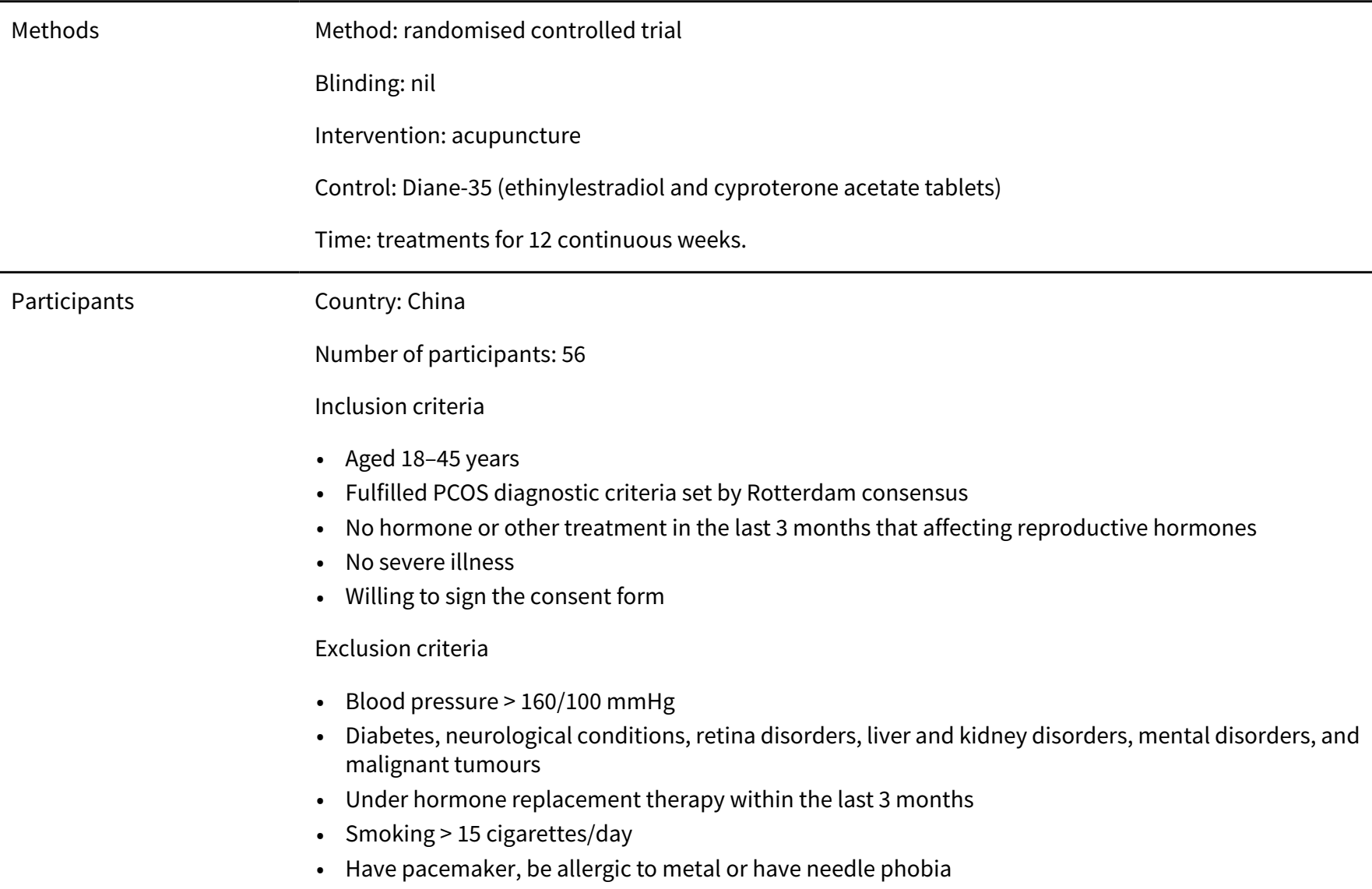

- 30 minutes 2 times/week for 12 weeks

Following were treated bilaterally, Fuke, Huanchao, Tianhuang (Yinlingquan, SP 9), Renhuang (Sanyinjiao, SP 6), Guanyuan (CV 4), Zigong (EX-CA 1)

Diane-35

- Once a day for 21 days with 7 days treatment-free interval between 2 sessions. Regimen was repeated for 3 menstrual cycles.

Outcomes

Primary

- LH:FSH ratio

Secondary

- Testosterone

- $\mathrm{FSH}$

- $\mathrm{LH}$

- BMI

- Ultrasound to evaluate ovary size and follicular number ovulation 
Cao 2017 (Continued)

- Menstruation duration

Notes

\section{Risk of bias}

\begin{tabular}{|c|c|c|}
\hline Bias & Authors' judgement & Support for judgement \\
\hline $\begin{array}{l}\text { Random sequence genera- } \\
\text { tion (selection bias) }\end{array}$ & Low risk & Participants randomised using random number method \\
\hline $\begin{array}{l}\text { Allocation concealment } \\
\text { (selection bias) }\end{array}$ & Unclear risk & No concealment described \\
\hline $\begin{array}{l}\text { Blinding of participants } \\
\text { and personnel (perfor- } \\
\text { mance bias) } \\
\text { All outcomes }\end{array}$ & High risk & No blinding described (difficult to blind when using different method) \\
\hline $\begin{array}{l}\text { Blinding of outcome as- } \\
\text { sessment (detection bias) } \\
\text { All outcomes }\end{array}$ & High risk & No blinding described \\
\hline $\begin{array}{l}\text { Incomplete outcome data } \\
\text { (attrition bias) } \\
\text { All outcomes }\end{array}$ & High risk & $\begin{array}{l}\text { 4/56 women dropped out during the intervention phase. The difference be- } \\
\text { tween age, BMI or clinical feature of the dropouts and the remainder of the co- } \\
\text { hort was not performed. There was no ITT analysis. }\end{array}$ \\
\hline $\begin{array}{l}\text { Selective reporting (re- } \\
\text { porting bias) }\end{array}$ & Low risk & All listed outcomes reported \\
\hline Other bias & Unclear risk & No other potential bias identified \\
\hline
\end{tabular}

\section{Du 2011}

Methods randomised controlled trial
Blinding: nil
Intervention: acupuncture
Control: clomiphene
Time: treatment for 3 continuous months or pregnancy. Follow-up 1 month
Country: China
Number of participants: 60
Inclusion criteria
- Aged 20-35 years
- Oligomenorrhoea, infertility or amenorrhoea
- Fulfilled PCOS diagnostic criteria set by Rotterdam consensus and relevant traditional diagnosis
Exclusion criteria
- Severe comorbid illness including malignancy
- Adrenal disease


Du 2011 (Continued)

- Organ failure

- Severe liver, kidney, cardiovascular or cerebrovascular disease

Acupuncture
$\begin{array}{ll}\text { Interventions } & 3 \times 30 \text {-day cycles of acupuncture regimen from } 5 \text { th day of menstruation or progesterone-induced with- } \\ & \text { drawal bleeding. Following points were treated bilaterally: Zhongwan Ren 12, Xiawan Ren } 10, \text { Qihai } \\ & \text { Ren 6, Guanyuan Ren 4, Zhongji } 4 \text { (RN 3), Dahe } 12 \text { (Ki 12), Shuidao (ST 28), lower rheumatism points, } \\ \text { Qixue (Ki 13) }\end{array}$

Clomiphene

- $50 \mathrm{mg} /$ day for 5 days from 5 th day of menstruation or progesterone-induced bleeding in women with amenorrhoea. Regimen repeated for 3 months

\begin{tabular}{ll}
\hline Outcomes & Basal body temperature \\
& - FSH \\
- & $\mathrm{LH}$ \\
- & Testosterone \\
& Oestradiol \\
- Ultrasound performed to evaluate ovulation at day 14 of menstrual cycle
\end{tabular}

Notes Study was from an unpublished thesis for Master's degree at Guangzhou University of Chinese Medicine.

\section{Risk of bias}

\begin{tabular}{|c|c|c|}
\hline Bias & Authors' judgement & Support for judgement \\
\hline $\begin{array}{l}\text { Random sequence genera- } \\
\text { tion (selection bias) }\end{array}$ & Low risk & $\begin{array}{l}\text { Computerised randomisation with PEMS } 3.1 \text { software was used to allocate } \\
\text { participants at 1:1 ratio into } 2 \text { groups. }\end{array}$ \\
\hline $\begin{array}{l}\text { Allocation concealment } \\
\text { (selection bias) }\end{array}$ & Low risk & $\begin{array}{l}\text { Computer-generated sequences were sealed in numbered opaque envelops. } \\
\text { Participants were allocated sequentially to envelops. }\end{array}$ \\
\hline $\begin{array}{l}\text { Blinding of participants } \\
\text { and personnel (perfor- } \\
\text { mance bias) } \\
\text { All outcomes }\end{array}$ & High risk & $\begin{array}{l}\text { Blinding of participants and personnel was not described. However, blinding } \\
\text { of participants or practitioner was unlikely given nature of intervention. }\end{array}$ \\
\hline $\begin{array}{l}\text { Blinding of outcome as- } \\
\text { sessment (detection bias) } \\
\text { All outcomes }\end{array}$ & High risk & Not described \\
\hline $\begin{array}{l}\text { Incomplete outcome data } \\
\text { (attrition bias) } \\
\text { All outcomes }\end{array}$ & Low risk & No withdrawal or exclusion after enrolment \\
\hline $\begin{array}{l}\text { Selective reporting (re- } \\
\text { porting bias) }\end{array}$ & High risk & Number of women with no ovulation during treatment period not reported \\
\hline Other bias & High risk & Reported as a part of thesis, instead of published in a peer-reviewed journal \\
\hline
\end{tabular}

\section{Jedel 2011}

Methods Method: randomised controlled clinical trial


Jedel 2011 (Continued)

\section{Blinding: nil}

Intervention: low-frequency electroacupuncture, physical exercise

Control: no active intervention

Time: 12-week observation period and baseline assessment, 16-week intervention, 16-week follow-up

Country: Sweden
Pumber of participants: low-frequency electroacupuncture: 33; physical exercise: 34 ; no active inter-
vention: 17
Inclusion criteria
- Ultrasound-verified polycystic ovaries with 12 follicles 2-9 mm or an ovarian volume of $10 \mathrm{~mL}$ in 1
or both ovaries (or both) together with oligo/amenorrhoea or clinical signs of hyperandrogenism (hir-
sutism or acne), or a combination of these
Exclusion criteria
- Aged $\geq 38$ years
Any pharmacological treatment within 12 weeks or breastfeeding within 24 weeks of entering the
study
Cardiovascular disease, diabetes mellitus, and endocrine or neoplastic causes of hyperandroge-
naemia, including androgen-secreting tumours, Cushing's syndrome, congenital adrenal hyperplasia
and hyperprolactinaemia

Interventions

3 groups

Low-frequency electroacupuncture

- Twice weekly for 2 weeks, once weekly for 6 weeks, and once every other week for 8 weeks, for a total of 14 treatments over 16 weeks

- Electroacupuncture points (low-frequency electroacupuncture $2 \mathrm{~Hz}$ ): CV 3, CV 6, ST 29, SP 6, SP 9 and LI 4, or PC 6 bilaterally

Physical exercise

- Brisk walking, cycling or any other aerobic exercise at a self-selected pace described as "faster than normal walking at a pace that could be sustained for at least 30 min at least 3 days per week."

- Physical exercise was self-monitored with a heart rate monitor to ensure a heart rate $\geq 120$ beats/ minute.

No active intervention

- Telephone information only

Outcomes Primary outcomes

- Changes in serum T between low-frequency electroacupuncture and physical exercise at week 16

Secondary outcomes

- Changes in serum T between low-frequency electroacupuncture and physical exercise at week 32

- Changes in menstrual frequency, acne and hirsutism, free T, 5a-dihydrotestosterone, oestrone, oestrone sulphate, oestradiol, dehydroepiandrosterone, dehydroepiandrosterone sulphate, androstenedione, 5 -androstene- $3 \beta, 17 \beta$-diol, androsterone glucuronide, $17 \beta$-diol-3glucuronide, $17 \beta$-diol-17-glucuronide, sex hormone-binding globulin, LH, FSH, LH:FSH ratio, BMI and maximum rate of oxygen consumption at weeks 16 and 32 between low-frequency electroacupuncture and physical exercise 
- Changes in primary and secondary outcome measures at weeks 16 and 32 between low-frequency electroacupuncture and no active intervention and between physical exercise and the no active intervention

- Adverse events

\section{Notes}

\section{Risk of bias}

\begin{tabular}{lll}
\hline Bias & Authors' judgement & Support for judgement \\
\hline $\begin{array}{l}\text { Random sequence genera- } \\
\text { tion (selection bias) }\end{array}$ & Low risk & $\begin{array}{l}\text { Participants stratified by age and BMI and randomised using computer-gener- } \\
\text { ated randomisation. }\end{array}$ \\
\hline $\begin{array}{l}\text { Allocation concealment } \\
\text { (selection bias) }\end{array}$ & Low risk & Concealed until interventions assigned. \\
\hline
\end{tabular}

Blinding of participants High risk No blinding described.

and personnel (perfor-

mance bias)

All outcomes

\begin{tabular}{lll}
\hline Blinding of outcome as- & High risk & No blinding described. \\
sessment (detection bias)
\end{tabular}

All outcomes

\begin{tabular}{lll}
\hline $\begin{array}{l}\text { Incomplete outcome data } \\
\text { (attrition bias) }\end{array}$ & Unclear risk & $\begin{array}{l}\text { Numbers and reasons for dropout in all phases were described. No compari- } \\
\text { son of baseline characteristics of dropouts and those remaining in trial was re- } \\
\text { ported. }\end{array}$ \\
\hline $\begin{array}{l}\text { Selective reporting (re- } \\
\text { porting bias) }\end{array}$ & Low risk & All listed outcomes reported. \\
\hline Other bias & Unclear risk & No other potential bias identified. \\
\hline
\end{tabular}

\section{Jin 2016}

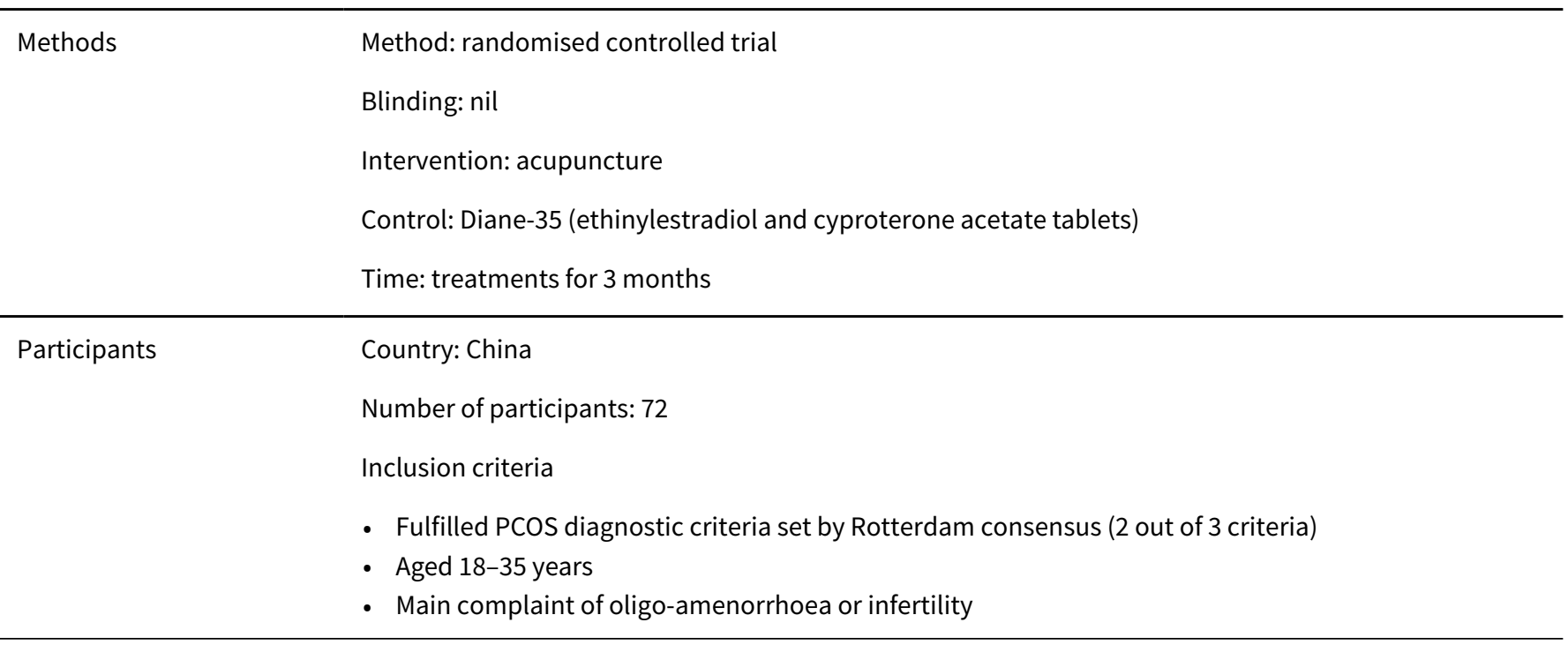


Jin 2016 (Continued)

- Menstrual cycle 35 days -6 months

- Menstrual bleeding $\leq 8$ days

- Liver stagnation score $\geq 3$ (inhouse method)

- No hormone or other treatment in the last 3 months that affected reproductive hormones

- No severe illness

- Willing to sign the consent form

Exclusion criteria

- Prolonged bleeding duration

- Acute gynaecological infection, endometriosis, premature ovarian failure, ovarian cyst

- Hyperinsulinaemia, fasting insulin level $\geq 85 \mathrm{pmol} / \mathrm{L}$

- Hyperprolactinaemia, prolactin $\geq 25 \mathrm{ng} / \mathrm{mL}$

- Primary liver, kidney, and blood disorders, mental disorders

- Under other treatment

- Unable to follow the treatment instructions

\begin{tabular}{|c|c|}
\hline Interventions & $\begin{array}{l}\text { Acupuncture } \\
\text { - } 30 \text { minutes } 3 \text { times/week for } 3 \text { months, in total } 40 \text { treatments } \\
\text { - Danzhong (CV 17), zhongwan (CV 12), Guanyuan (CV 4) } \\
\text { - Following were treated bilaterally: Qimen (LR 14), Ganshu (BL 18), Tianshu (ST 25), sanyinjiao (SP 6), } \\
\text { zusanli (DT 36), taichong (LV 3), Zigong (EX-CA 1) } \\
\text { - After deqi, Zhongwan, Guanyuang, Zigong and Tianshu were connected with electric needles. } \\
\text { Diane-35 } \\
\text { - From the 5th day of bleeding, once/day for } 21 \text { days with } 7 \text { days' treatment-free interval between } 2 \\
\text { sessions. Regimen was repeated for } 3 \text { menstrual cycles. }\end{array}$ \\
\hline Outcomes & $\begin{array}{l}\text { - Safety } \\
\text { - BMI } \\
\text { - Restoration of menstruation } \\
\text { - Ovulation } \\
\text { - Testosterone } \\
\text { - FSH } \\
\text { - LH } \\
\text { - Progesterone } \\
\text { - LH:FSH ratio } \\
\text { - Prolactin } \\
\text { - Hirsutism } \\
\text { - Acne } \\
\text { - Symptoms }\end{array}$ \\
\hline
\end{tabular}

Notes

\section{Risk of bias}

\section{Bias}

Random sequence genera- Low risk tion (selection bias)

\section{Authors' judgement Support for judgement}

Participants randomised using computer method.

No concealment described.

Allocation concealment

(selection bias)
Unclear risk 
Jin 2016 (Continued)

Blinding of participants and personnel (perfor-

High risk

No blinding described (difficult to blind when using different method). mance bias)

All outcomes

\begin{tabular}{lll}
\hline Blinding of outcome as- & High risk & No blinding described. \\
sessment (detection bias)
\end{tabular}

All outcomes

Incomplete outcome data High risk

(attrition bias)

All outcomes

Selective reporting (re-

Selective reporting (re- Low risk

porting bias)
4/72 dropped out during the intervention phase. The difference between age, $\mathrm{BMI}$ or clinical feature of the dropouts and the remainder of the cohort was not performed. No ITT analysis.

Other bias

High risk

All listed outcomes reported.

Reported as a part of thesis, instead of published in a peer-reviewed journal.

Johansson 2013

\begin{tabular}{ll}
\hline Methods & Method: randomised controlled trial \\
Blinding: single, investigators blinded until statistical analysis \\
Intervention: acupuncture \\
Control: relaxation \\
Time: $10-13$ weeks' intervention. Measurements were taken within 1 week of interventions. \\
Country: Sweden \\
Number of participants: acupuncture: 16; relaxation: 16 \\
Inclusion criteria \\
- Pcos diagnosed according to the Rotterdam consensus \\
Exclusion criteria \\
- Aged $<18$ or $>38$ years \\
- BMl $>30$ \\
- Any pharmacological therapy in previous 3 months \\
- Cardiovascular disease \\
- Diabetes mellitus
\end{tabular}

Interventions

Acupuncture

- Twice weekly acupuncture session with alternating 11 (CV 3, CV 6, ST 29, SP 6, SP 9, LI 4, GV 20) or 13 (CV 3, CV 6, ST 25, ST 29, SP 6, LR 3, PC 6, GV 20) point protocols

Attention control (relaxation)

- Visit to the same therapist for the same amount of time, consisting of relaxation and resting

Outcomes Primary outcomes


- Ovulation frequency, confirmed by bleeding and progesterone measurement

- LH secretion pattern from baseline to the end of treatment

Secondary outcomes

- Measurements of fasting glucose, insulin level, anti-Mullerian hormone level, inhibin B level, lipid profile, sex hormone binding globulin level, ovarian volume, endometrial thickness, antral follicle by ultrasound, body fat percentage, hirsutism

\section{Notes}

\section{Risk of bias}

\begin{tabular}{lll}
\hline Bias & Authors' judgement & Support for judgement \\
\hline $\begin{array}{l}\text { Random sequence genera- } \\
\text { tion (selection bias) }\end{array}$ & Low risk & Computer-generated sequence \\
\hline $\begin{array}{l}\text { Allocation concealment } \\
\text { (selection bias) }\end{array}$ & Unclear risk & Not mentioned \\
\hline $\begin{array}{l}\text { Blinding of participants } \\
\begin{array}{l}\text { and personnel (perfor- } \\
\text { mance bias) } \\
\text { All outcomes }\end{array}\end{array}$ & High risk & $\begin{array}{l}\text { Blinding of participants or therapists was not possible because of natures of } \\
\text { intervention and control in this study. }\end{array}$ \\
\hline $\begin{array}{l}\text { Blinding of outcome as- } \\
\text { sessment (detection bias) } \\
\text { All outcomes }\end{array}$ & Unclear risk & $\begin{array}{l}\text { Biological outcomes were measured at an independent laboratory. It was un- } \\
\text { clear what was meant by "investigators were blinded until statistical analy- } \\
\text { ses." There was potential risk from blinding of outcome assessment if blinding } \\
\text { was stopped prior to statistical analysis. }\end{array}$ \\
\hline
\end{tabular}

Incomplete outcome data Low risk Dropouts were adequately described.

(attrition bias)

All outcomes

\begin{tabular}{|c|c|c|}
\hline $\begin{array}{l}\text { Selective reporting (re- } \\
\text { porting bias) }\end{array}$ & Unclear risk & $\begin{array}{l}\text { All predetermined outcomes were reported. However, there was no mention } \\
\text { of adverse events. }\end{array}$ \\
\hline
\end{tabular}

\begin{tabular}{ll}
\hline Other bias $\quad$ Unclear risk $\quad$ No other potential bias identified. \\
\hline
\end{tabular}

\section{Lim 2014}

\begin{tabular}{l} 
Methods $\quad$ Blinding: single (participants) \\
Intervention: acupuncture \\
Control: sham acupuncture \\
Time: 7 months \\
\hline
\end{tabular}

Country: Australia and China
Pumber of participants: acupuncture: $98:$ sham acupuncture: 48
Inclusion criteria
- Rotterdam consensus diagnostic criteria


Lim 2014 (Continued)

- Kidney yang deficiency syndrome as per Chinese medicine diagnosis

Exclusion criteria

- Lack of consent to agree to participate in the study determined through the informed consent forms given to qualifying women

- Aged $<18$ years

- Abnormal full blood count, renal or liver function tests

\begin{tabular}{ll}
\hline Interventions & True acupuncture \\
- & Ren 3, M-CA 18, SP 6, Ren 4, ST 36, ST 40, LV 3, ST 29 and SP 10 \\
Sham body acupuncture \\
- 10 mm outside the classical point and outside of the meridian using superficial needling methods \\
Intervention frequency: weekly for 3 months \\
\hline Primary outcome \\
- Return of menstruation from amenorrhoea \\
Secondary outcomes \\
- Changes in serum hormone profiles (LH and FSH concentration, LH:FSH ratio, progesterone concen- \\
tration, oestrogen concentration, androgenic hormone concentration)
\end{tabular}

Notes

Live birth was not measured. Clarification from author was sought regarding adverse events. There were no adverse events noted in the study and hence was not reported.

\section{Risk of bias}

\begin{tabular}{|c|c|c|}
\hline Bias & Authors' judgement & Support for judgement \\
\hline $\begin{array}{l}\text { Random sequence genera- } \\
\text { tion (selection bias) }\end{array}$ & Low risk & Randomisation achieved by computer-generated program. \\
\hline $\begin{array}{l}\text { Allocation concealment } \\
\text { (selection bias) }\end{array}$ & Low risk & Presealed identical envelopes used. \\
\hline $\begin{array}{l}\text { Blinding of participants } \\
\text { and personnel (perfor- } \\
\text { mance bias) } \\
\text { All outcomes }\end{array}$ & Unclear risk & Trial described as single blinded, only participants were blinded. \\
\hline $\begin{array}{l}\text { Blinding of outcome as- } \\
\text { sessment (detection bias) } \\
\text { All outcomes }\end{array}$ & Low risk & $\begin{array}{l}\text { Outcome assessment was done by statisticians who were independent of the } \\
\text { study. }\end{array}$ \\
\hline $\begin{array}{l}\text { Incomplete outcome data } \\
\text { (attrition bias) } \\
\text { All outcomes }\end{array}$ & Low risk & $\begin{array}{l}\text { Number and reason for dropout between enrolment and allocation were de- } \\
\text { scribed. No participants dropped out or lost to follow-up during intervention. }\end{array}$ \\
\hline $\begin{array}{l}\text { Selective reporting (re- } \\
\text { porting bias) }\end{array}$ & Unclear risk & $\begin{array}{l}\text { All listed outcomes were reported; however, adverse effects were not report- } \\
\text { ed. }\end{array}$ \\
\hline Other bias & Unclear risk & No other potential bias identified. \\
\hline
\end{tabular}


Pastore 2011

\begin{tabular}{|c|c|}
\hline \multirow[t]{5}{*}{ Methods } & Method: randomised controlled trial \\
\hline & Blinding: double blind \\
\hline & Intervention: acupuncture \\
\hline & Control: sham acupuncture \\
\hline & Time: 5 months \\
\hline \multirow[t]{17}{*}{ Participants } & Country: US \\
\hline & Number of participants: acupuncture: 46 ; sham acupuncture: 50 \\
\hline & Inclusion criteria \\
\hline & - Women with PCOS confirmed by presence of oligomenorrhoea and hyperandrogenism \\
\hline & - Aged $18-43$ years \\
\hline & $\begin{array}{l}\text { - } \geq 1 \text { menses in the last } 6 \text { months but no more than } 8 \text { menses in the most recent } 12 \text { months without } \\
\text { hormonal intervention }\end{array}$ \\
\hline & $\begin{array}{l}\text { - Agreement to not take hormonal contraceptives, metformin or fertility medication for the } 5 \text { months } \\
\text { of study participation }\end{array}$ \\
\hline & Exclusion criteria \\
\hline & $\begin{array}{l}\text { - Diagnosed with Cushing's syndrome, uncontrolled thyroid disease, hyperprolactinaemia, congenital } \\
\text { adrenal hyperplasia or diabetes mellitus }\end{array}$ \\
\hline & - Use of metformin or hormonal contraceptives in the 60 days before enrolment \\
\hline & $\begin{array}{l}\text { - Use of any other hormonal drug in the } 30 \text { days before entry into study, including fertility medications, } \\
\text { and non-prescription hormonal supplements or herbs (i.e. black cohosh, clover, soy, dong quai/Chi- } \\
\text { nese angelica root, fructus rubi, white peony root) }\end{array}$ \\
\hline & - Currently pregnant or breastfeeding during the prior 30 days \\
\hline & - Any acupuncture treatment for ovulatory disorders in the prior 30 days \\
\hline & $\begin{array}{l}\text { - Weight }>250 \mathrm{lb}(113 \mathrm{~kg}) \text { because these women were reported to be the most resistant to medical } \\
\text { intervention at the time of our study design development }\end{array}$ \\
\hline & - Currently taking anticoagulation medication other than low-dose ( $\leq 81 \mathrm{mg}$ ) aspirin \\
\hline & - Immune deficiency \\
\hline & - History of any bleeding disorder \\
\hline
\end{tabular}

Interventions

Time: 12 acupuncture/sham session: twice weekly for the first 4 weeks followed by once weekly for an additional 4 weeks

True acupuncture

- Electroacupuncture points: BL 23, BL 28, SP 6 and SP 9 bilaterally

- Manual stimulation: PC 6, TE 5 and GV 20

Sham acupuncture

- Standardised points on all 4 extremities (Achilles tendon and lateral head of the triceps)

Outcomes Ovulation rate

LH:FSH ratio thors.

\section{Risk of bias}

Acupuncture for polycystic ovarian syndrome (Review) 
Pastore 2011 (Continued)

\section{Bias Authors' judgement Support for judgement}

Random sequence genera- Low risk Randomisation achieved by random number generator program.

tion (selection bias)

Participants stratified by obese (BMI) and non-obese.

Allocation concealment Low risk Consecutive study identifications were assigned to a treatment arm by a grad(selection bias) uate student independent of the study.

Quote: "These assignments were placed in individual sealed, opaque envelopes labelled with the study identifications."

$\begin{array}{ll}\begin{array}{l}\text { Blinding of participants } \\ \text { and personnel (perfor- }\end{array} & \text { Low risk } \\ \begin{array}{l}\text { mance bias) } \\ \text { All outcomes }\end{array} & \begin{array}{l}\text { The trial was described as blinded, parties who were blinded and method of } \\ \text { blinding was described. }\end{array} \\ & \begin{array}{l}\text { Quote: "The participants, principal investigator, clinical research coordinator, } \\ \text { and biostatistician (J.T.P.) were all blind to the intervention arm." }\end{array}\end{array}$

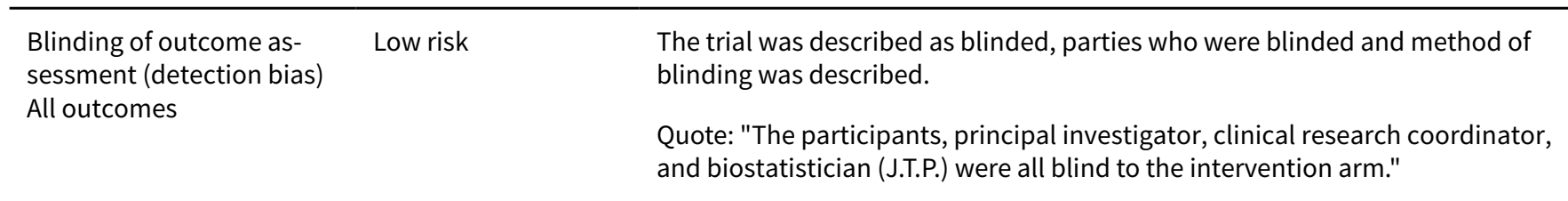

Incomplete outcome data High risk Number and reason for dropout during intervention described. Number and (attrition bias) reason for dropout during 3-month follow-up not given.

All outcomes

ITT not performed

Selective reporting (re- Low risk $\quad$ All listed outcomes reported.
porting bias)

\begin{tabular}{ll}
\hline Other bias $\quad$ Unclear risk $\quad$ No other potential bias identified. \\
\hline
\end{tabular}

\section{Wu 2017}

Method: factorial trial
Blinding: acupuncture double blinded to participants and study investigators, known to acupunctur-
ists and data manager at each site; clomiphene and placebo assignments double blinded to participant
and study investigators, known to data manager at each site.
Intervention: acupuncture, clomiphene
Control: control acupuncture and placebo drug

Participants

Country: China

Number of participants: active acupuncture + clomiphene: 250; control acupuncture + clomiphene: 250; active acupuncture + placebo: 250; control acupuncture + placebo: 250

Inclusion criteria

- Modified Rotterdam criteria: oligomenorrhoea or amenorrhoea, together with clinical or biochemical hyperandrogenism (modified Ferriman-Gallwey hirsutism score $\geq 5$ in Chinese) or polycystic ovaries, or both

Exclusion criteria 
Wu 2017 (Continued)

- Other endocrine disorders resembling PCOS, including hyperprolactinaemia, uncorrected thyroid disease, Type I or Type II diabetes, and Cushing's syndrome

- Use of hormonal or other medication including Chinese herbal prescriptions in the past 3 months

- Pregnancy with the past 6 weeks

- Within 6 weeks postabortion or postpartum

- Breastfeeding within the last 6 months

- Not willing to give written consent to the study

Interventions

Participants randomised to 4 arms

- Active acupuncture + clomiphene

- Control acupuncture + clomiphene

- Active acupuncture + placebo

- Control acupuncture + placebo

Active acupuncture

- Acupuncture treatment for 30 minutes twice weekly, maximum of 32 acupuncture treatments

- 2 sets of acupuncture points alternated every second treatment

- First set: CV 3, CV 6, ST 29, SP 6, SP 9, LI 4 bilaterally; GV 20

* All points stimulated manually first

* CV 3, CV 6, ST 29, SP 6 and SP 9 then stimulated with low-frequency electroacupuncture

- Second set

* ST 25, ST 29, SP 6 and LR 3 bilaterally stimulated with low-frequency electroacupuncture

* CV 3, CV 6 and GV 20; PC 6 bilaterally with manual stimulation

Control acupuncture

- Acupuncture treatment for 30 minutes twice weekly, maximum of 32 acupuncture treatments

- Needles inserted to a depth of $<5 \mathrm{~mm}, 1$ in each shoulder and 1 in each upper arm at non-acupuncture points

- Electrodes attached and stimulator turned on at an intensity of 0

- No manual stimulation of needles performed

Clomiphene

- Clomiphene citrate $50 \mathrm{mg} /$ day ( 1 tablet) for 5 days from days 3 to 7 of the menstrual cycle

- Dosage of clomiphene citrate increased by $50 \mathrm{mg}$ (1 tablet) in absence of ovulation or maintained in the presence of ovulation

- Maximum dosage of clomiphene citrate did not exceed $150 \mathrm{mg} /$ day or $750 \mathrm{mg} /$ cycle

- Treatment repeated for up to 4 cycles

Placebo

- Placebo tablet in place of clomiphene tablet with same increase in tablet schedule as clomiphene citrate

$\begin{array}{ll}\text { Outcomes } & \text { Primary outcome } \\ \text { - Live birth at } \geq 20 \text { weeks' gestation } \\ \text { Secondary outcomes } \\ \text { - Ovulation } \\ \text { - Conception } \\ \text { - Pregnancy } \\ \text { - Pregnancy loss } \\ \text { - Multiple (twin or triplet) pregnancies } \\ \text { - Anthropometrics }\end{array}$


Wu 2017 (Continued)

- Hirsutism

- Acne

- Hormonal changes

- Quality of life scores

- Adverse events

- Treatment credibility

Notes

\section{Risk of bias}

\begin{tabular}{lll}
\hline Bias & Authors' judgement & Support for judgement \\
\hline $\begin{array}{ll}\text { Random sequence genera- } \\
\text { tion (selection bias) }\end{array}$ & Low risk & Randomisation stratified within 21 participating sites and defined with a ran- \\
& & dom block size of 4 or 8 . Participants were randomly allocated in a ratio of \\
& & gram in a central office.
\end{tabular}

\begin{tabular}{ll}
\hline $\begin{array}{l}\text { Allocation concealment } \\
\text { (selection bias) }\end{array}$ & Low risk \\
& $\begin{array}{l}\text { Medication bottles had preprinted barcode labels and were distributed to sites } \\
\text { and assigned to the participants as they were enrolled. }\end{array}$
\end{tabular}

\begin{tabular}{|c|c|c|}
\hline $\begin{array}{l}\text { Blinding of participants } \\
\text { and personnel (perfor- }\end{array}$ & Low risk & $\begin{array}{l}\text { Active and control acupuncture treatments single blinded to participant. } \\
\text { Treatments known to acupuncturists and data manager at each site. }\end{array}$ \\
\hline
\end{tabular}

mance bias)

All outcomes

Clomiphene and placebo assignments double blinded to participants and study investigators. Known to data manager.

Blinding of outcome as- High risk

Not described in the report.

sessment (detection bias)

All outcomes

Incomplete outcome data Unclear risk

(attrition bias)

All outcomes

Numbers and reasons for dropout in all phases were described.

4 participants who conceived after randomisation and before intervention commenced. These participants completed the last visit and were included in the primary analysis. During the intervention phase, 74 participants dropped out from the study. 15 participants dropped out from the active acupuncture + clomiphene arm; 14 participants dropped out from the control acupuncture + clomiphene arm; 27 participants dropped out from the active acupuncture + placebo arm and 18 participants dropped out from the control acupuncture + placebo arm. Out of the 14 participants who dropped out from the control acupuncture + clomiphene arm, 2 were due to intervention adverse effects. Out of the 27 participants who dropped out from the active acupuncture + placebo arm, 3 were due to intervention adverse effects. There was no ITT analysis.

Selective reporting (re- Low risk $\quad$ All listed outcomes were reported.
porting bias)
porting bias)

Other bias Low risk

Conflict of interest disclosed by 1 author (Legro) who reported serving as consultant to Bayer, Kindex, Euroscreen, Millendo, Takeda, Clarus, Sprou and AstraZeneca; serving as a site investigators and receiving grants from Ferring and AstraZeneca.

The study was supported by various government and non-government grants.

Quote: "The funding agencies had no role in the design and conduct of the study; collection, management, analysis, and interpretation of the data; 
Wu 2017 (Continued)

preparation, review, or approval of the manuscript; and decision to submit the manuscript for publication."

BMI: body-mass index; FSH: follicle-stimulating hormone; ITT: intention to treat; LH: luteinising hormone; PCOS: polycystic ovarian syndrome.

\section{Characteristics of excluded studies [ordered by study ID]}

\begin{tabular}{ll}
\hline Study & Reason for exclusion \\
\hline Cai 2016 & $\begin{array}{l}\text { Additional acupuncture points were used based on traditional Chinese medicine patterns for } \\
\text { both electroacupuncture and acupoint catgut-embedding therapy groups. The frequency for elec- } \\
\text { troacupuncture was not a set value for each participant. }\end{array}$
\end{tabular}

Chen 2014

Acupuncture combined with another therapy. Embedded short suture as additional intervention in acupuncture group. There was also a lack of outcome measurement specified in this review.

Chen 2015b

Acupuncture combined with another therapy. Chinese herbal medicine combined with acupuncture, multiple conventional medicine used in control group.

\begin{tabular}{|c|c|}
\hline Fang 2016 & Lack of outcome measures specified in this review. \\
\hline Нао 2015 & Ineligible comparison intervention. 2 different forms of acupuncture compared. \\
\hline He 2017 & Lack of outcome measures specified in this review. \\
\hline Huang 2016 & Ineligible intervention, both acupuncture and western medicine were used in treatment group. \\
\hline Jiang 2014 & $\begin{array}{l}\text { Acupuncture combined with another therapy. Herbal medicine given to all groups apart from } \\
\text { clomiphene-only group. }\end{array}$ \\
\hline Jiang 2015a & $\begin{array}{l}\text { Acupuncture combined with another therapy. Herbal medicine given to all groups except for } \\
\text { clomiphene-only group. }\end{array}$ \\
\hline Jiang 2015b & $\begin{array}{l}\text { Ineligible treatment/comparison either using a combination of Chinese herbal medicine and } \\
\text { acupuncture, with or without conventional medicine. }\end{array}$ \\
\hline Jin 2014 & Lack of outcome measures specified in this review. \\
\hline Kuang 2013 & $\begin{array}{l}\text { Acupuncture combined with another therapy. Effects of clomiphene citrate combined with } \\
\text { acupuncture as intervention studied. }\end{array}$ \\
\hline Li 2010 & Lack of outcome measures specified in this review. \\
\hline Li $2011 a$ & Diagnostic criteria used differed significantly from Rotterdam consensus. \\
\hline Li 2011b & $\begin{array}{l}\text { Acupuncture combined with another therapy. Controlled ovarian hyperstimulation given as coint- } \\
\text { ervention to both groups. }\end{array}$ \\
\hline Li 2013 & Diagnostic criteria used were different from Rotterdam consensus. \\
\hline Li 2014 & $\begin{array}{l}\text { Acupuncture combined with another therapy. Controlled ovarian hyperstimulation performed on } \\
\text { both acupuncture and conventional group. }\end{array}$ \\
\hline Li 2015 & Ineligible comparison intervention: conventional medicine was used in both groups. \\
\hline
\end{tabular}




\begin{tabular}{|c|c|}
\hline Study & Reason for exclusion \\
\hline Li 2017 & $\begin{array}{l}\text { Different points were used for each participant during treatments in } 2 \text { types of acupuncture regi- } \\
\text { men. }\end{array}$ \\
\hline Liu 2012 & Acupuncture combined with another therapy. Oral contraceptives given to both groups. \\
\hline Liu 2017 & $\begin{array}{l}\text { Diagnostic criteria used differed significantly from Rotterdam consensus. It was unclear which type } \\
\text { of conventional medicine was used in the control group. Lack of outcome measure specified in this } \\
\text { review. }\end{array}$ \\
\hline Peng 2017 & Ineligible comparator, Electroacupuncture on real points vs manual acupuncture on sham points. \\
\hline Qu 2012 & Women with clinical or biochemical hyperandrogenism excluded from the study. \\
\hline Rashidi 2013 & $\begin{array}{l}\text { Ineligible comparison intervention. Acupuncture compared to in vitro fertilisation treatment in- } \\
\text { stead of treatment for polycystic ovarian syndrome. }\end{array}$ \\
\hline Sun 2010 & $\begin{array}{l}\text { Acupuncture combined with another therapy. Controlled ovarian hyperstimulation given to both } \\
\text { groups. }\end{array}$ \\
\hline Wang 2013 & Acupuncture combined with another therapy. \\
\hline Yang 2015 & $\begin{array}{l}\text { Not a randomised study. Additional points were used during different stages of menstrual cycle. } \\
\text { Multiple drugs were used for the control group. }\end{array}$ \\
\hline Yang 2017 & Different additional points were used for each participant during treatment of acupuncture. \\
\hline Yu 2013 & $\begin{array}{l}\text { Ineligible comparison intervention. Acupuncture compared with electrical acupuncture and herbal } \\
\text { medicine. Studies involving herbal medicine excluded because of coexisting review. }\end{array}$ \\
\hline Zhang 2013 & Acupuncture combined with another therapy. \\
\hline Zhou 2016 & $\begin{array}{l}\text { Different additional points were used for each participant during treatment of acupuncture. Multi- } \\
\text { ple type of conventional medicine may be used for patients. Acupuncture treatment duration may } \\
\text { be inconsistent due to ultrasound evaluation of ovulation. }\end{array}$ \\
\hline
\end{tabular}

Characteristics of ongoing studies [ordered by study ID]

\section{ChiCTR-IOR-15007358}

Trial name or title A randomized controlled trial to evaluate the effectiveness of electroacupuncture for polycystic ovary syndrome

\section{Methods}

Randomised parallel controlled trial
Inclusion criteria

- Women, aged 20-40 years

- Diagnosed with PCOS

- Signed the inform consent

Exclusion criteria

- Allergic constitution or allergic to various types of medicine

- Hyperandrogenism due to other reasons, including hyperprolactinaemia, thyroid disease, congenital adrenal hyperplasia, Cushing's syndrome, etc. 
- Pathological endometrial changes, uterine malformation, hysteromyoma, etc. diagnosed by B ultrasound

- Genital tract malformation, gonadal dysgenesis, fallopian tube block, etc.

- Severe heart, liver or renal dysfunction and haematological, respiratory, cardiovascular, psychiatric or other metabolic diseases

- Within 6 weeks postabortion

- Use of hormonal or other medication including Chinese herbal prescriptions in the past 3 months

- Participation in other clinical trials at the same time

\begin{tabular}{ll} 
Interventions & Electroacupuncture \\
& Clomiphene citrate \\
\hline Outcomes & $\begin{array}{l}\text { Ovulation rate, } \mathrm{LH}, \mathrm{E} 2, \text { dominant follicle rate } \\
\text { The time point of ovulation, mean number of dominant follicle, follicular size before ovulation, } \\
\text { pregnancy rate }\end{array}$
\end{tabular}

Starting date

1 January 2015

Contact information

Feng Shuwei. Chengdu University of TCM

Notes

\section{ChiCTR1800015738}

\begin{tabular}{|c|c|}
\hline Trial name or title & Intervention of acupuncture based on metabonomics on key targets of PCOS dampness syndrome \\
\hline Methods & Randomised parallel controlled trial \\
\hline Participants & $\begin{array}{l}\text { Inclusion criteria } \\
\text { - Diagnostic criteria for Chinese and Western medicine in accordance with spleen deficiency and } \\
\text { dampness PCOS } \\
\text { - Aged } 20-45 \text { years } \\
\text { - Normal liver and kidney function } \\
\text { - To understand and voluntarily join the trial and voluntarily sign the informed consent form. } \\
\text { Exclusion criteria } \\
\text { - People with adrenal, thyroid, pituitary and other endocrine dysfunction, such as adrenal hyper- } \\
\text { - plasia, adrenal insufficiency, hyperthyroidism, hypothyroidism, pituitary tumour, diabetes, etc. } \\
\text { - People with severe chronic wasting diseases such as heart, liver and kidney } \\
\text { - People with reproductive system tumours and genital organic diseases } \\
\text { - Taking contraceptives or other hormone-containing drugs within } 3 \text { months } \\
\text { - Physiological menstruation and amenorrhoea } \\
\text { - People whose compliance was crossed. }\end{array}$ \\
\hline
\end{tabular}

Interventions

Acupuncture

Western medicine

Acupuncture + western medicine 
ChiCTR1800015738 (Continued)

\begin{tabular}{ll} 
Outcomes & Biomarkers \\
\hline Starting date & 1 May 2018 \\
\hline Contact information & Xiaoxia Li, Shandong University of Traditional Chinese Medicine \\
\hline Notes & \\
\hline
\end{tabular}

\section{ChiCTR1800017304}

Trial name or title

A multicenter, randomized, controlled trial for comparing personalized acupuncture versus standardized acupuncture, versus letrozole, placebo in the treatment of anovulatory women with polycystic ovary syndrome

\section{Methods}

Randomised, parallel controlled trial

Participants
Inclusion criteria

- Women aged 20-40 years

- Chronic oligomenorrhoea or amenorrhoea. Oligomenorrhoea defined as an intermenstrual inter$\mathrm{val}>35$ days or $<8$ menstrual bleedings in the past year. Amenorrhea defined as an intermenstrual interval $>90$ days

- Hyperandrogenism (either hirsutism or hyperandrogenaemia) or polycystic ovaries on ultrasound. Hirsutism determined by a modified Ferriman-Gallwey Score at screening examination, and biochemical hyperandrogenism defined as total testosterone $>2.6 \mathrm{nmol} / \mathrm{L}$ and free testosterone $6.0 \mathrm{pg} / \mathrm{mL}$. Polycystic ovaries present when there were 12 antral follicles $(2-9 \mathrm{~mm})$ or ovarian volume $>10 \mathrm{~mL}$ on transvaginal scanning

- $\geq 1$ patent tube shown by hysterosalpingogram or diagnostic laparoscopy within 3 years if the participant did not have a history of abortion or pelvic operation. If the patient had a history of pregnancy and no history of pelvic operation within the past 5 years, she was not required to undergo a tubal patency test

- Sperm concentration $\geq 15 \times 10^{6} / \mathrm{mL}$ and total motility $\geq 40 \%$ or total motile sperm count $\geq 10$ million in the semen analysis of the husband. Agree to have regular intercourse, i.e. 2-3 times per week during the study period.

Exclusion criteria

- Exclusion of other endocrine disorders

* Hyperprolactinaemia (defined as 2 prolactin levels of $25 \mathrm{ng} / \mathrm{mL} \geq 1$ week apart)

* FSH levels $>15 \mathrm{mIU} / \mathrm{mL}$

* Normal level within the last year was adequate for entry

* Uncorrected thyroid disease (defined as TSH $<0.2 \mathrm{mIU} / \mathrm{mL}$ or $>5.5 \mathrm{mIU} / \mathrm{mL}$ ). A normal level within the last year was adequate for entry

* Type I or Type II diabetes who were poorly controlled (defined as HbAlc level $>7.0 \%$ ), or receiving antidiabetic medications such as metformin, insulin, thiazolidinediones, acarbose or sulphonylureas

* Suspected Cushing's syndrome

- Use of hormonal or other medication including Chinese herbal prescriptions in the past 3 months

- Pregnancy within the past 6 weeks

- Within 6 weeks postabortion or postpartum

- Breastfeeding within the last 6 months

- Not willing to give written consent to the study

- Additional exclusion criteria as follows

* Using oral contraceptives, depot progestins or hormonal implants (including Implanon). A 2month washout period was required prior to screening for people on these agents. Longer 
washouts may have been necessary for certain depot contraceptive forms or implants, especially where the implants are still in place. A 1-month washout will be required for people on oral cyclic progestins

* Liver disease defined as AST or ALT $>2$ times normal or total bilirubin $>2.5 \mathrm{mg} / \mathrm{dL}$. People with renal disease defined as blood urea $>30 \mathrm{mg} / \mathrm{dL}$ or serum creatinine $>1.4 \mathrm{mg} / \mathrm{dL}$

* Haemoglobin $<10 \mathrm{~g} / \mathrm{dL}$

* History of deep venous thrombosis, pulmonary embolus or cerebrovascular accident

* Known heart disease that is likely to be exacerbated by pregnancy

* History of, or suspected cervical carcinoma, endometrial carcinoma or breast carcinoma. A normal Pap smear result was required for women aged $\geq 21$ years

* Current alcohol abuse defined as $>14$ drinks/week or binge drinking

* Enrolled into other investigative studies that require medications, prescribe the study medications, limit intercourse or otherwise prevent compliance with the protocol

* Anticipate taking longer than a 1-month break during the protocol were not enrolled

* Other medications known to affect reproductive function or metabolism. These medications included oral contraceptives, GnRH agonists and antagonists, antiandrogens, gonadotropins, antiobesity drugs, Chinese herbal formula, antidiabetic drugs such as metformin and thiazolidinediones, somatostatin, diazoxide, angiotensin-converting-enzyme inhibitors and calcium channel blockers. Washout period on all these medications was 2 months

* Suspected adrenal or ovarian tumour-secreting androgens

* Couples with previous sterilisation procedures (vasectomy, tubal ligation), which had been reversed. The prior procedure may affect study outcomes, and people with both a reversed sterilisation procedure and PCOS were rare enough that exclusion should not adversely affect recruitment

* Undergone a bariatric surgery procedure in past 12 months and in a period of acute weight loss or have been advised against pregnancy by their bariatric surgeon

* Untreated poorly controlled hypertension defined as a systolic blood pressure $>160 \mathrm{mmHg}$ or a diastolic $>100 \mathrm{mmHg}$ obtained on 2 measures obtained at least 60 minutes apart

* Known congenital adrenal hyperplasia

Interventions 2 different acupuncture regimens

Letrozole

Placebo

\begin{tabular}{ll}
\hline Outcomes & Live birth rate, ovulation rate, ongoing pregnancy rate, multiple pregnancy rate, miscarriage rate, \\
hormonal profile, metabolic profile, adverse effect profile
\end{tabular}
hormonal profile, metabolic profile, adverse effect profile

\begin{tabular}{ll}
\hline Starting date & 1 August 2018 \\
\hline Contact information & Ma Hongxia, the First Affiliated Hospital of Guangzhou Medical University \\
\hline Notes &
\end{tabular}

\section{NCT02491333}

\begin{tabular}{ll}
\hline Trial name or title & The RCT of acupuncture on PCOS combined with IR \\
\hline Methods & Randomised controlled trial \\
\hline Participants & 342 Chinese women with BMI > 18.5 who satisfy Rotterdam criteria \\
\hline
\end{tabular}

Interventions True acupuncture


NCT02491333 (Continued)

\author{
Sham acupuncture \\ Metformin \\ Placebo metformin
}

\title{
Outcomes
}

HOMA-IR, HOMA-B, AUCglu, menstrual frequency, body composition, metabolic profile, hormonal profile, questionnaires, side effect profile, expectation and credibility of treatment, AUCins, ovulation rate

\begin{tabular}{ll}
\hline Starting date & August 2015 \\
\hline Contact information & Hongxia Ma, The First Affiliated Hospital of Guangzhou Medical University \\
\hline Notes & \\
\hline
\end{tabular}

\section{NCT02647827}

Trial name or title $\quad \begin{aligned} & \text { Acupuncture or metformin for insulin resistance in women with polycystic ovary syndrome: a ran- } \\ & \text { domized controlled trial }\end{aligned}$

\begin{tabular}{ll}
\hline Methods & Randomised controlled trial \\
\hline Participants & 303 Swedish women with BMI 25-40 who satisfy Rotterdam criteria \\
\hline Interventions & Acupuncture \\
Metformin & Lifestyle intervention \\
\hline
\end{tabular}

Outcomes

Primary outcomes

- Changes from baseline to after 4 months in HOMA-IR

- Changes from baseline to after 4 months of treatment in $\mathrm{HbAlc}$

- Changes from baseline to after 4 months of treatment in insulin response to glucose during the oral glucose tolerance test

Secondary outcomes

- Changes from baseline to after 4 months and again 4 months after last treatment in secondary metabolic measures

- Changes from baseline to after 4 months and again 4 months after last treatment gene expression and DNA methylation profiles related to insulin sensitivity in fat, muscle and endometrial tissue biopsies, and biomarkers in whole blood

- Changes from baseline to after 4 months and again 4 months after last treatment in menstrual pattern

- Changes from baseline to after 4 months and again 4 months after last treatment in circulating reproductive hormones

- Changes from baseline to after 4 months and again 4 months after last treatment in women's health-related quality of life

- Changes from baseline to after 4 months and again 4 months after last treatment in women's symptoms of anxiety and depression

- Changes from baseline to after 4 months and again 4 months after last treatment in women's dieting and eating patterns

- Cost-effectiveness of the different treatments throughout the study 
NCT02647827 (Continued)

Starting date December 2015

\section{Contact information}

Notes
Elisabet Stener-Victorin, PhD, Karolinska Institutet

Estimated study completion date: December 2019

\section{NCT02653911}

Trial name or title Efficacy of acupuncture on menstrual frequency in women with polycystic ovary syndrome: protocol for a randomized, controlled trial

\begin{tabular}{|c|c|}
\hline Methods & Randomised controlled trial \\
\hline Participants & 172 participants diagnosed with polycystic ovary syndrome \\
\hline \multirow[t]{2}{*}{ Interventions } & Electroacupuncture \\
\hline & Sham-acupuncture \\
\hline \multirow[t]{8}{*}{ Outcomes } & Primary outcome \\
\hline & - Proportion of participants with $\geq 50 \%$ increase from baseline in monthly menstrual frequency \\
\hline & Secondary outcomes \\
\hline & - Difference in anthropometrics \\
\hline & - Serum hormone level \\
\hline & - Ovarian morphology \\
\hline & - Anxiety and depression \\
\hline & $\begin{array}{l}\text { - Quality of life from baseline to after } 12 \text { weeks' intervention and to } 12 \text { weeks postintervention fol- } \\
\text { low-up }\end{array}$ \\
\hline Starting date & July 2018 \\
\hline Contact information & $\begin{array}{l}\text { Zhou Jing, Department of Acupuncture, Guang'anmen Hospital of China Academy of Chinese Med- } \\
\text { ical Sciences }\end{array}$ \\
\hline Notes & Estimated study completion date: June 2020 \\
\hline
\end{tabular}

ALT: alanine aminotransferase; AST: aspartate aminotransferase; AUCglu: area under the glucose curve; AUCins: area under the insulin curve; BMI: body-mass index; E2: 17ß-estradiol; FSH: follicle-stimulating hormone; GnRH: gonadotropin-releasing hormone; HbA1c: glycated haemoglobin; HOMA-B: homeostatic model assessment for $\beta$-cell function; HOMA-IR: homeostatic model assessment for insulin resistance; LH: luteinising hormone; PCOS: polycystic ovarian syndrome; TSH: thyroid-stimulating hormone.

\section{DATA AND ANALYSES}


Comparison 1. True acupuncture versus sham acupuncture

\begin{tabular}{|c|c|c|c|c|}
\hline Outcome or subgroup title & $\begin{array}{l}\text { No. of } \\
\text { studies }\end{array}$ & $\begin{array}{l}\text { No. of } \\
\text { partici- } \\
\text { pants }\end{array}$ & Statistical method & Effect size \\
\hline 1 Live birth rate & 1 & 926 & Risk Ratio (M-H, Fixed, 95\% Cl) & $0.97[0.76,1.24]$ \\
\hline 2 Multiple pregnancy rate & 1 & 926 & Risk Ratio (M-H, Fixed, 95\% Cl) & $0.89[0.33,2.45]$ \\
\hline 3 Ovulation rate & 2 & & $\begin{array}{l}\text { Std. Mean Difference (Fixed, 95\% } \\
\text { CI) }\end{array}$ & $0.02[-0.15,0.19]$ \\
\hline 4 Clinical pregnancy rate & 3 & 1117 & Risk Ratio (M-H, Fixed, 95\% Cl) & $1.03[0.82,1.29]$ \\
\hline 5 Restored regular menstrual period & 1 & 141 & Mean Difference (IV, Fixed, 95\% CI) & $-312.09[-344.59,-279.59]$ \\
\hline 6 Miscarriage rate & 1 & 926 & Risk Ratio (M-H, Fixed, 95\% Cl) & $1.10[0.77,1.56]$ \\
\hline 7 Adverse events & 3 & 1230 & Risk Ratio (M-H, Fixed, 95\% Cl) & $1.16[1.02,1.31]$ \\
\hline
\end{tabular}

Analysis 1.1. Comparison 1 True acupuncture versus sham acupuncture, Outcome 1 Live birth rate.

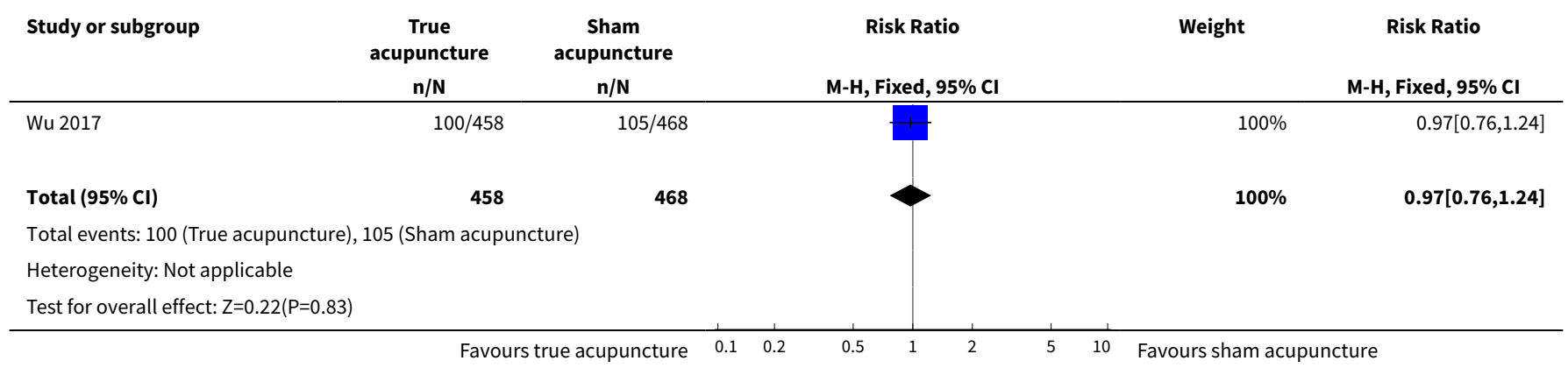

Analysis 1.2. Comparison 1 True acupuncture versus sham acupuncture, Outcome 2 Multiple pregnancy rate.

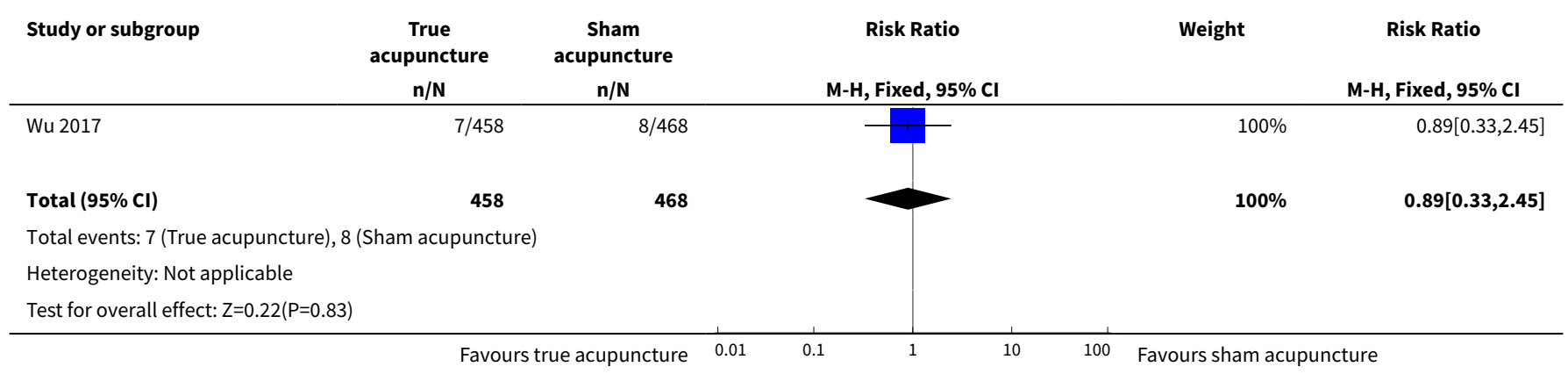


Analysis 1.3. Comparison 1 True acupuncture versus sham acupuncture, Outcome 3 Ovulation rate.

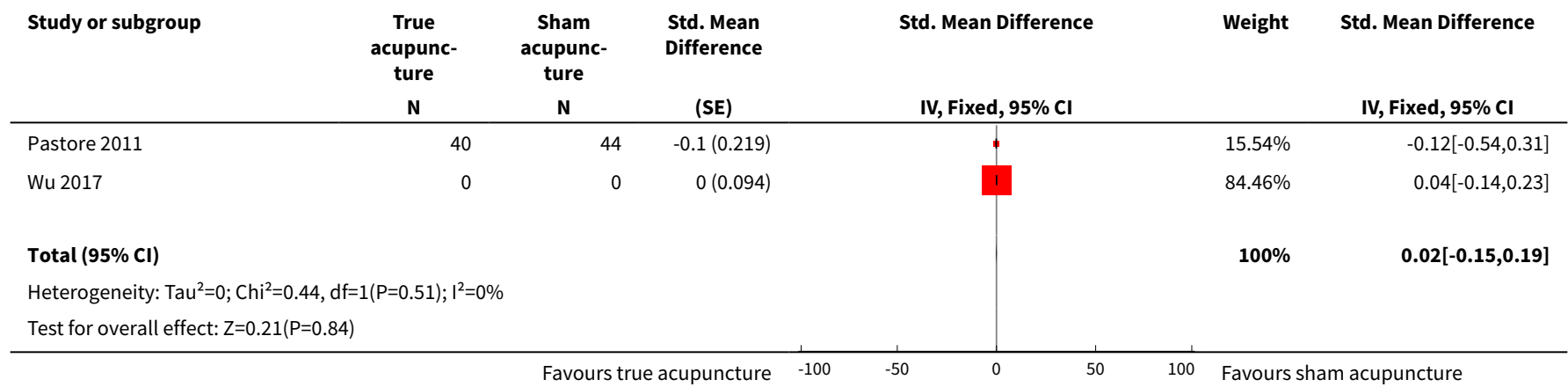

Analysis 1.4. Comparison 1 True acupuncture versus sham acupuncture, Outcome 4 Clinical pregnancy rate.

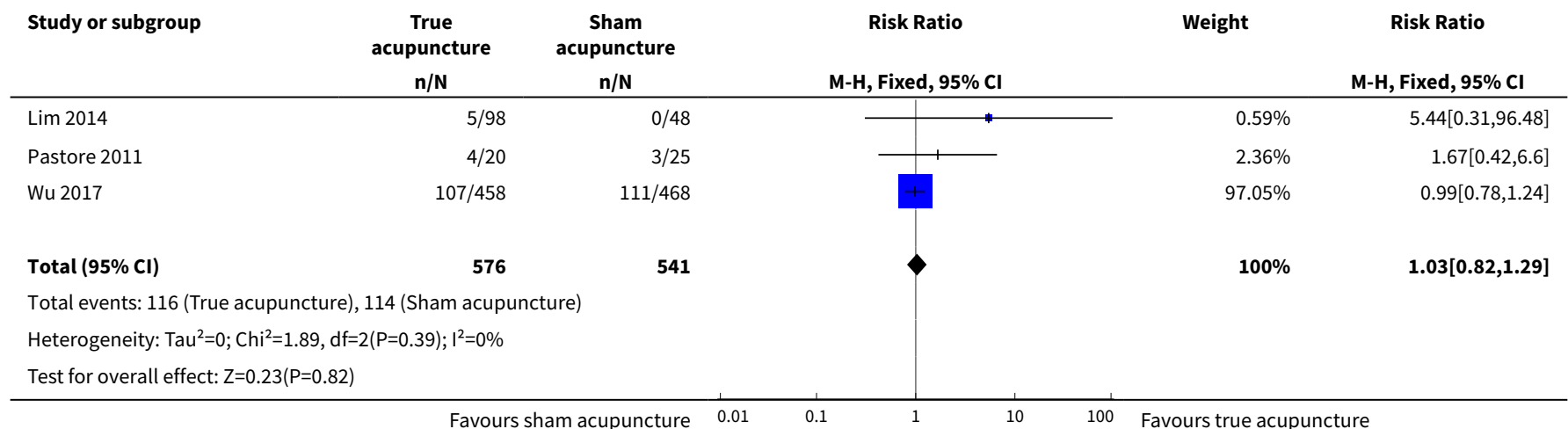

Analysis 1.5. Comparison 1 True acupuncture versus sham acupuncture, Outcome 5 Restored regular menstrual period.

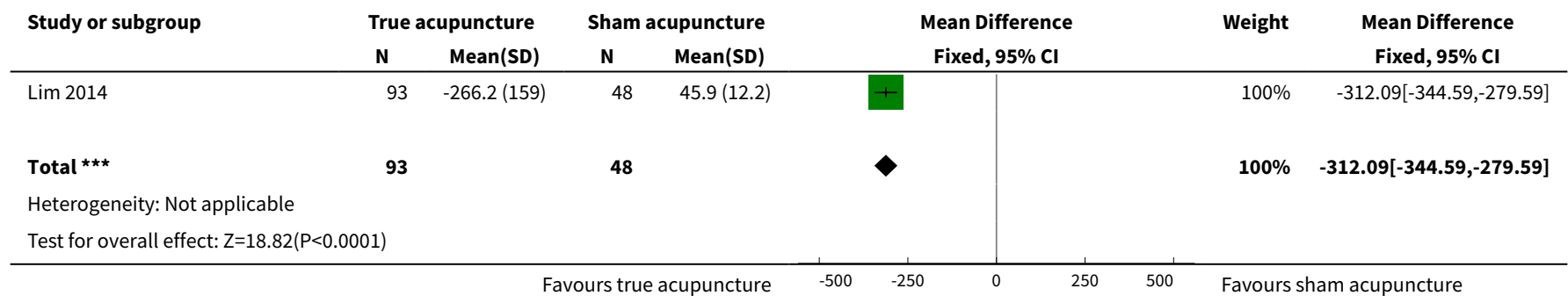

Analysis 1.6. Comparison 1 True acupuncture versus sham acupuncture, Outcome 6 Miscarriage rate.

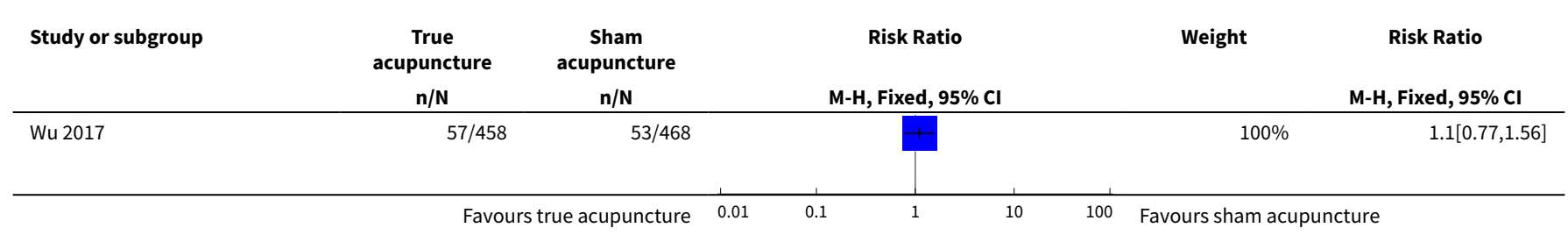




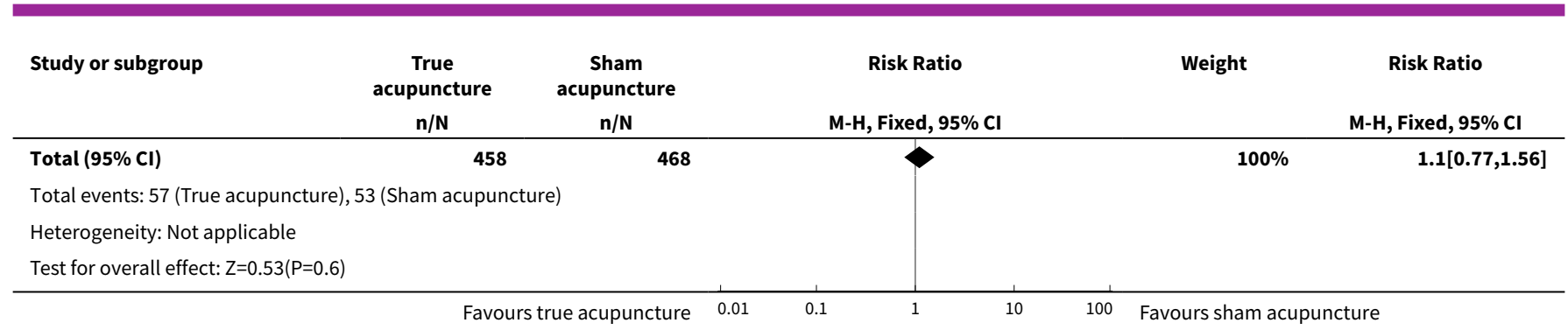

\section{Analysis 1.7. Comparison 1 True acupuncture versus sham acupuncture, Outcome 7 Adverse events.}

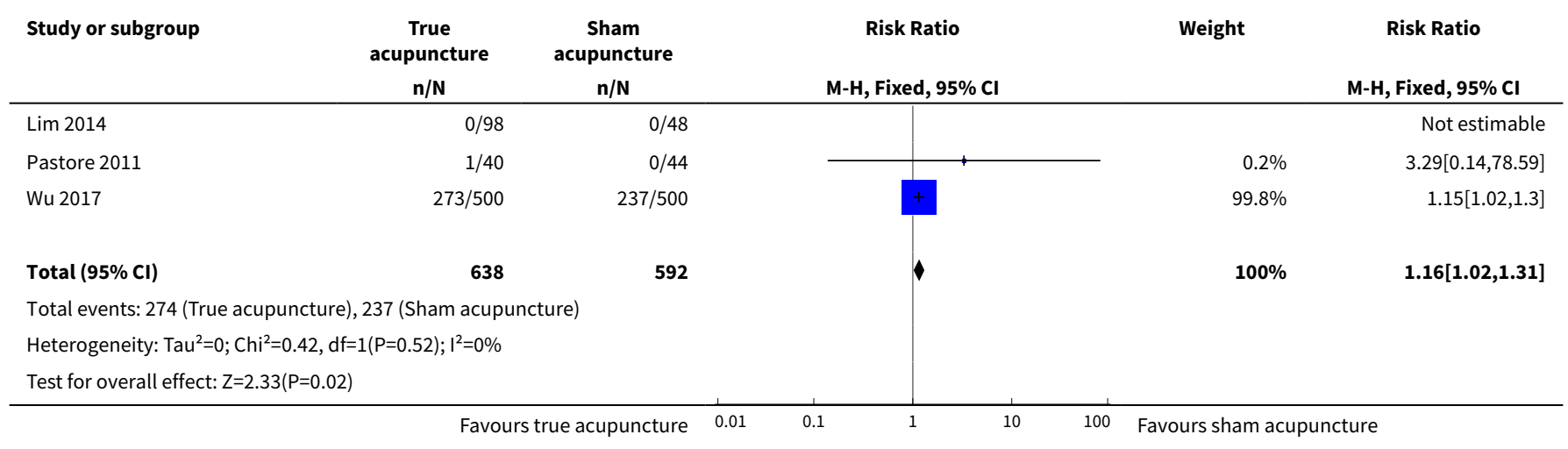

\section{Comparison 2. Low-frequency electroacupuncture versus physical exercise or no intervention}

\begin{tabular}{|c|c|c|c|c|}
\hline Outcome or subgroup title & $\begin{array}{l}\text { No. of } \\
\text { studies }\end{array}$ & $\begin{array}{l}\text { No. of } \\
\text { partici- } \\
\text { pants }\end{array}$ & Statistical method & Effect size \\
\hline 1 Restored regular menstrual period & 1 & & $\begin{array}{l}\text { Mean Difference (IV, Fixed, 95\% } \\
\mathrm{CI})\end{array}$ & Subtotals only \\
\hline $\begin{array}{l}\text { 1.1 Low-frequency electroacupuncture ver- } \\
\text { sus physical exercise }\end{array}$ & 1 & 40 & $\begin{array}{l}\text { Mean Difference (IV, Fixed, 95\% } \\
\mathrm{CI})\end{array}$ & $0.22[-0.01,0.45]$ \\
\hline $\begin{array}{l}1.2 \text { Low-frequency electroacupuncture ver- } \\
\text { sus no intervention }\end{array}$ & 1 & 31 & $\begin{array}{l}\text { Mean Difference (IV, Fixed, 95\% } \\
\mathrm{CI})\end{array}$ & $0.37[0.21,0.53]$ \\
\hline 2 Adverse events & 1 & 201 & Risk Ratio (M-H, Fixed, 95\% Cl) & $4.46[0.77,25.78]$ \\
\hline 2.1 Haematoma & 1 & 67 & Risk Ratio (M-H, Fixed, 95\% Cl) & $7.21[0.39,134.32]$ \\
\hline 2.2 Dizziness & 1 & 67 & Risk Ratio (M-H, Fixed, 95\% Cl) & $3.09[0.13,73.20]$ \\
\hline 2.3 Nausea & 1 & 67 & Risk Ratio (M-H, Fixed, 95\% Cl) & $3.09[0.13,73.20]$ \\
\hline
\end{tabular}


Analysis 2.1. Comparison 2 Low-frequency electroacupuncture versus physical exercise or no intervention, Outcome 1 Restored regular menstrual period.

\begin{tabular}{|c|c|c|c|c|c|c|c|}
\hline \multirow[t]{2}{*}{ Study or subgroup } & \multicolumn{2}{|c|}{ Acupuncture } & \multicolumn{2}{|c|}{ Physical exercise } & \multirow{2}{*}{$\begin{array}{c}\text { Mean Difference } \\
\text { Fixed, } 95 \% \mathrm{Cl}\end{array}$} & \multirow[t]{2}{*}{ Weight } & \multirow{2}{*}{$\begin{array}{c}\text { Mean Difference } \\
\text { Fixed, } 95 \% \mathrm{Cl}\end{array}$} \\
\hline & $\mathbf{N}$ & Mean(SD) & $\mathbf{N}$ & $\operatorname{Mean}(S D)$ & & & \\
\hline \multicolumn{8}{|c|}{ 2.1.1 Low-frequency electroacupuncture versus physical exercise } \\
\hline Jedel 2011 & 21 & $0.3(0.4)$ & 19 & $0.1(0.4)$ & & $100 \%$ & $0.22[-0.01,0.45]$ \\
\hline Subtotal ${ }^{\star \star \star}$ & 21 & & 19 & & & $100 \%$ & $0.22[-0.01,0.45]$ \\
\hline \multicolumn{8}{|c|}{ Heterogeneity: Not applicable } \\
\hline \multicolumn{8}{|c|}{ Test for overall effect: $Z=1.9(P=0.06)$} \\
\hline \multicolumn{8}{|c|}{ 2.1.2 Low-frequency electroacupuncture versus no intervention } \\
\hline Jedel 2011 & 21 & $0.3(0.4)$ & 10 & $-0(0.1)$ & & $100 \%$ & $0.37[0.21,0.53]$ \\
\hline 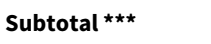 & 21 & & 10 & & & $100 \%$ & $0.37[0.21,0.53]$ \\
\hline \multicolumn{8}{|c|}{ Heterogeneity: Not applicable } \\
\hline \multicolumn{8}{|c|}{ Test for overall effect: $Z=4.42(P<0.0001)$} \\
\hline \multicolumn{8}{|c|}{ Test for subgroup differences: $\mathrm{Chi}^{2}=1.11, \mathrm{df}=1(\mathrm{P}=0.29), \mathrm{I}^{2}=9.56 \%$} \\
\hline
\end{tabular}

Analysis 2.2. Comparison 2 Low-frequency electroacupuncture versus physical exercise or no intervention, Outcome 2 Adverse events.

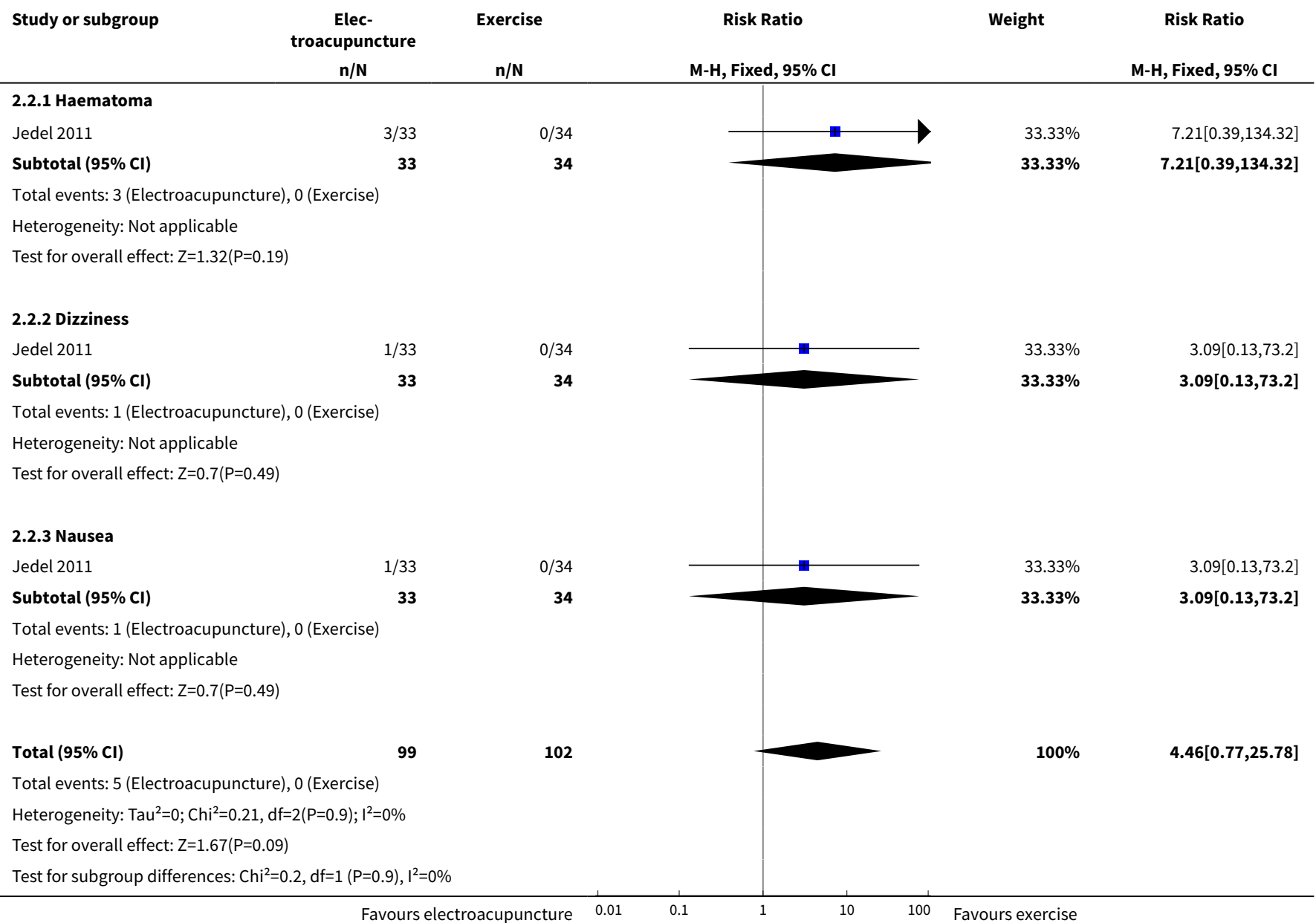


Comparison 3. True acupuncture versus relaxation

\begin{tabular}{lllll}
\hline Outcome or subgroup title & $\begin{array}{l}\text { No. of } \\
\text { studies }\end{array}$ & $\begin{array}{l}\text { No. of partici- } \\
\text { pants }\end{array}$ & Statistical method & Effect size \\
\hline 1 Ovulation rate & 1 & 28 & Mean Difference (IV, Fixed, 95\% Cl) & $0.35[0.14,0.56]$ \\
\hline
\end{tabular}

Analysis 3.1. Comparison 3 True acupuncture versus relaxation, Outcome 1 Ovulation rate.

\begin{tabular}{|c|c|c|c|c|c|c|c|c|}
\hline \multirow{3}{*}{$\begin{array}{l}\text { Study or subgroup } \\
\text { Johansson } 2013\end{array}$} & \multicolumn{2}{|c|}{ Relaxation } & \multicolumn{2}{|c|}{ True acupuncture } & \multirow{2}{*}{\multicolumn{2}{|c|}{$\begin{array}{c}\text { Mean Difference } \\
\text { Fixed, } 95 \% \mathrm{Cl}\end{array}$}} & \multirow[t]{2}{*}{ Weight } & \multirow{2}{*}{$\begin{array}{c}\text { Mean Difference } \\
\text { Fixed, } 95 \% \mathrm{Cl}\end{array}$} \\
\hline & $\mathbf{N}$ & $\operatorname{Mean}(\mathrm{SD})$ & $\mathbf{N}$ & $\operatorname{Mean}(S D)$ & & & & \\
\hline & 16 & $0.8(0.3)$ & 12 & $0.4(0.3)$ & & - & $100 \%$ & $0.35[0.14,0.56]$ \\
\hline 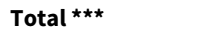 & 16 & & 12 & & & & $100 \%$ & $0.35[0.14,0.56]$ \\
\hline \multicolumn{9}{|c|}{ Heterogeneity: Not applicable } \\
\hline \multicolumn{9}{|c|}{ Test for overall effect: $Z=3.32(P=0)$} \\
\hline
\end{tabular}

\section{Comparison 4. True acupuncture versus clomiphene}

\begin{tabular}{|c|c|c|c|c|}
\hline Outcome or subgroup title & $\begin{array}{l}\text { No. of } \\
\text { studies }\end{array}$ & $\begin{array}{l}\text { No. of } \\
\text { partici- } \\
\text { pants }\end{array}$ & Statistical method & Effect size \\
\hline $\begin{array}{l}1 \text { Restored regular menstrual peri- } \\
\text { od }\end{array}$ & 1 & & Risk Ratio (M-H, Fixed, 95\% CI) & Subtotals only \\
\hline $\begin{array}{l}\text { 1.1 Restored menstruation at the } \\
\text { end of treatment }\end{array}$ & 1 & 60 & Risk Ratio (M-H, Fixed, 95\% Cl) & $1.64[0.94,2.85]$ \\
\hline $\begin{array}{l}\text { 1.2 Restored menstruation } 1 \\
\text { month after end of treatment }\end{array}$ & 1 & 60 & Risk Ratio (M-H, Fixed, 95\% Cl) & $1.5[1.03,2.19]$ \\
\hline 2 Adverse events & 1 & 120 & Risk Ratio (M-H, Fixed, 95\% Cl) & $1.33[0.30,5.83]$ \\
\hline 2.1 Haematoma & 1 & 60 & Risk Ratio (M-H, Fixed, 95\% Cl) & $7.0[0.38,129.93]$ \\
\hline $\begin{array}{l}2.2 \text { Gastrointestinal adverse ef- } \\
\text { fects }\end{array}$ & 1 & 60 & Risk Ratio (M-H, Fixed, 95\% Cl) & $0.2[0.01,4.00]$ \\
\hline
\end{tabular}

Analysis 4.1. Comparison 4 True acupuncture versus clomiphene, Outcome 1 Restored regular menstrual period.

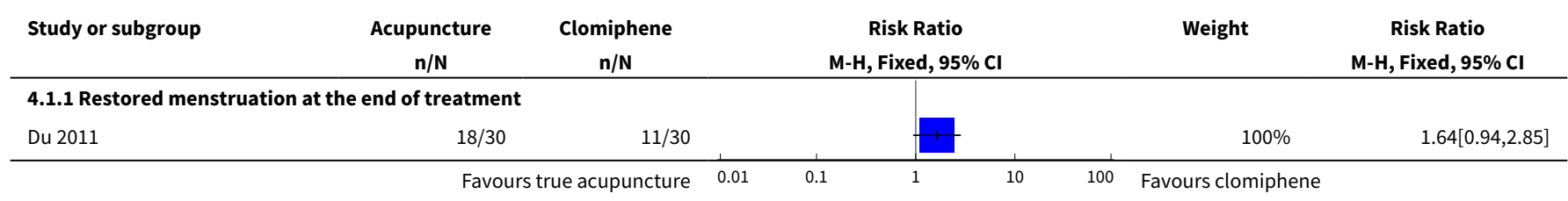




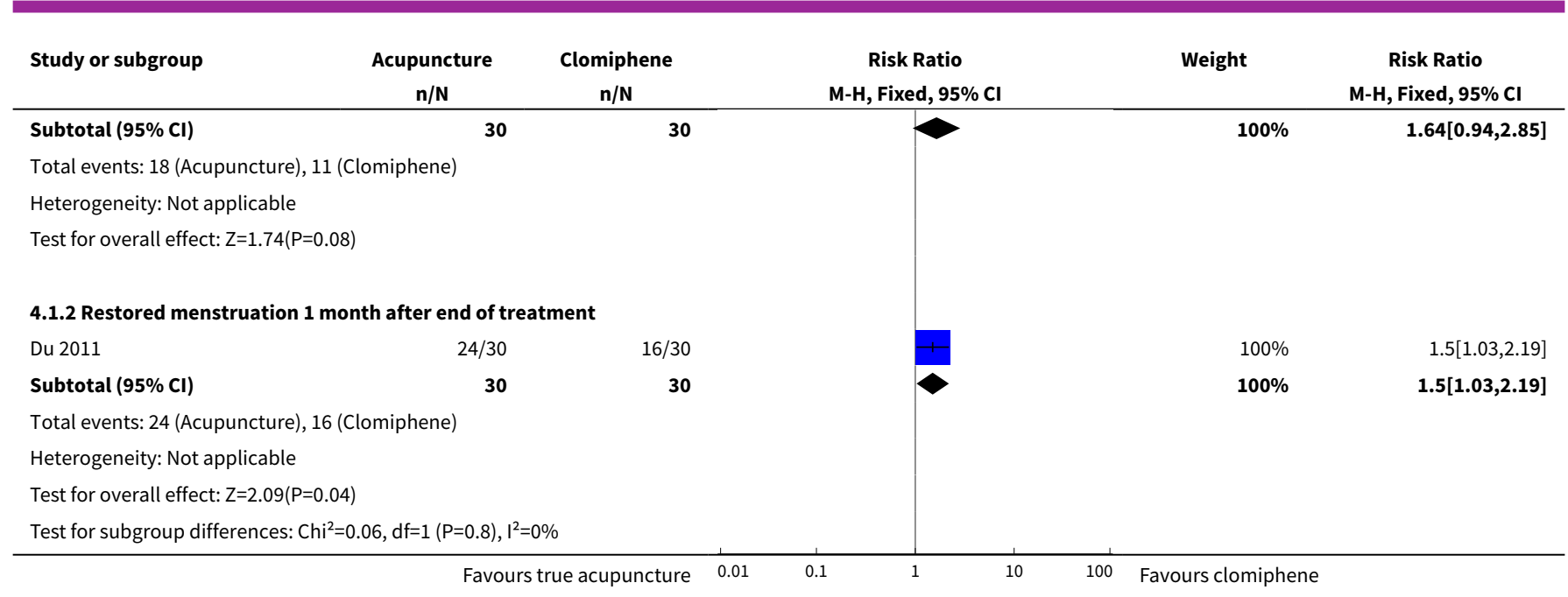

Analysis 4.2. Comparison 4 True acupuncture versus clomiphene, Outcome 2 Adverse events.

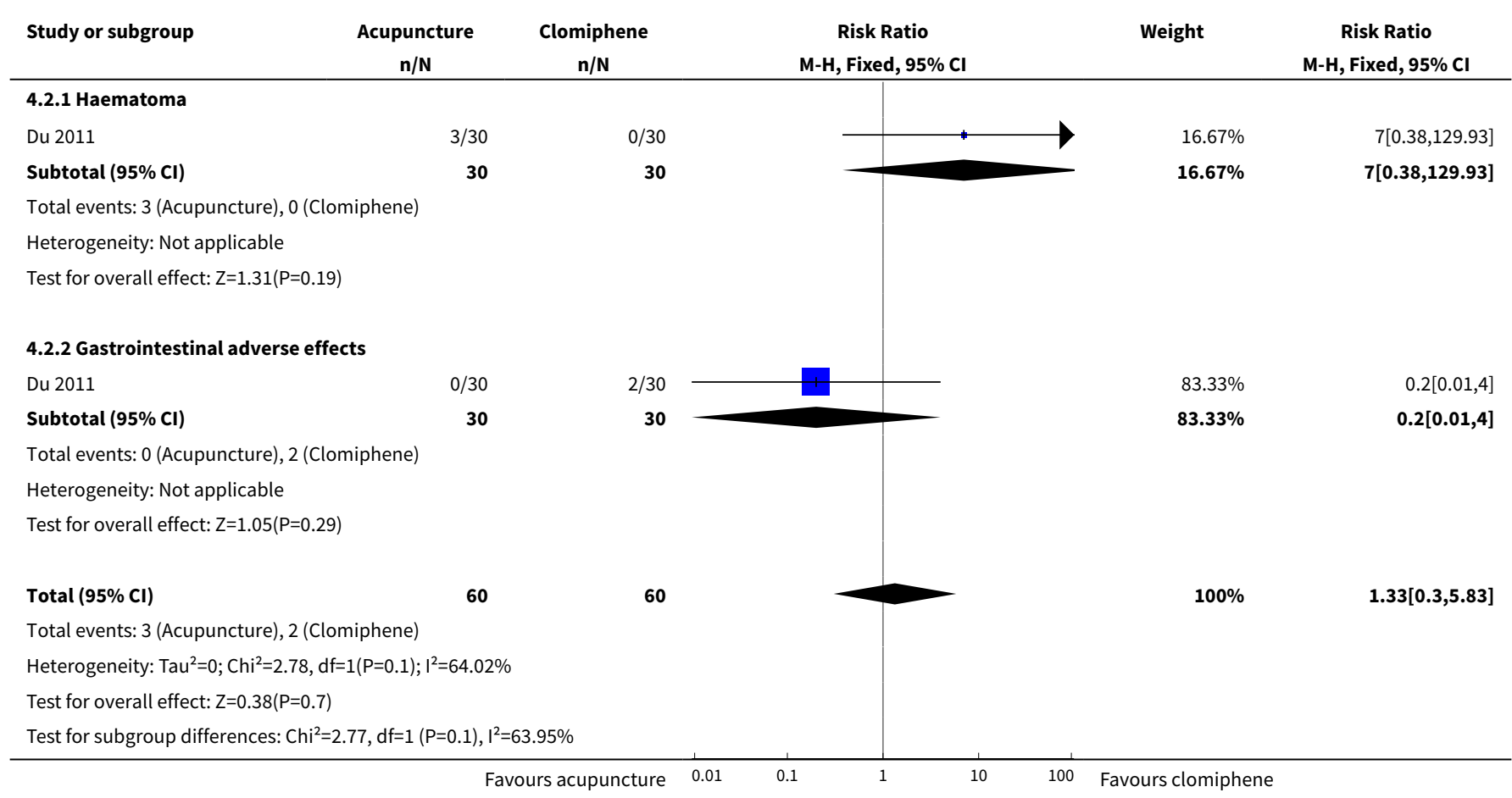

\section{Comparison 5. True acupuncture versus Diane-35}

\begin{tabular}{lllll}
\hline Outcome or subgroup title & $\begin{array}{l}\text { No. of } \\
\text { studies }\end{array}$ & $\begin{array}{l}\text { No. of } \\
\text { partici- } \\
\text { pants }\end{array}$ & Statistical method & Effect size \\
\hline 1 Ovulation rate & 1 & 68 & Risk Ratio $(\mathrm{M}-\mathrm{H}$, Fixed, 95\% Cl) & $1.45[0.87,2.42]$ \\
\hline 2 Adverse events & 2 & 360 & Risk Ratio $(\mathrm{M}-\mathrm{H}$, Fixed, 95\% Cl) & $0.70[0.25,1.99]$ \\
\hline
\end{tabular}




\begin{tabular}{lllll}
\hline Outcome or subgroup title & $\begin{array}{l}\text { No. of } \\
\text { studies }\end{array}$ & $\begin{array}{l}\text { No. of } \\
\text { partici- } \\
\text { pants }\end{array}$ & Statistical method & Effect size \\
\hline 2.1 Haematoma & 2 & 120 & Risk Ratio $(\mathrm{M}-\mathrm{H}$, Fixed, 95\% Cl) & $3.74[0.43,32.53]$ \\
\hline 2.2 Nausea & 1 & 52 & Risk Ratio $(\mathrm{M}-\mathrm{H}$, Fixed, 95\% Cl) & $0.19[0.01,3.69]$ \\
\hline 2.3 Gastrointestinal upset & 1 & 68 & Risk Ratio $(\mathrm{M}-\mathrm{H}$, Fixed, 95\% Cl) & $0.31[0.01,7.47]$ \\
\hline 2.4 Headache & 1 & 52 & Risk Ratio $(\mathrm{M}-\mathrm{H}$, Fixed, 95\% Cl) & $0.31[0.01,7.26]$ \\
\hline 2.5 Weight gain & 1 & 68 & Risk Ratio $(\mathrm{M}-\mathrm{H}$, Fixed, $95 \% \mathrm{Cl})$ & $0.31[0.01,7.47]$ \\
\hline
\end{tabular}

\section{Analysis 5.1. Comparison 5 True acupuncture versus Diane-35, Outcome 1 Ovulation rate.}

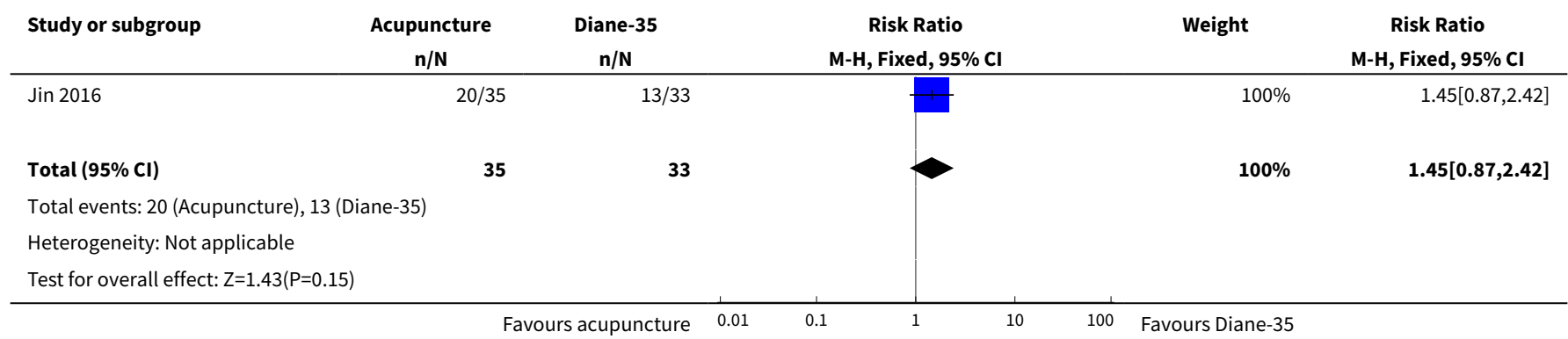

Analysis 5.2. Comparison 5 True acupuncture versus Diane-35, Outcome 2 Adverse events.

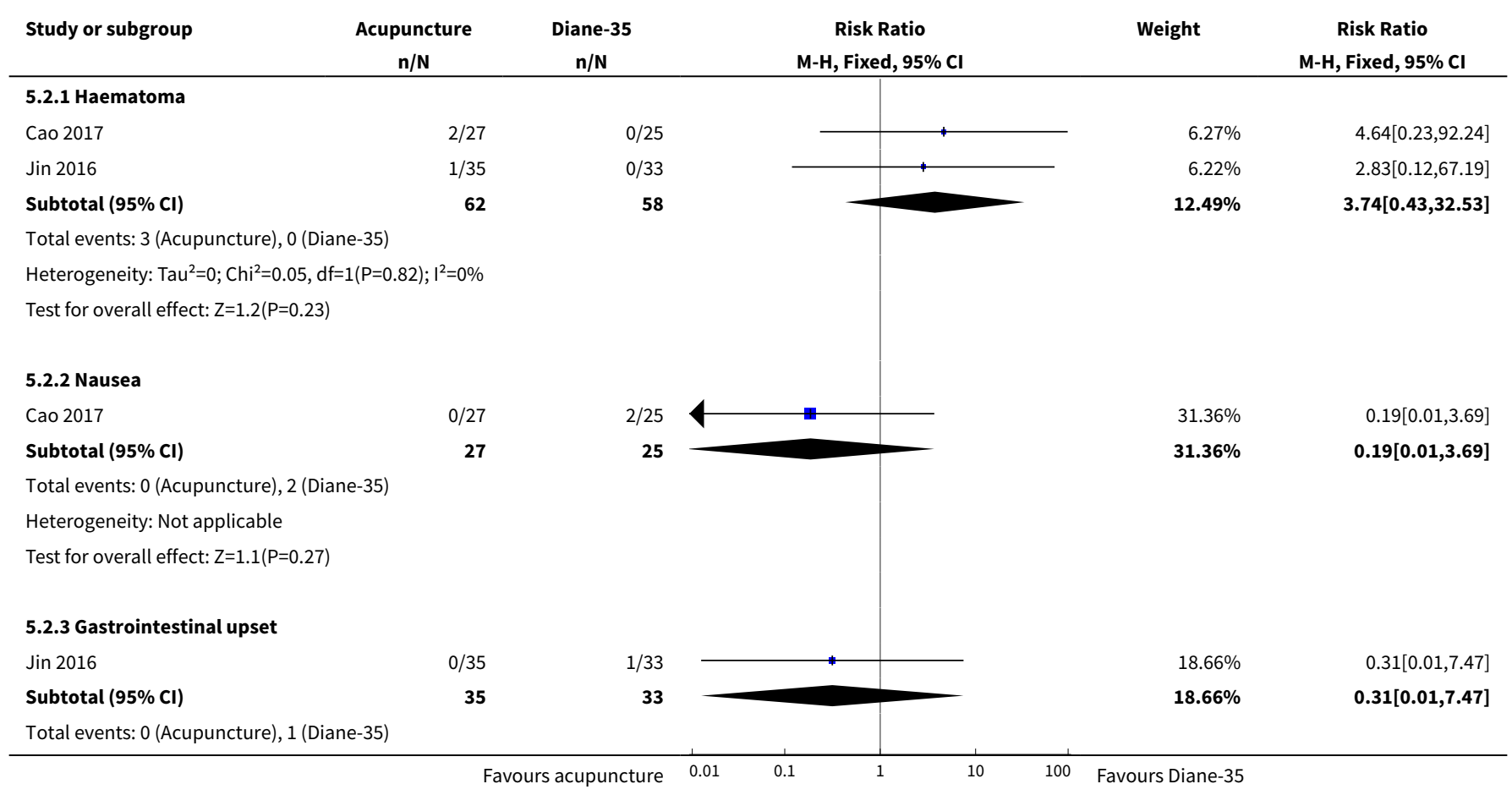




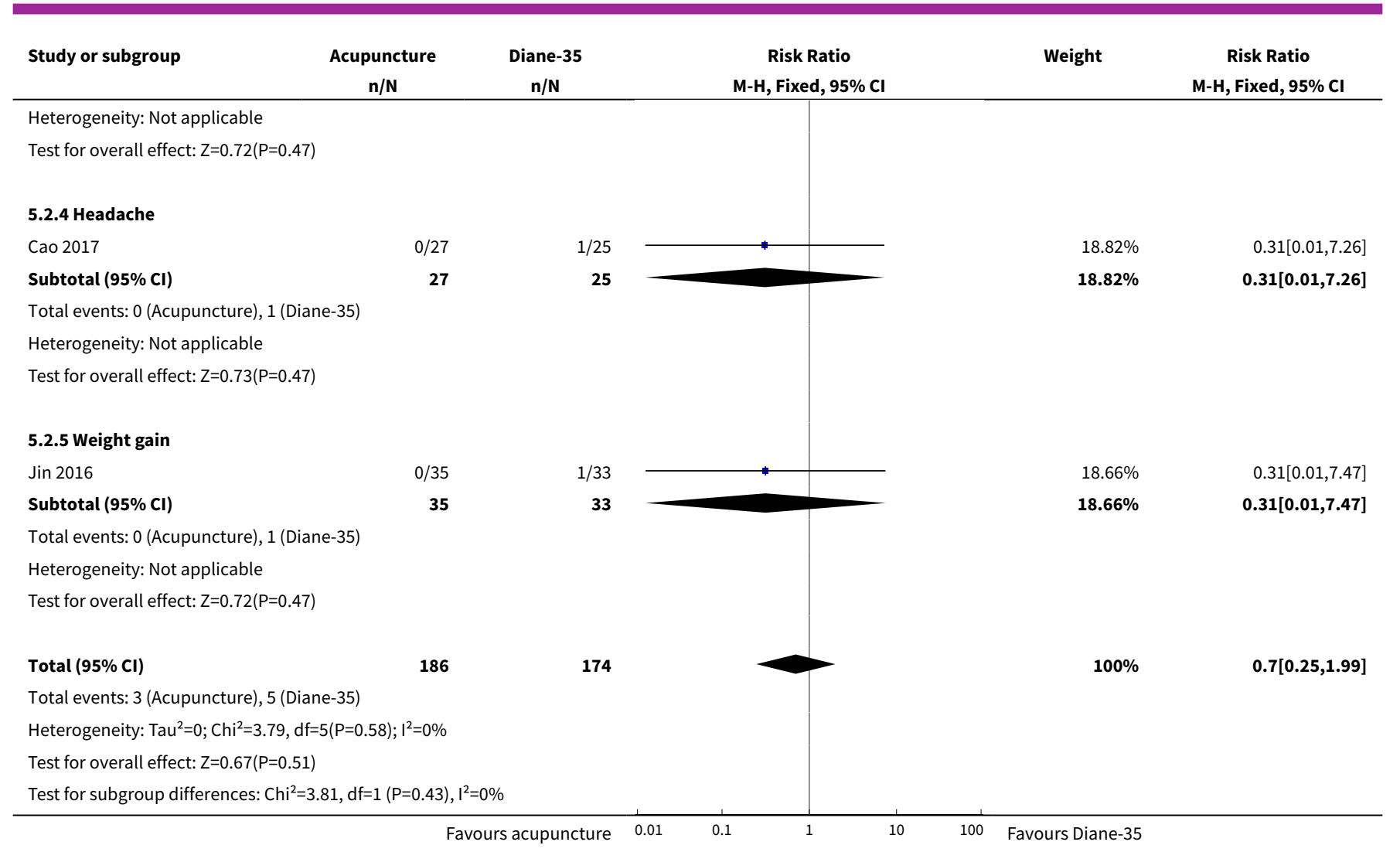

\section{APPENDICES}

\section{Appendix 1. Cochrane Gynaecology and Fertility Group Specialised Register search strategy}

Searched 22 May 2018

PROCITE platform

Keywords CONTAINS "polycystic ovary morphology" or "*Polycystic Ovary Syndrome" or "PCOS" or "Oligo-amenorrhea" or "oligoamenorrhea" or "oligoanovulatory" or "oligohypomenorrhea" or "amenorrhea" or "amenorrhoea" or "hirsutism" or Title CONTAINS "polycystic ovary morphology" or "^Polycystic Ovary Syndrome" or "PCOS" or "Oligo-amenorrhea" or "oligoamenorrhea" or "oligoanovulatory" or "oligohypomenorrhea" or "amenorrhea" or "amenorrhoea" or "hirsutism"

AND

Keywords CONTAINS "acupoint" or "acupressure" or "acupressure-acupuncture therapy" or "acupuncture" or "electro-acupuncture" or "electroacupuncture" or "moxibustion" or "Tui Na" or Title CONTAINS "acupoint" or "acupressure" or "acupressure-acupuncture therapy" or "acupuncture" or "electro-acupuncture" or "electroacupuncture" or "moxibustion" or "Tui Na" (36 hits)

\section{Appendix 2. CENTRAL Register of Studies Online (CRSO) search strategy}

Searched 22 May 2018

Web platform

\#1 MESH DESCRIPTOR Polycystic Ovary Syndrome EXPLODE ALL TREES 1170

\#2 (polycystic ovar ${ }^{\star}$ ):TI,AB,KY 2370

\#3 (PCOS or PCOD):TI,AB,KY 1928

\#4 (stein-leventhal syndrome):TI,AB,KY 3 
\#5 hirsut*:TI,AB,KY 591

\#6 \#1 OR \#2 OR \#3 OR \#4 OR \#5 2924

\#7 MESH DESCRIPTOR Acupuncture Therapy EXPLODE ALL TREES 3825

\#8 Acupuncture:TI,AB,KY 10622

\#9 electroacupuncture:TI,AB,KY 1518

\#10 meridian:TI,AB,KY 528

\#11 needling:TI,AB,KY 1353

\#12 moxi*:TI,AB,KY 2537

\#13 acup*?point*:TI,AB,KY 2

\#14 (acup* point ${ }^{\star}$ ):TI,AB,KY 2197

\#15 (shiatsu or tui na):TI,AB,KY 28

\#16 shu:TI,AB,KY 258

\#17 acupressure:TI,AB,KY 763

\#18 (trigger adj3 point $\left.{ }^{\star}\right): T I, A B, K Y ~ 682$

\#19 \#7 OR \#8 OR \#9 OR \#10 OR \#11 OR \#12 OR\#13 OR \#14 OR \#15 OR \#16 OR \#17 OR \#18 14633

\#20 \#6 AND \#19 74

\section{Appendix 3. MEDLINE search strategy}

Searched from 1946 to 22 May 2018

Ovid Platform

1 exp Polycystic Ovary Syndrome/ (12729)

2 polycystic ovar\$.tw. (14304)

3 stein-leventhal syndrome.tw. (561)

4 PCOS.tw. (9242)

5 PCOD.tw. (280)

6 hirsut\$.tw. (8470)

7 exp Amenorrhea/ or exp Oligomenorrhea/ or exp Hirsutism/ (13627)

8 oligomenorrh\$.tw. (1345)

9 amenorrh\$.tw. (13508)

10 or/1-9 (40945)

11 acupuncture.tw. (19129)

12 exp Acupuncture/ (1501)

13 exp acupuncture therapy/ or exp acupuncture, ear/ or exp electroacupuncture/ or exp meridians/ or exp acupuncture points/ or exp moxibustion/ (21203)

14 electroacupuncture.tw. (3716)

15 meridian\$.tw. (4886)

16 needling.tw. (2398)

17 moxi\$.tw. (7063)

18 acup\$ point $\$ . t w . ~(1544)$

19 (shiatsu or tui na).tw. (108)

20 shu.tw. (759)

21 acupressure.tw. (894)

22 (trigger adj3 point\$).tw. (1905)

23 or/11-22 (38977)

24 randomized controlled trial.pt. (462119)

25 controlled clinical trial.pt. (92434)

26 randomized.ab. (413162)

27 randomised.ab. (82543) 
28 placebo.tw. (194596)

29 clinical trials as topic.sh. (183822)

30 randomly.ab. (291200)

31 trial.ti. (183145)

32 (crossover or cross-over or cross over).tw. (76588)

33 or/24-32 (1211060)

34 exp animals/ not humans.sh. (4462498)

3533 not 34 (1115554)

3610 and 23 and 35 (75)

\section{Appendix 4. Embase search strategy}

Searched from 1980 to 22 May 2018

Ovid Platform

1 exp ovary polycystic disease/ (23430)

2 polycystic ovar\$.tw. (19736)

3 stein-leventhal syndrome.tw. (370)

4 PCOS.tw. (14034)

5 PCOD.tw. (379)

6 hirsut\$.tw. (9566)

7 exp "amenorrhea and oligomenorrhea"/ or exp secondary amenorrhea/ or exp amenorrhea/ or exp primary amenorrhea/ (27466) 8 exp oligomenorrhea/ (2823)

9 oligomenorrh\$.tw. (1798)

10 amenorrh\$.tw. (15759)

11 or/1-10 (62000)

12 exp acupuncture/ or exp acupressure/ or exp electroacupuncture/ (40601)

13 electroacupuncture.tw. (4439)

14 meridian\$.tw. (5663)

15 needling.tw. (3136)

16 moxi\$.tw. (9532)

17 acup\$ point\$.tw. (2359)

18 (shiatsu or tui na).tw. (154)

19 shu.tw. (1578)

20 acupressure.tw. (1187)

21 (trigger adj3 point\$).tw. (2894)

22 or/12-21 (56901)

2311 and 22 (320)

24 Clinical Trial/ (964217)

25 Randomized Controlled Trial/ (499723)

26 exp randomization/ (78253)

27 Single Blind Procedure/ (31333)

28 Double Blind Procedure/ (147013)

29 Crossover Procedure/ (55360)

30 Placebo/ (311217)

31 Randomi?ed controlled trial\$.tw. (181155)

32 Rct.tw. (28426)

33 random allocation.tw. (1779)

34 randomly allocated.tw. (29590)

35 allocated randomly.tw. (2315)

36 (allocated adj2 random).tw. (796)

37 Single blind\$.tw. (20811)

38 Double blind\$.tw. (181979)

39 ((treble or triple) adj blind\$).tw. (775)

40 placebo\$.tw. (267842)

41 prospective study/ (448348)

42 or/24-41 (1902190)

43 case study/ (54421)

44 case report.tw. (353224)

45 abstract report/ or letter/ (1037032)

46 or/43-45 (1436046)

4742 not 46 (1854050) 
4823 and $47(129)$

\section{Appendix 5. PsycINFO search strategy}

Searched from 1806 to 22 May 2018

Ovid Platform

1 exp endocrine sexual disorders/ (1133)

2 polycystic ovar\$.tw. (375)

3 stein-leventhal syndrome.tw. (2)

4 PCOS.tw. (243)

5 PCOD.tw. (6)

6 hirsut\$.tw. (148)

7 exp amenorrhea/ (254)

8 oligomenorrh\$.tw. (49)

9 amenorrh\$.tw. (827)

10 or/1-9 (2275)

11 exp acupuncture/ (1340)

12 electroacupuncture.tw. (259)

13 meridian\$.tw. (795)

14 needling.tw. (125)

15 moxi\$.tw. (60)

16 acup\$ point\$.tw. (147)

17 acupuncture.tw. (1823)

18 (shiatsu or tui na).tw. (22)

19 shu.tw. (202)

20 acupressure.tw. (160)

21 (trigger adj3 point\$).tw. (322)

22 or/11-21 (3398)

2310 and $22(2)$

\section{Appendix 6. AMED (Allied and Complementary Medicine) search strategy}

Searched from 1985 to 22 May 2018

Ovid Platform

1 exp ovarian disease/ (220)

2 polycystic ovar\$.tw. (72)

3 stein-leventhal syndrome.tw. (1)

4 PCOS.tw. (34)

5 PCOD.tw. (17)

6 hirsut\$.tw. (71)

7 exp amenorrhea/ (37)

8 Hirsut\$.tw. (71)

9 amenorrh\$.tw. (94)

10 oligomenorrh\$.tw. (10)

11 or/1-10 (400)

12 exp acupuncture/ (3302)

13 exp Acupoints/ or exp Electroacupuncture/ or exp Acupuncture therapy/ (7814)

14 acupuncture.tw. (9739)

15 electroacupuncture.tw. (1060)

16 meridian\$.tw. (677)

17 needling.tw. (879)

18 moxi\$.tw. (646)

19 exp Moxibustion/ (543)

20 acup\$ point\$.tw. (646)

21 (shiatsu or tui na).tw. (341)

22 shu.tw. (91)

23 acupressure.tw. (395)

24 (trigger adj3 point\$).tw. (472)

25 or/12-24 (11584)

2611 and $25(40)$

Acupuncture for polycystic ovarian syndrome (Review) 


\section{Appendix 7. CNKI search strategy}

Searched December 2010 to May 2018

Web platform

1 polycystic ovary syndrome

2 polycystic ovary

3 ovary polycystic disease

$4 \# 1^{\sim} \# 3 /$ or

5 acupuncture

6 electroacupuncture

7 traditional medicine

8 traditional Chinese medicine

9 traditional Chinese medicine combined with western medicine

$10 \# 4^{\sim} \# 9 /$ or

11 random *

$12 \# 3$ and \#10 and \#11

All of the search terms were translated into Chinese terms when we conduct the searches in Chinese databases.

\section{Appendix 8. SinoMed (CBM) search strategy}

Searched 2010 to November 2015

Web platform

Title or Keywords or Abstract CONTAINS: "random" AND ("polycystic ovarian syndrome" OR "polycystic ovaries") AND ("needling" OR "acupuncture" OR "electroacupuncture" OR "traditional Chinese medicine" OR "traditional medicine" OR "traditional Chinese medicine combined with western medicine")

All of the search terms were translated into Chinese terms when we conduct the searches in Chinese databases.

\section{Appendix 9. Chinese VIP database search strategy}

Searched 2010 to May 2018

Web platform

Keyword and Title CONTAINS "polycystic ovarian syndrome" OR "polycystic ovaries" AND ((Keyword and Title CONTAINS "needling" OR "electroacupuncture" OR "acupuncture" OR "traditional Chinese medicine" OR "traditional medicine" OR "traditional Chinese medicine combined with western medicine") OR (Abstract CONTAINS needling" OR "electroacupuncture" OR "acupuncture" OR "traditional Chinese medicine" OR "traditional medicine" OR "traditional Chinese medicine combined with western medicine")) AND Full text CONTAINS "random"

All of the search terms were translated into Chinese terms when we conduct the searches in Chinese databases.

\section{Appendix 10. Ongoing trials}

Ongoing trials were also searched in:

- ClinicalTrials.gov

- World Health Organization International Trials Registry

- Australian and New Zealand Clinical Trial Registry

WHAT'S NEW

\begin{tabular}{lll}
\hline Date & Event & Description \\
\hline 4 July 2019 & Amended & Editing PLS using GRADE terminology \\
\hline
\end{tabular}




\section{H IS T O R Y}

Protocol first published: Issue 2, 2009

Review first published: Issue 8, 2011

\begin{tabular}{lll}
\hline Date & Event & Description \\
\hline 24 May 2019 & New search has been performed & Three studies included in this update (Cao 2017; Jin 2016; Wu \\
& 2017), and ongoing studies identified (ChiCTR-IOR-15007358; \\
& ChiCTR1800015738; NCT02653911; ChiCTR1800017304; \\
& NCT02647827; NCT02491333). \\
\hline
\end{tabular}

24 May $2019 \quad$ New citation required but conclusions have not changed
The updated review now has included three new studies however conclusions have not changed.

\section{CONTRIBUTIONS OFAUTHORS}

DL: for the protocol: protocol development and revision; topic conception and methodological aspects; protocol review and final proof. For the systematic review: study selection, methodology, adequacy of treatment, data analysis, interpretation of findings and writing the review.

$\mathrm{RN}$ : for the systematic review of the English literature: study selection, methodology, adequacy of treatment, data extraction, data analysis, interpretation of findings and writing the review.

GZ: for the systematic review of the Chinese literature: study selection, methodology, adequacy of treatment, data extraction, data analysis, interpretation of findings and writing the review.

LC: for the protocol: topic conception; protocol final proof. For the systematic review: final proof; provided expert advice on gynaecology for the studies found.

HC: for the systematic review: dispute resolution for study selection, adequacy of treatment and revision, and review of final interpretations of findings and provided expert advice on acupuncture treatment in the studies found.

\section{DECLARATIONS OF INTEREST}

The primary author of one included study is also the primary author (DL) of this review (Lim 2014). In order to minimise any potential risk of bias during the review process, two review authors (RN, GZ) independently extracted data using a piloted data extraction form. All studies were then assessed independently and any dispute was resolved by a third independent review author (HC).

\section{SOURCES OF SUPPORT}

\section{Internal sources}

- No sources of support supplied

\section{External sources}

- South Western Sydney Clinical School Scholarship, University of New South Wales, Australia, Australia.

CED Lim received the postgraduate scholarship from South Western Sydney Clinical School, Faculty of Medicine, University of New South Wales (2008-10) to support the work in this project

\section{DIFFERENCES BETWEEN PROTOCOL AND REVIEW}

Authors: we added Dr Wei Chen and Dr Lisa N Cheng to the authors, as data extractors and review manuscript developers at the 2015 version of this systematic review.

Authors: Dr Wei Chen, Prof A O'Sullivan and Prof Felix Wong stepped down and were replaced by Dr Rachel Ng, Dr Ke Xu and Ms Nini Chen as data extractors and review manuscript developers at the second edition of this systematic review.

Authors: Dr Ke Xu and Ms Nini Chen stepped down and were replaced by Dr George Shengxi Zhang and Dr Hui Chen as data extractors and review manuscript developers at the third edition of this systematic review. 
Methods: in the third edition of the systematic review we changed multiple pregnancy from a secondary outcome to a primary outcome.

Methods: we added adverse events as a secondary outcome in the review.

Methods: we added lifestyle intervention as a comparison as per advice of referee.

Methods: we described subgroup analysis in a more concise way, as per advice of referee.

Methods: we changed the definition of the outcome restored regular menstrual period to 'as defined by authors'.

Methods: we were unable to access Chinese BioMedical Literature Database (CBM) for this version of the review and therefore have not been able to update the search for this database

Methods: we changed measurement of dichotomous outcomes from Mantel Haenszel odds ratio to risk ratio.

Methods: we changed the definition of Live birth rate from "Live birth rate per couple (in studies or study subgroups of women seeking a live birth)" to "Live birth rate (defined as delivery of live foetus after 20 completed weeks of gestation) - for women seeking fertility"

Methods: we changed the definition of Clinical pregnancy rate from "Clinical pregnancy rate per woman" to "Clinical pregnancy rate (defined as evidence of gestational sac or foetal heart motion, confirmed with ultrasound)."

\section{IN DEX TERMS}

\section{Medical Subject Headings (MeSH)}

*Acupuncture Therapy; Abortion, Spontaneous; Cyproterone Acetate; Drug Combinations; Ethinyl Estradiol; Infertility, Female [therapy]; Menstruation; Ovulation Induction [ ${ }^{\star}$ methods]; Polycystic Ovary Syndrome [ ${ }^{\star}$ therapy]; Pregnancy Outcome; Pregnancy Rate; Pregnancy, Multiple; Randomized Controlled Trials as Topic

\section{MeSH check words}

Female; Humans; Pregnancy 